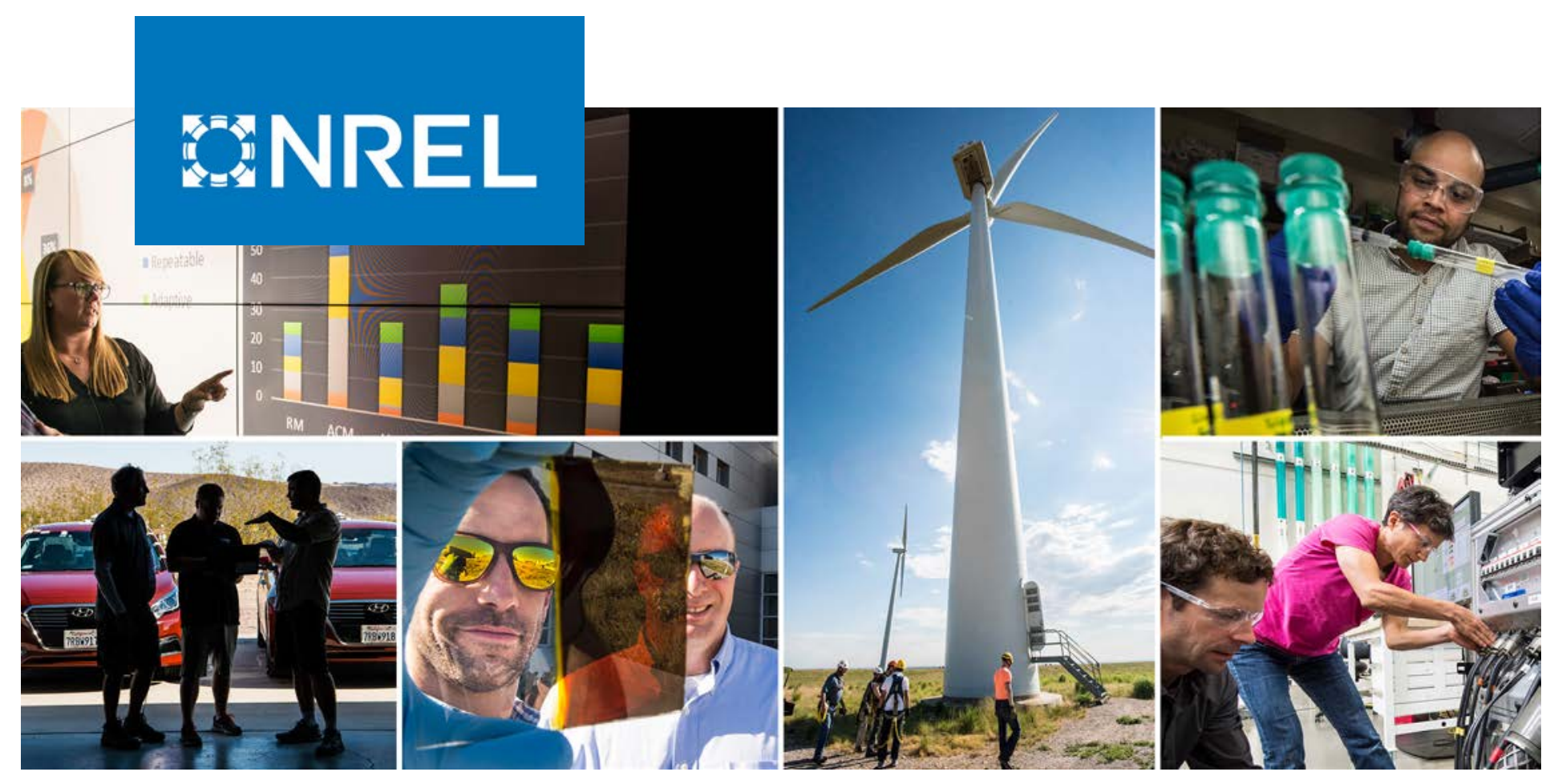

\title{
Wind Energy Instrumentation Atlas
} \author{
and Tommy Herges ${ }^{3}$ \\ 1 National Renewable Energy Laboratory \\ 2 University of Colorado \\ 3 Sandia National Laboratories
}

Julie K. Lundquist, ${ }^{1,}, 2$ Andrew Clifton, ${ }^{1}$ Scott Dana, ${ }^{1}$ Arlinda Huskey, ${ }^{1}$ Patrick Moriarty, ${ }^{1}$ Jeroen van Dam, ${ }^{1}$

NREL is a national laboratory of the U.S. Department of Energy Office of Energy Efficiency \& Renewable Energy

Operated by the Alliance for Sustainable Energy, LLC

This report is available at no cost from the National Renewable Energy Laboratory (NREL) at www.nrel.gov/publications.
Technical Report

NREL/TP-5000-68986

May 2019 


\title{
GNREL
}

\section{Wind Energy Instrumentation Atlas}

\author{
Julie K. Lundquist, ${ }^{1,2}$ Andrew Clifton, ${ }^{1}$ Scott Dana, ${ }^{1}$ \\ Arlinda Huskey, ${ }^{1}$ Patrick Moriarty, ${ }^{1}$ Jeroen van Dam, ${ }^{1}$ \\ and Tommy Herges ${ }^{3}$
}

1 National Renewable Energy Laboratory

2 University of Colorado

3 Sandia National Laboratories

\section{Suggested Citation}

Lundquist, Julie K., Andrew Clifton, Scott Dana, Arlinda Huskey, Patrick Moriarty, Jeroen van Dam, and Tommy Herges. 2019. Wind Energy Instrumentation Atlas. Golden, CO: National Renewable Energy Laboratory. NREL/TP-5000-68986.

https://www.nrel.gov/docs/fy19osti/68986.pdf.

NREL is a national laboratory of the U.S. Department of Energy Office of Energy Efficiency \& Renewable Energy Operated by the Alliance for Sustainable Energy, LLC

This report is available at no cost from the National Renewable Energy Laboratory (NREL) at www.nrel.gov/publications.

Contract No. DE-AC36-08GO28308
Technical Report NREL/TP-5000-68986 May 2019

National Renewable Energy Laboratory 15013 Denver West Parkway Golden, CO 80401 303-275-3000 • www.nrel.gov 


\section{NOTICE}

This work was authored in part by the National Renewable Energy Laboratory, operated by Alliance for Sustainable Energy, LLC, for the U.S. Department of Energy (DOE) under Contract No. DE-AC36-08GO28308. Funding provided by the U.S. Department of Energy Office of Energy Efficiency and Renewable Energy Wind Energy Technologies Office. The views expressed herein do not necessarily represent the views of the DOE or the U.S. Government.

This report is available at no cost from the National Renewable Energy Laboratory (NREL) at www.nrel.gov/publications.

U.S. Department of Energy (DOE) reports produced after 1991 and a growing number of pre-1991 documents are available free via www.OSTI.gov.

Cover Photos by Dennis Schroeder: (clockwise, left to right) NREL 51934, NREL 45897, NREL 42160, NREL 45891, NREL 48097, NREL 46526.

NREL prints on paper that contains recycled content. 


\section{Table of Contents}

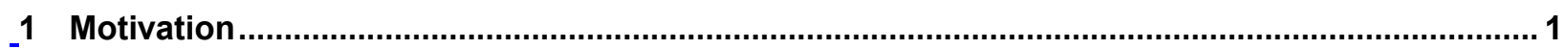

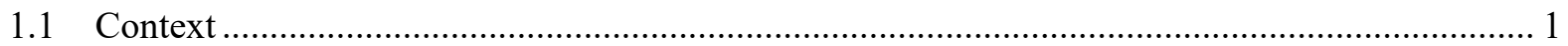

1.2 Verification and Validation ......................................................................................... 1

1.3 Perspective of Testing Models for Wind Energy Applications ........................................... 2

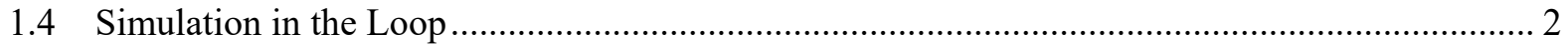

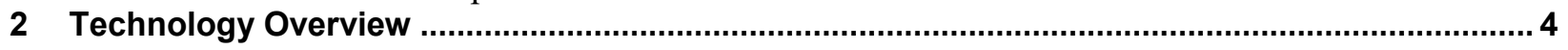

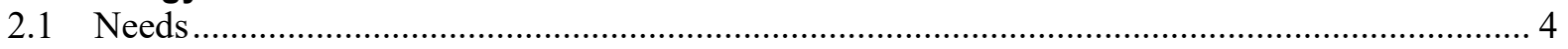

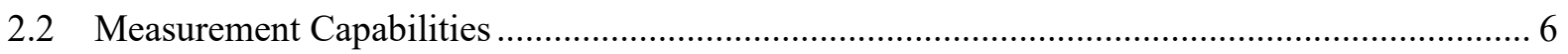

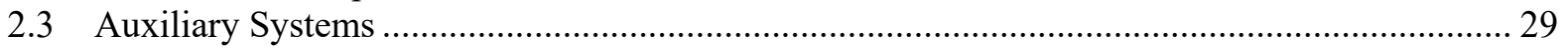

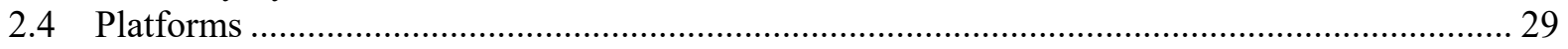

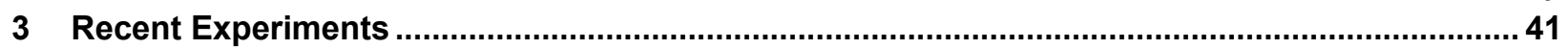

3.1 eXperimental Planetary boundary layer Instrumentation Assessment .................................... 41

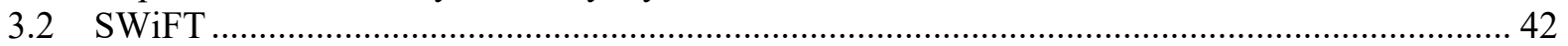

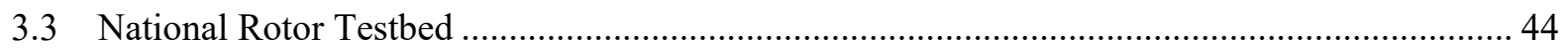

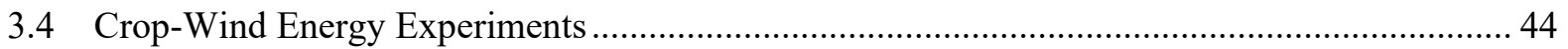

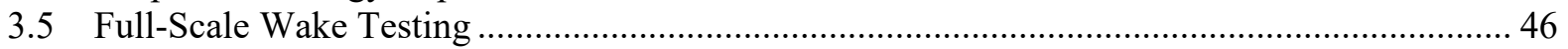

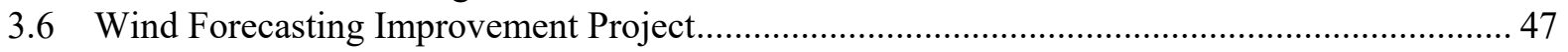

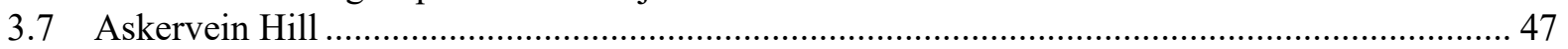

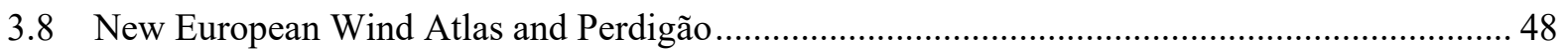

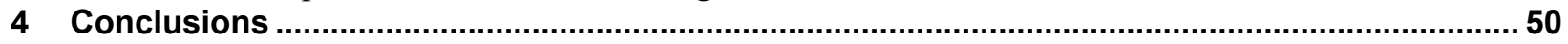

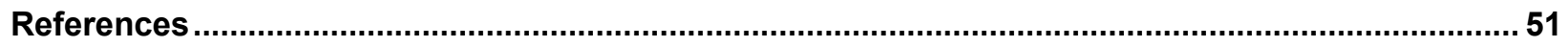

Appendix

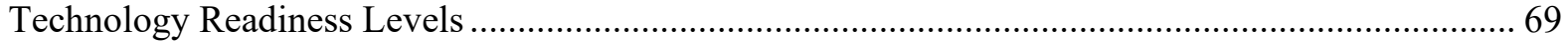




\section{List of Figures}

Figure 1. Example of an iterative experimental and observation process.......................................... 3

Figure 2. Campbell Scientific six-plate solar radiation shield ........................................................6

Figure 3. A three-dimensional sonic anemometer from Campbell Scientific ..................................... 9

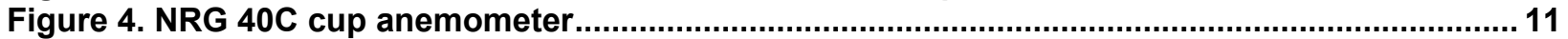

Figure 5. Schematic of the scan technique of a Doppler lidar. Lower part: velocity-azimuth-display scan; upper part: Doppler-beam-swinging scan ........................................................................ 12

Figure 6. DTU SpinnerLidar installed at the SWiFT facility in Lubbock, Texas ................................ 14

Figure 7. Measurements of the SWiFT turbine wake from the DTU SpinnerLidar at 1-5 $D(D=27 \mathrm{~m})$ downwind with a stable atmospheric inflow and positive veer.............................................. 15

Figure 8. The OpenLidar modular architecture enables collaboration and experimentation ........... 15

Figure 9. A dual-Doppler-synthesized horizontal wind speed at hub height (A) with an algorithmdefined wake centerline and cross-section lines. Vertical cross sections within the wake of horizontal wind speed reduction from the free-stream wind profile are shown in (B) two rotor diameters (2D) and (C) five rotor diameters (5D) downwind. The black circle describes the projected rotor sweep.

Figure 10. Schematic of PIV setup and processing (left)............................................................ 20

Figure 11. Example cross-correlation interrogation region processing for PIV .............................21

Figure 12. Representative flow field simulating the wind turbine tip vortex region .........................22

Figure 13. Example of a possible SWIS setup ..............................................................................

Figure 14. Comparison of (left) expected SWIS measurement with current equipment, and (right) anticipated measurement with upgraded system; results predicted using the SWIS modeling tool.

Figure 15. Microwave radiometer deployed at the National Wind Technology Center at the National Renewable Energy Laboratory as part of the TWICS campaign ............................................. 25

Figure 16. Deployment of the CIRES Tethered Lifting System at the NWTC in September 2012.

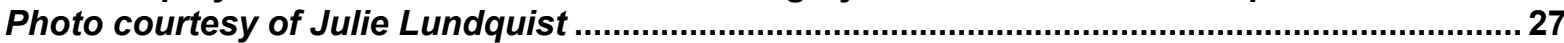

Figure 17. Growth of the convective boundary layer at two locations in southeastern Kansas (Beaumont and Whitewater) on two different days. Colored contours are range-corrected, 915MHz radar SNR profiles (colors, from weak to strong SNR: white, black, violet, dark blue, bluegreen, green, light green, yellow, orange, red, and white). Solid black lines represent radiosonde potential temperature profiles with the scale of 5 kelvins $(K)$ indicated in the upper-left corner of each plot. Symbols indicate a mixed-layer top as defined by Coulter and Holdridge (1998). From LeMone et al. (2000)

Figure 18. A technician use a manlift to service a sensor mounted on a boom on one of the NWTC's 135-m lattice masts. Photo courtesy of Andrew Clifton, National Renewable Energy Laboratory (NREL).

Figure 19. Different motion characteristics at deployment sites can lead to changes in uncertainty

Figure 20 Schematic diagram of the XPIA deployment. Inset: the location of the XPIA measurement site in northern Colorado. Main figure: the location of the BAO $300-\mathrm{m}$ tower (BAO Tower); the lidar supersite (Lidar SS); the Visitor Center (VC), location of National Oceanic and Atmospheric Administration (NOAA) Dalek 02, the radar wind profiler/RASSs, the NOAA and CU microwave radiometers, and several radiosonde launches); the water tank (WT), location of the NOAA HRDL, the UMBC lidar and radiometer, and some radiosonde launches; Erie High School (EHS), location of the NOAA Dalek 01; UTD, the location of the UTD 200S lidar, and the locations of the two TTU Ka-band Doppler radars (TTU 01 and TTU 02). Contours show elevation in meters above sea level. From Lundquist et al. (2017).

Figure 21. Configuration and example measurements of the SWiFT turbine with the lidar measuring the velocity $1-5$ rotor diameters $(D)(D=27 \mathrm{~m})$ downstream; the yellow portion of the laser schematic depicts the probe volume ................................................................................ 43

Figure 22. Velocity deficit (\%) vs. downwind distance at different vertical positions for wakes from a) an outer turbine and b) an inner turbine. Gray horizontal dashed lines represent the vertical limits of the rotor disk of the turbines; the horizontal continuous gray line shows the hub height of the turbines. Data collected from 5:31 to 5:42 Coordinated Universal Time (from 
00:31 to 00:42 Mountain Daylight Time), August 26, 2013, from a succession of six PPI scans performed at six different elevation angles. From Bodini et al. (2017)

Figure 23. Photo of the University of Stuttgart lidar installed on the nacelle of the DOE 1.5-MW turbine. The lidar faces backwards to measure wakes and can rotate with yaw angles to capture the changing wake direction. Photo by...

Figure 24. (Top) A panoramic view of Vale Cobrão, as viewed from \#13 (30-m tower) in the lower figure. The wind turbine is between \#18 and \#21, on the ridge. (Bottom) A screenshot of the instrumentation placement map for Perdigão campaign IOP. Most of the instrument towers have been erected and other instrumentation is currently arriving at the site. Each instrument is identified by a number and color coding. From Fernando, Lundquist, and Oncley (2017) .... 49

\section{List of Tables}

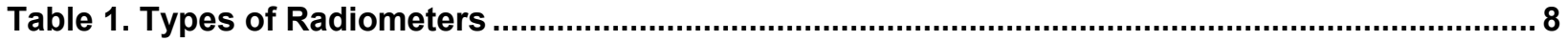

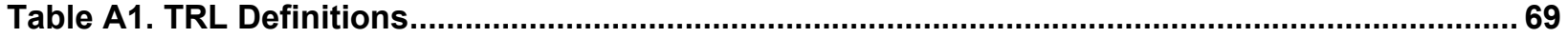




\section{Motivation}

\subsection{Context}

The U.S. Department of Energy (DOE) Atmosphere to Electrons (A2e) program is focused on developing the next generation of predictive tools to better understand wind plant performance and help industry lower the overall cost of energy. A formal verification and validation process is required to demonstrate improved accuracy of these new models beyond those currently employed. A critical part of model validation is utilization of a diverse set of accurate observations of atmospheric forcing and wind plant response. A number of existing data sets will be used for this purpose, but A2e researchers realize that new data sets will be required to meet validation objectives. As such, plans for new experiments based on model validation priorities are currently being developed.

This report is intended to serve as a reference to experimental study planners that describes the capability, accuracy, and resolution of existing and developing measurement technologies to observe quantities of interest for wind plant model validation. Such systems can be broken into two major categories: those that measure the flow field and surrounding atmosphere around and within a wind plant and those that measure the turbine response within the wind plant. The A2e validation team will use this catalogue of instrument capability in conjunction with the validation plan, to choose the optimal set of instruments to be deployed, inform instrument placement and operation and estimate the types of validation that may be gathered through new field campaigns. Where existing instrumentation is deficient, this document will help highlight areas in which instrumentation development is required to meet validation objectives. Further, A2e technology development funding may be required.

The domain of interest is the wind plant microscale, within and surrounding a single wind plant, typically, tens of kilometers on a side in horizontal dimensions and to the top of the atmospheric boundary layer $(\sim 1-2$ kilometers $[\mathrm{km}])$ in the vertical. Some observations of dominant mesoscale forcing phenomena are required, with the highest resolution measurements occurring in the wind turbine wakes and on the turbines themselves. The simulation tools to be validated are mesoscale-driven large-eddy simulations of the atmosphere with full aeroelastic response of individual turbines within the plant. Use cases vary slightly among tool users, but should focus on research insights and the primary end customers of the simulations, which would be turbine manufacturers and wind power plant developers and owners. Broadly speaking, their interests are maximizing energy output while maintaining turbine reliability and lifetime.

\subsection{Verification and Validation}

Measurements and field observations do not take place without context or motivation. Instead, they are usually intended to answer specific scientific or research goals. Measurements can help identify physical processes, but can also help in testing models of those processes. The measurements usually try to include the dominant forcing or boundary conditions and the important outputs. These measurements therefore contribute to model validation, which assesses the degree to which the model agrees with reality. Validation is different from verification, which is the process of confirming that a model's numerics were coded correctly. These concepts are introduced in the American Institute of Aeronautics and Astronautics' Guide for the 
Verification and Validation of Computational Fluid Dynamics Simulations (American Institute of Aeronautics and Astronautics [AIAA] 1988).

\subsection{Perspective of Testing Models for Wind Energy Applications}

Following the AIAA methodology, DOE-funded researchers have developed a verification and validation process specifically tailored to wind energy applications (Hills et al. 2015). This process was developed using feedback from over 100 domain experts over 2 years of meetings. It relies on Phenomena Importance and Rankings Tables (PIRT) at different scales that are important for wind energy applications. The dominant scales of import are mesoscale, wind power plant scale, and turbine scale. Within each of these scales, the Phenomena Importance Rankings Tables identify the physical processes that are most influential to wind power production and turbine reliability. The tables also highlight which physics are least mature from both a fundamental understanding and existing model perspective. Phenomena with the largest influence and lowest levels of understanding or model maturity are flagged as the highest priority for model development and validation. Many also require new experiments for improved fundamental understanding.

\subsection{Simulation in the Loop}

In an ideal validation program, the effort is not merely one way with experimental observations gathered and then compared with isolated simulations. A preferred approach involves more intertwined feedback between simulation and observation (Figure 1). Simulation prior to observational campaigns can inform instrument location and operational behavior, as well as provide guidance as to the resolution and accuracy to be expected from the experimental campaign. This approach, sometimes referred to as an Observing System Simulation Experiment (OSSE), has been widely used in the meteorological community to quantify the benefit of new observing systems or to define optimal locations for new instrumentation (Arnold and Dey 1986). Specific instrument behavior can be directly simulated, and this approach is beginning to be incorporated into wind energy applications. For example, researchers have reproduced lidar transfer functions directly into large-eddy simulations (Lundquist et al. 2015), which have been used to modify scan patterns and reproduce sampled flow fields of simulations to obtain a more realistic picture that can be used when comparing to observations (Churchfield et al. 2016). 


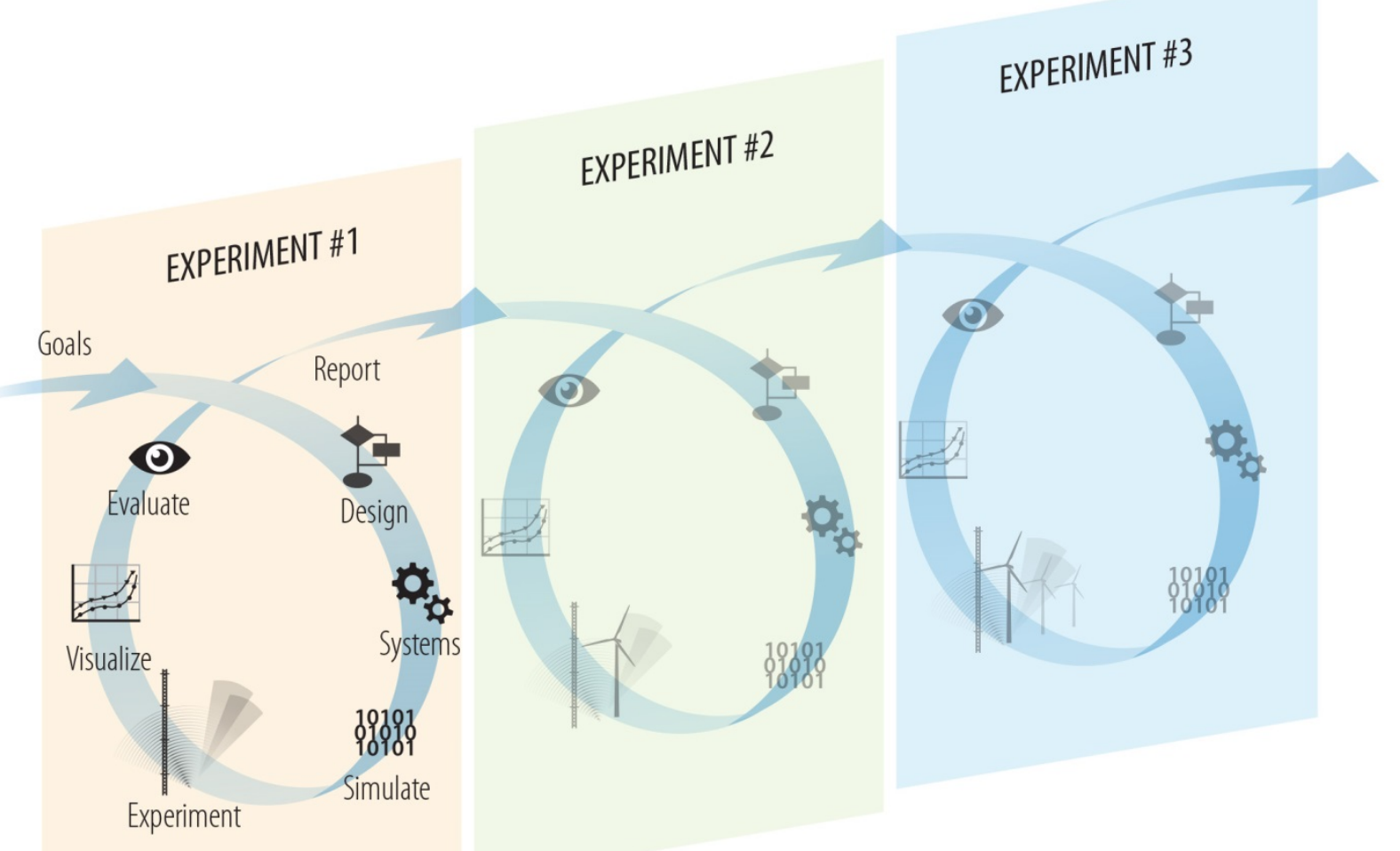

Figure 1. Example of an iterative experimental and observation process. Illustration by John Frenzl, NREL

Simulation during experimental campaigns provides direct feedback to researchers as to the usefulness of data gathered, as well as helps identify areas or phenomena that might need further or more detailed examination, which may ultimately lead to modified and more impactful field campaigns. Note that not all validation data should be used immediately to validate and tune models. Instead, some portion of the data should be reserved for future blind validation studies, which are useful when comparing multiple simulation codes or different submodels. Blind studies are also useful for demonstrating a simulation tool's ability to predict unique environments for which limited data will be available. 


\section{Technology Overview}

\subsection{Needs}

The A2e high-fidelity validation roadmap (Maniaci et al. 2017) details the requirements for validation over a variety of model applications and use cases. The quantities of interest for validation depend on the use case and scale of interest. For example, developers interested in how wakes from multiple turbines move and interact throughout the wind farm and may impact overall energy production. To validate models for this use case, we are primarily interested in profiles and planes of both averaged and unsteady velocity data. However, assuming that velocity profile validation is not universally accurate, we are also interested in the quantities that influence the velocity profiles, including atmospheric conditions (e.g., temperature profiles, the height of the atmospheric boundary layer) and surface conditions (e.g., surface roughness and heat and moisture fluxes into the atmosphere). The domain encompasses the entire wind farm in the horizontal direction as well as the height of the atmospheric boundary layer in the vertical. Further, the domain may be influenced by phenomena occurring outside of the atmospheric boundary layer during some types of weather conditions. Also, if the primary focus is energy production, the resolution of quantities needed for power production application might be limited to those on the order of the rotor radius (Berg et al. 2016), although wind farms themselves can generate larger structures (Fitch et al. 2012, Platis et al. 2018, Siedersleben et al. 2018, Allaerts and Myers 2018, Lundquist et al. 2019).

For many use cases, observations are needed for model initialization. For example, when modeling an unsteady event, such as a storm passage through a wind farm, observations are required to initialize the simulation at the boundaries and within the domain. Further, these observations would include many of the atmospheric quantities of interest for validation as well as the larger mesoscale processes that drive them.

For another application, such as a manufacturer interested in predicting blade loads on individual turbines within a wind farm, a smaller scale set of quantities of interest can be imagined. For this case, we would measure local inflow into the turbine, corresponding changes in airfoil angle of attack, pressure distribution, and blade root loads. Here, the scales might be as small as millimeters on the blade surface and the domain size no larger than the rotor diameter.

Maniaci et al. (2017) examine the important use cases, the highest priority phenomena identified in the PIRTs, and then provides details on quantities of interest and resolution requirements required for validation. The use of this report, in conjunction with Maniaci et al. (2017), helps provide a pathway for successful validation studies with existing data sets as well as guidance for gathering new data to provide a new level of understanding and resolution. Of note, Maniaci et al. (2017) may not emphasize the collection of atmospheric quantities that are of interest for other applications. For example, air quality metrics such as PM2.5 concentration and precipitation type and rate may affect the ability of some instrumentation to observe the highestpriority measurements such as wind speed, wind direction, and turbulence (Aitken et al. 2012). Further, future wind energy studies may be leveraged with solar energy studies or greenhouse gas attribution studies that would benefit from the collection of other data (Cui et al. 2015). Other applications using large-eddy simulation and microscale modeling include dispersion modeling of hazardous materials or trace gases. The air quality community has established rigorous statistical model evaluation standards (Chang and Hanna 2004) that evaluate the 
concentrations of the scalar of concern between models and observations. Typical quantities of concern include particulate matter, ozone, tracer gases released in dispersion studies, or greenhouse gases, such as carbon dioxide and methane (Rieker et al. 2014).

The setup and initialization of a microscale model requires specification of initial and boundary conditions. "Initial conditions" refer to the fact that a model is integrated from an initialization that is based on observations at the beginning of the study period. "Boundary conditions" refer both to conditions at the bottom and top of the domain as well as at the lateral edges. Lower boundary conditions may include specification of surface friction velocity, given by MoninObukhov similarity theory (MOST; Monin and Obukhov 1954). MOST requires specification of surface roughness $\left(z_{0}\right)$, which may be related to land use and land cover characteristics as well as terrain variability and vegetation cover (if any). Additionally, MOST requires the definition of a surface sensible heat flux, which may be obtained from a sonic anemometer deployed near the surface. A time series of surface temperature may also be used to specify lower boundary conditions. Lower boundary conditions for velocities are usually assumed to be zero, corresponding to a no-slip condition.

Upper boundary conditions may be imposed in several ways. Free slip is often used for horizontal velocity components, and fluxes of heat and momentum are often set to zero (Churchfield et al. 2012). Vertical components may be damped. In situations with substantial vertical motion, subsidence rates may be imposed (Mirocha and Kosović 2009).

Just as the values of dependent variables must be specified (i.e., not internally calculated) at the lateral edges of the computational domain, the boundary condition must be defined. Periodic boundary conditions may be used (e.g., Zhou and Chow 2011; Churchfield et al. 2012). This data set may be based on extrapolation of a single profile (often from a weather balloon sounding or tower profile), as in Mirocha and Kosović (2009), or Mazzaro et al. (2017). Boundary conditions may also be provided from a mesoscale model at a coarser resolution.

If boundary conditions come from a mesoscale model, several issues arise. First, the mesoscale simulation must be as accurate as possible, as compared with observations. Best practices in atmospheric modeling are summarized by Warner (2011), and a detailed discussion of the procedure for setting up a mesoscale numerical weather prediction model is presented in detail in Warner (2010). These steps include determining the physical processes that must be simulated and defining the appropriate horizontal and vertical grid resolution for these important physical processes, with some attention paid to vertical structures, such as boundary-layer gradients and low-level jets. Map projections can influence the results of mesoscale models, so it is important to select a map projection that is appropriate for the range of latitudes to be simulated. The mapscale factor at all horizontal grid cells should be as close to unity as possible. Second, because the parameterizations of important physical processes, like turbulence, are necessarily different between the mesoscale and the microscale model, spurious gradients and feedbacks between the two grids may unduly influence the solution in the microscale model. For example, numerous authors have observed the challenge in "spinning up" turbulence in a microscale domain embedded within a mesoscale model (Muñoz-Esparza et al. 2014). Spurious convective structures from inappropriate mesoscale simulations can undermine the development of desired flow in a large-eddy simulation domain (Mazzaro et al. 2017). 


\subsection{Measurement Capabilities}

To gather observations of sufficient quality for model validation, a variety of instrumentation is available. Often instruments are categorized by the quantities of interest that they measure. Some instruments can measure multiple quantities of interest. In the upcoming sections, we provide a summary of existing and developing instrumentation that represents the current state of the art, grouped by observed quantities. For each instrument, we include a short description including information on how it operates and its spatial and temporal resolution. For many of the instruments, we also list their technology readiness level, an indication of the maturity of the instrument, as explained in Appendix A.

\subsubsection{Temperature, Pressure, and Relative Humidity}

Typical meteorological quantities measured close to the surface include temperature, pressure, and relative humidity. These quantities are part of the "standard" set of surface observations. In the United States, such observations are collected regularly by Automated Surface Observing Stations. ${ }^{1}$ A time series of surface temperature may be used to provide a bottom boundary condition for simulations, and temperature and pressure are used together to estimate air density, which directly affects wind power production. Surface air density at sea level is, on average, $1.225 \mathrm{~kg} \mathrm{~m}^{-3}$, but at altitudes of approximately $1.6 \mathrm{~km}$, surface air density decreases to nominally $1.0 \mathrm{~kg} \mathrm{~m}^{-3}$.

Temperature, pressure, and relative humidity measurements are typically considered at a technology readiness level (TRL) of $>8$ and have been so for several years. As summarized by U.S. Environmental Protection Agency (2000), sensors for monitoring ambient temperature include wire bobbins, thermocouples, and thermistors, but platinum resistance temperature detectors are most widely used in the atmospheric science community. Temperature and relative humidity probes are typically coupled together and housed within an aspirated radiation shield, such as that shown in Figure 2, and mounted at a standard altitude of approximately 2 meters (m) or $10 \mathrm{~m}$ above the surface. A barometer to measure pressure is typically mounted nearby, preferably at the same altitude as the thermometer.

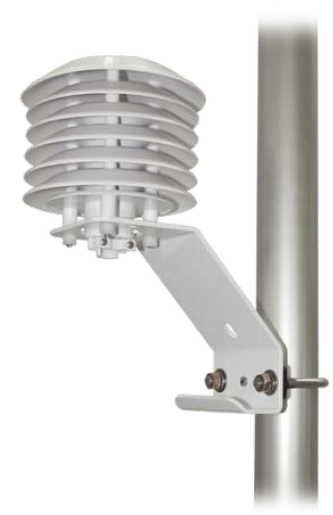

Figure 2. Campbell Scientific six-plate solar radiation shield. Image from Campbell Scientific, Inc. (2018a)

\footnotetext{
${ }^{1}$ See http://www.srh.noaa.gov/jetstream/remote/asos.html for more information.
} 


\subsubsection{Surface Radiation}

The amount of solar radiation reaching the ground impacts the weather, the operation of renewable energy systems, and human activities (Wallace and Hobbs 2006). Devices for measuring irradiance are known as radiometers, which are usually characterized by their sensitivity to specific frequency bands as well as by how they are operated (e.g., passive versus active). More information can be obtained in the "Best Practices Handbook for the Collection and Use of Solar Resource Data for Solar Energy Applications" (Sengupta et al. 2015).

Solar radiation at the ground is usually divided into two main frequency bands. The shortwave band (wavelengths less than 4 microns, including near-infrared, visible, and ultraviolet bands) includes most of the energy associated with solar radiation, whereas the longwave band (wavelengths greater than 4 microns, including the infrared spectrum) includes most radiation emitted from the atmosphere and the Earth itself.

Other bands that are sometimes measured include ultraviolet bands - used for photosynthesisand the bands used by different types of solar photovoltaic modules. Measurement devices for surface radiation are summarized in Table 1.

Irradiance can be measured in several different orientations including:

- Horizontal, facing up, to measure the incoming shortwave and/or longwave radiation; together, they provide the global horizontal irradiance

- Horizontal, facing down, to measure the shortwave radiation reflected by the surface and/or the longwave radiation emitted by the surface

- Tilted but at a fixed angle, to measure the irradiance available to a solar panel or some other inclined surface

- Sun-tracking and with a narrow field of view, to measure the direct irradiance from the sun, called the direct normal irradiance

- Sun-tracking but with the sun blocked out, which can be combined with global horizontal irradiance measurements to calculate the diffuse component of solar radiation.

Table 1 provides a guide to the different types of radiometers. All sensors currently on the market have a TRL of 8 or higher. Current areas of research include investigating more affordable sensors and sensor packages that are easier and more cost-effective to deploy and maintain. 
Table 1. Types of Radiometers

\begin{tabular}{|c|c|c|}
\hline Type & Measurement & Data Obtained \\
\hline Photometer & $\begin{array}{l}\text { Irradiance flux of visible light, also } \\
\text { known as shortwave radiation }\end{array}$ & Photoptic irradiance \\
\hline $\begin{array}{l}\text { Pyranometer } \\
\text { (broadband) }\end{array}$ & $\begin{array}{l}\text { Solar irradiance on a horizontal } \\
\text { plane }\left(180^{\circ} \text { field of view }\right)\end{array}$ & $\begin{array}{c}\text { Global horizontal irradiance or } \\
\text { diffuse irradiance if a shading ball is } \\
\text { used }\end{array}$ \\
\hline $\begin{array}{l}\text { Pyranometer } \\
\text { (tilted) }\end{array}$ & $\begin{array}{l}\text { Solar irradiance on a tilted plane } \\
\left(180^{\circ} \text { field of view }\right)\end{array}$ & $\begin{array}{c}\text { Irradiance in the plane of array or } \\
\text { at other angles; also global or } \\
\text { diffuse }\end{array}$ \\
\hline \multirow{3}{*}{$\begin{array}{l}\text { Pyranometer } \\
\text { (narrowband) }\end{array}$} & \multirow[t]{3}{*}{ Irradiance in specific spectral bands } & Ultraviolet irradiance \\
\hline & & Photosynthetically active radiation \\
\hline & & Spectral band of PV modules \\
\hline Pyrgeometer & $\begin{array}{l}\text { Irradiance in the infrared band } \\
\left(180^{\circ} \text { field of view }\right)\end{array}$ & $\begin{array}{c}\text { Downwelling or upwelling infrared } \\
\text { radiation }\end{array}$ \\
\hline Pyrheliometer & $\begin{array}{c}\text { Irradiance in a narrow field of view } \\
\left(\text { approximately } 6^{\circ}\right) \text { centered on the } \\
\text { sun }\end{array}$ & Direct normal irradiance \\
\hline Reference cell & $\begin{array}{l}\text { Irradiance available to a } \\
\text { photovoltaic module }\left(180^{\circ} \text { field of }\right. \\
\text { view) }\end{array}$ & Photovoltaic module power \\
\hline Spectral radiometer & $\begin{array}{l}\text { Radiation in multiple spectral } \\
\text { bands }\end{array}$ & Spectrally resolved irradiance \\
\hline
\end{tabular}

Radiometers use photodiodes or thermocouples to measure the irradiance. For example:

- Thermopile-based radiometers use a thermal detector with black coating that has a flat spectral absorption typically ranging from 200 nanometers $(\mathrm{nm})$ to $50,000 \mathrm{~nm}$. The detector is usually protected by hemispherical precision-ground glass or sapphire domes that have a flat spectral response (typically $280 \mathrm{~nm}$ to $3,000 \mathrm{~nm}$ ).

- Photodiode radiometers have a limited and nonuniform spectral response (typically 400 to $1,100 \mathrm{~nm}$ ), which covers about $75 \%$ of the solar spectrum. The detector is usually installed behind a diffuser that scatters or randomizes the direction of the photons. Photodiodes have a higher temperature and angular sensitivity.

Thermopile radiometers are preferred for research applications because of their flat and wide spectral response. Photodiode radiometers are typically less expensive but more sensitive to ambient conditions.

\subsubsection{Surface Fluxes}

Surface fluxes of heat, moisture, and momentum are typically used to provide surface boundary conditions for time-dependent atmospheric simulations with large-eddy simulations. Some investigations have suggested that using a time series of surface temperature provides better agreement with observations (Kumar et al. 2010).

\subsubsection{Sonic Anemometer Thermometers}

Since the early 1960s, sonic anemometer thermometers (typically referred to as sonic anemometers or sonics) have been employed by atmospheric scientists to measure three- 
dimensional wind vectors, temperature, and surface-sensible heat and momentum fluxes quickly and accurately (Kaimal and Businger 1963; Kaimal et al. 1968). Sonic anemometers can measure the wind speed between $0-60 \mathrm{~m} \mathrm{~s}^{-1}$, at rates up to 100 hertz $(\mathrm{Hz})$, allowing turbulent structures on scales of a few centimeters to be resolved. One popular model, the Campbell Scientific CSAT3 sonic anemometer, is pictured in Figure 3. Sonic anemometers operate by measuring the time required for a pulse of sound to travel between a pair of transducers. This time depends on the distance between the transducers, the speed of sound, and the air speed along the axis of the transducers. In turn, the speed of sound depends on air temperature, moisture, and pressure along the path. A sonic anemometer thermometer sequentially transmits and receives a pulse of sound so that air speed and direction may also be inferred. The temperature measured by a sonic anemometer is not exactly the air temperature, but is a function of both temperature and moisture and is not strictly identical to the virtual temperature (Burns et al. 2012). However, the fluctuating component of the sonic temperature may be considered equivalent to the fluctuating component of the air temperature, and so the high-rate measurements of sonic temperature may be used in Reynolds decomposition to measure a surface heat flux.

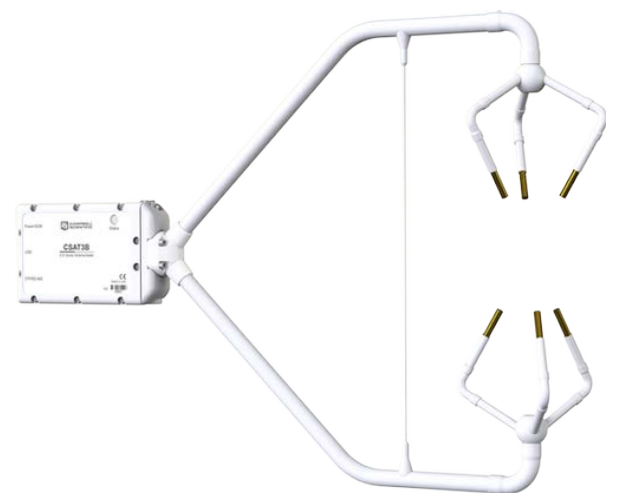

Figure 3. A three-dimensional sonic anemometer. Image from Campbell Scientific (2018b)

Atmospheric field campaigns have deployed sonic anemometers at several altitudes within the surface layer and boundary layer. Measurements have been as low as $0.5 \mathrm{~m}$ (Poulos et al. 2002), but the lowest measurement is typically between 2 and $10 \mathrm{~m}$ to observe the development of eddies within the surface layer (Oncley et al. 1996). Comprehensive guidance for the use of sonic anemometers to estimate turbulence fluxes using the eddy covariance method, profile method, flux-variance method, and accumulation methods is provided by Foken (2008). An intercomparison of sonic anemometer approaches was presented by Loescher et al. (2005).

\subsubsection{Scintillometer}

Beyond the sonic-anemometer-based point-measurement methods for estimating heat and momentum fluxes, areal-averaging methods, such as those used by scintillometers, are used in boundary-layer meteorology. Especially over heterogeneous landscapes, the long path length of these systems provides areal averages up to several kilometers that can be useful for incorporation heat and momentum fluxes into numerical weather prediction models (Chehbouni et al. 2000; Lagouarde et al. 2002; Meijninger et al. 2006; Zeweldi et al. 2010; Kleissl et al. 2008). The scintillometer transmits a beam of electromagnetic radiation to a distant receiver and measures the received signal and its intensity variations. The variations directly correspond to variations in the refractive index of the air, which is related to the structure parameter for the 
refractive index $\left(C_{N}^{2}\right)$ of the air, which can then be used to estimate the structure function parameter of temperature $\left(C_{T}^{2}\right)$ and the sensible heat flux as well as momentum flux.

\subsubsection{Wind Profiles}

Wind profiles can be obtained by measuring wind at multiple heights directly. These sensors are usually mounted on towers, masts, or other structures, and are known as anemometers. The main types of anemometers are cup anemometers, propeller anemometers, and sonic anemometers (described in Section 2.2.3.1). They all have low power requirements and can operate with 1 watt (W) of power or less. All can be triggered and sampled by a field data logger. Overviews of the different measurement techniques are provided in Arya (2001) and Brower (2012).

Cup, propeller, and sonic anemometers are all impacted by all rain and freezing conditions. Rain has an unclear effect on anemometers and is usually flagged as a potential source of problems for sonic anemometers. The influence of precipitation on measurements can be mitigated by using directional wicks that prevent water from pooling on sensors. Freezing conditions result in reduced measured wind speeds and frequency response. Freezing can be mitigated via heating coils or wraps, but such measures increase the power required by the sensor (heating an anemometer can require up to $100 \mathrm{~W}$ ), and may influence other data derived from the sonic anemometer, such as heat fluxes.

Guidance for the installation of cup anemometers on towers for power performance testing of wind turbines can be found in the International Electrotechnical Commission (IEC) 61400-12-1 (2005). That document provides the standard for mounting cups for power performance tests, which require high accuracy and repeatability. IEC 61400-12-1 is therefore considered the defacto standard for wind resource assessment and other monitoring activities in which highquality data are required.

For field campaigns with atmospheric science and simulation verification goals, the use of 3D sonic anemometers is preferred if budgets and field conditions permit. This preference is because sonic anemometers can provide high-rate measurements of wind fluctuations and temperature fluctuations, enabling the calculation of turbulence kinetic energy, momentum fluxes, and heat flux to provide boundary conditions for driving numerical simulations of the atmosphere. Cup anemometers tend to be preferred by the wind energy industry because of their relatively low cost, legacy of use, and the fact that they appear in IEC standards.

\subsubsection{Cup Anemometers}

Cup anemometers measure the rotation induced by the wind on three or more cups mounted on a central axis. This rotation is then converted into an electrical signal via an encoder. The electrical signal is related to the horizontal wind speed around the cup via a calibration function. Cups must be installed carefully to avoid the effects of the surrounding structure on the measurement. Cups do not always measure off-horizontal winds accurately. This capability is known as a cosine response and is often limited to flows with inclinations of less than $10^{\circ}$. The accuracy of a cup compared to a reference device (usually a pitot-static tube) can be better than $1 \%$, but this depends on cleanliness, service period, turbulence, and other factors. The IEC 61400-12-1 (2005) wind turbine power performance standard can be used as a starting point for literature related to making accurate cup anemometer measurements. Cup anemometers have TRL $>8$. The history of 
cup anemometers is outlined by Pindado et al. (2014). One example of a cup anemometer is shown in Figure 4.

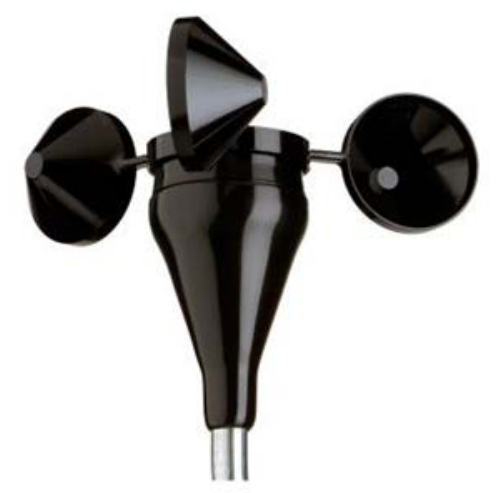

Figure 4. NRG 40C cup anemometer

Source: NRG Systems (2017)

\subsubsection{Propeller Anemometers}

Propeller anemometers use the rotation of a propeller mounted on an aerodynamic body to measure wind speed. As for a cup anemometer, a calibration function is required. Experience suggests that propeller anemometers tend to have lower accuracy and reduced frequency response because of their larger mass. They also generate torque that can result in increased error at high wind speeds. They are, however, considered to be more rugged than cup anemometers. Propeller anemometers have a TRL $>8$.

\subsubsection{Sonic Anemometers}

Sonic anemometers (see Section 2.2.3.1) use the change of frequency of a beam of sound along a short ( $20 \mathrm{~cm}$ or less) path to determine the wind speed along the path. There are a range of sonic anemometer designs that measure in one, two, or three dimensions. Sonic anemometers have high sampling rates compared to cup or propeller anemometers. Together with the small measurement volume, they have a higher frequency response than other anemometers. Sonic anemometers have a TRL $>8$.

\subsubsection{Five-Hole Pressure Probes}

Five-hole pressure probes, or pitot tubes, measure the pressure simultaneously at five points on a small bluff object (typically a sphere a few centimeters in diameter) mounted on a rod. This pressure information can be converted to a wind vector using a wind tunnel calibration. Other shapes, such as wedges and cones, have also been used. These probes have been deployed on towers, aircraft, and unmanned aerial vehicles for turbulence measurements. Wildmann et al. (2014) provide a useful introduction to the design and deployment of a five-hole probe on an unmanned aerial vehicle. 


\subsubsection{Lidars}

Numerous types of lidars have been employed for atmospheric science field studies; a comprehensive summary of lidar theory, and retrieval methods is given in Weitkamp (2005). Doppler wind lidars are used extensively in wind energy and will be discussed in more detail in the next section. The international wind energy industry has taken steps to develop recommended practices for the use of sodar (and other ground-based remote-sensing devices) for wind energy applications. Recommended practices for resource assessment and a summary of other relevant standards can be found in Clifton et al. (2013a).

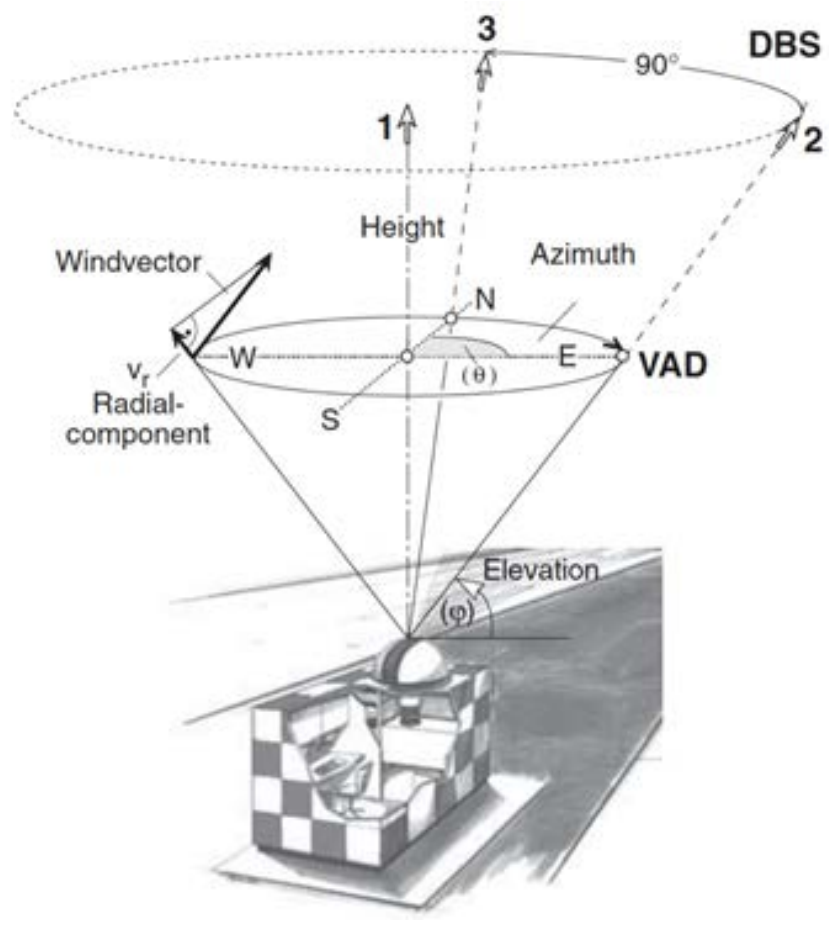

Figure 5. Schematic of the VAD and DBS scan techniques of a Doppler lidar. Lower part: velocityazimuth-display scan; upper part: Doppler-beam-swinging scan

Source: Weitkamp (2005)

Other types of lidars (differential absorption lidar and Raman lidar) may be used to measure the concentration of atmospheric gases, including water vapor and ozone. The differential absorption lidar uses absorption, as evidenced by reduced backscatter from greater distances, to measure these concentration of atmospheric gases (Spuler et al. 2015). A Raman lidar detects atmospheric components (such as water vapor) by measuring the wavelength-shifted return from selected molecules (Strauch et al. 1971). A Raman-shifted eye-safe lidar uses very short pulses of invisible, eye-safe, near-infrared electromagnetic radiation to sense aerosol particles and their variations and movement to quantify atmospheric motions (Mayor and Spuler 2004; Dérian et al. 2015). Commercial lidars have a TRL $>8$. 


\section{Pulsed Doppler Lidar}

A pulsed Doppler lidar transmits short bursts of light (whereas radar transmits short bursts of radio waves) at short wavelengths to use aerosol particles as atmospheric scattering targets. Because aerosols are generally suspended in atmospheric flow, they are excellent tracers of air motions. By observing the Doppler shift of the light backscattered by aerosols, the lidar can remotely measure air velocities. While Doppler lidar has been employed in atmospheric science experiments since the mid-1980s (Post and Cupp 1990; Banta et al. 1992; Grund et al. 2001), the advent of cost-effective and reliable fiber-optic lasers in the mid-2000s ushered in an era of widespread deployment of lidars for wind-profiling applications (Courtney et al. 2008).

Pulsed Doppler lidars measure profiles along the beam of the line-of-sight wind velocity. Therefore, a system pointed vertically will only provide a profile of the vertical wind velocity. To measure the horizontal wind, the lidar's beam must be tilted slightly out of the vertical direction to allow the horizontal wind to contribute to the line-of-sight velocity. With appropriate scanning schemes, and by assuming horizontal homogeneity across the measurement volume, the three-dimensional wind vector can be inferred. Lidars can have ranges on the order of $200 \mathrm{~m}$ (for Windcube v1 and v2 systems) up to $20 \mathrm{~km}$ (for the Lockheed Martin WindTracer system), with range gates varying between 10 and $100 \mathrm{~m}$.

Doppler wind lidars can operate in several different modes, as summarized in Banta et al. (2015). Two of these modes (velocity-azimuth display (VAD) and Doppler beam swinging (DBS)) are visualized in Figure 4. Both DBS and VAD scanning consider data from one elevation angle and multiple azimuth angles; DBS considers three or four azimuth angles, whereas VAD typically considers at least 20. "Profiling" lidars (commercial examples include Leosphere Windcube $\mathrm{v} 1 / \mathrm{v} 2$ ) rely on a four-beam (v1) or five-beam (v2) DBS approach (as opposed to the three-beam approach shown in Figure 5). A plan-position-indicator (PPI) scan involves changing azimuth angles while keeping a constant elevation angle. At very low elevation angles and short ranges, the PPI can almost be considered a horizontal scan. A range-height-indicator (RHI) scan holds an azimuth angle constant and changes the elevation angle to provide a vertical cross section of the area of interest (the PPI and RHI terminology is derived from the use of these types of scans by radars.) By combining multiple lidars looking at the same point or points in space, multiple components of the flow can be resolved (Newsom et al. 2008; Hill et al. 2010; Carbajo Fuertes et al. 2014; Berg et al. 2015; Klein et al. 2015; Yazicioglu et al. 2016; Debnath et al. 2017a, b).

In contrast to the Doppler wind lidar method, the continuous wave lidar does not use pulses but rather continuously emits laser light through a constantly rotating prism deflected by some angle (typically $30^{\circ}$ ) from the vertical direction. The ZephIR lidar makes one complete rotation per second (s), sampling the backscattered light at a frequency of 100 megahertz (MHz). Fifty radial velocities, one for every $360^{\circ} / 50=7.2^{\circ}$, are available from each rotation. Each of the several available heights is scanned for $1 \mathrm{~s}$, and the beam is then refocused to the next height in the sequence and the scanning procedure is repeated. Continuous wave lidars tend to have shorter ranges than pulsed Doppler lidars. 


\subsection{Technical University of Denmark SpinnerLidar}

The Technical University of Denmark (DTU) SpinnerLidar is a velocity measurement device that can acquire velocity measurements at a temporal and spatial resolution that is higher than offered by most lidar measurement systems. DTU developed the SpinnerLidar to be a turbinemounted lidar for rapid scanning of the wind field in a two-dimensional plane (Mikkelsen et al. 2013; Sjöholm et al. 2013b; Angelou and Sjöholm 2015; Machefaux et al. 2016; Churchfield et al. 2016; Herges et al. 2017). An image of the DTU SpinnerLidar installed at the Scaled Wind Farm Technology (SWiFT) facility is shown in Figure 6.

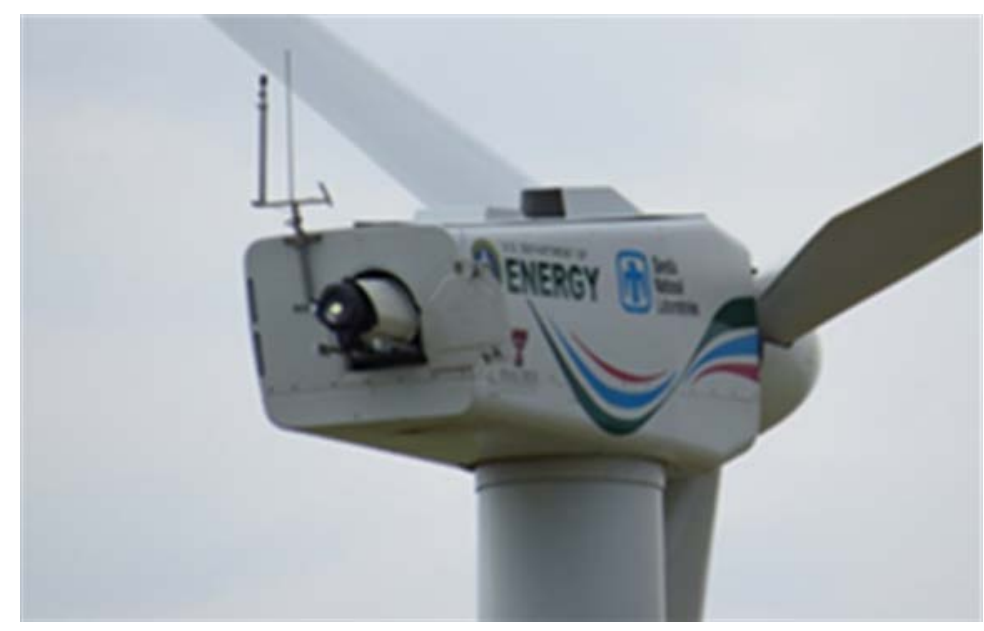

Figure 6. DTU SpinnerLidar installed at the SWiFT facility in Lubbock, Texas. Image courtesy of Tommy Herges

The SpinnerLidar scan head consists of two co-rotating $\sim 15^{\circ}$ wedge-shaped prisms integrated on a ZephIR 300 continuous-wave coherent Doppler lidar. The lidar produces laser light at a wavelength of 1,565 nm and was configured to stream-averaged Doppler spectra at a rate of about 500 measurements per second. The prisms have a fixed gear ratio with adjustable motor settings to change the duration and number of measurements per scan (motor speed fixed for each scan) (Sjöholm et al. 2013b; Angelou and Sjöholm 2015). At each focus distance, the SpinnerLidar scans the two-dimensional surface of a sphere with an approximately $30^{\circ}$ half angle, capturing the line-of-sight velocity component at each measurement location. The lidar can also cycle through focus distances with a change in focus distance occurring in the same amount of time as a full scan. The position of the measurement relative to the symmetry axis is calculated from the instantaneous position of the two wedge-shaped prisms. Changes in the orientation of the rotation axis are accounted for using an integrated three-axis accelerometer. 


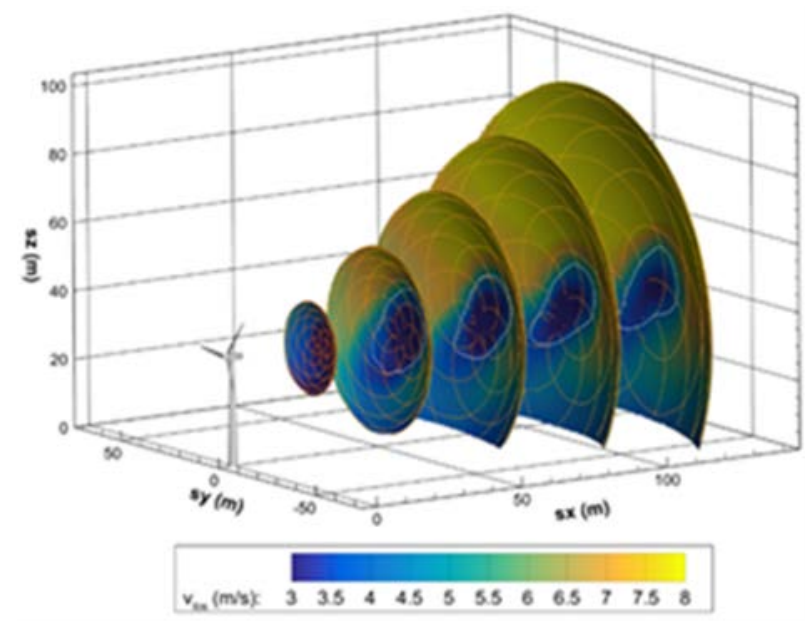

Figure 7. Measurements of the SWiFT turbine wake from the DTU SpinnerLidar at 1-5 $D(D=27 \mathrm{~m})$ downwind with a stable atmospheric inflow and positive veer. From https://www.osti.gov/servlets/purl/1431720

The DTU SpinnerLidar has a TRL of 8. Example measurements from the DTU SpinnerLidar are displayed in Figure 7. The measurements captured a wind turbine wake at the SWiFT facility with a stable atmospheric inflow and positive veer from 1 to $5 \mathrm{D}(\mathrm{D}=27 \mathrm{~m})$ downstream over a duration of $18 \mathrm{~s}$.

\subsection{OpenLidar}

OpenLidar is an initiative that arose from the International Energy Agency Wind Task 32 and is intended to enable collaboration on lidar design, operation, and data processing across the worldwide wind lidar community. The OpenLidar platform is a combination of a modular lidar system architecture (Figure 8), guidelines for documenting modules and their interfaces, and a user-edited website for documentation and software (www.openlidar.net).

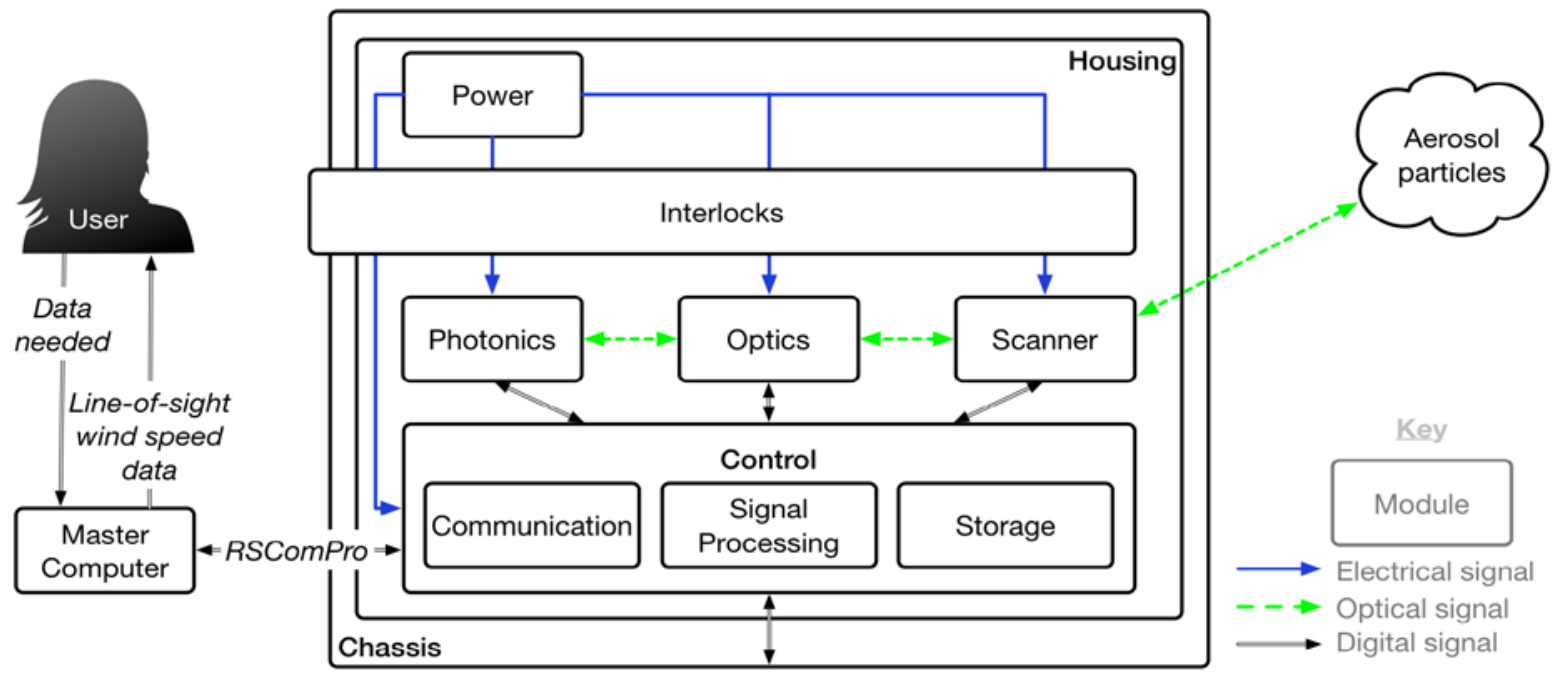

Figure 8. The OpenLidar modular architecture enables collaboration and experimentation

Source: OpenLidar website [undated] 
The OpenLidar architecture is similar to existing lidar designs. New modules developed under OpenLidar will have clear power, data, and safety requirements, and interfaces. The same modular architecture concept and documentation can be applied to existing modules or lidars. Therefore, participants in OpenLidar can customize modules or design new modules knowing that they will work with other modules designed for this architecture, or integrate modules to create a lidar for specific use cases. OpenLidar facilitates collaboration and experimentation as well as reduces the learning curve involved with developing new lidar designs.

OpenLidar follows a four-stage plan. An initial, high-level system architecture and collaboration website has been created. In the near future, developers hope that participants will start detailed design work on individual modules. The last two stages include building hardware demonstrations and the mass customization of the modules. The current goal of OpenLidar is to raise awareness of the initiative and gain a critical mass of researchers.

OpenLidar is currently being used at the University of Stuttgart to help integrate a new lidar scanner with a lidar module developed by the University of Oldenburg. This collaboration forms part of the Application Oriented Wind Field Research and Measurements for Wind Turbines $(A N W I N D)^{2}$ project to develop and deploy a rugged, scanning lidar in the offshore environment.

\subsubsection{Sodar}

Sodar devices use the active emission of sound to measure winds in the atmosphere. In its simplest form, sodar measures the Doppler shift as a result of reflections from the density gradients associated with turbulent eddies of heat in the atmosphere.

The most common type of sodar in the wind energy industry and for general atmospheric boundary layer sensing is the monostatic system, wherein the emitter and receiver are co-located. As with DBS or VAD lidar, monostatic sodar devices measure the wind speed in multiple different azimuth angles to obtain the data required to measure wind speed and direction. This measurement can be done using multiple "horns" pointing in different directions, or a single speaker array that uses phased array techniques to steer the beam.

Sodar devices are relatively inexpensive compared to most Doppler lidar systems with a similar nominal range of a few hundred meters, and have generally lower power requirements for the same range. Several commercially available systems are sold to operate off grid, relying on a small solar panel and battery. Sodars have also been operated in snowy or freezing environments using inbuilt heaters to keep the antenna array free of snow or ice.

Like lidars, sodars are usually optimized around a specific measurement range that has implications for the minimum measurement range or the probe length; a sodar that can measure to more distant locations usually has a greater probe length and a first measurement point farther from the source.

Sodars have limitations that result from the measurement technique. They lose sensitivity and availability with height because of beam spreading and signal attenuation, and lose availability in neutral or stable conditions as the atmospheric turbulence that they use for measurements

\footnotetext{
${ }^{2} \mathrm{http}$ ///www.rave-offshore.de/en/anwind.html
} 
decreases. This response can result in systematic loss of data in stable atmospheric conditions at height. These and other issues are discussed in Bradley (2007) and Emeis (2010).

Sodar retrievals are also undermined by ambient noise, which can reduce the signal-to-noise ratio (SNR) of the signal from the atmosphere. Although this can be cancelled out by monitoring and removing ambient noise, such processing increases the complexity of the system. Similarly, sodar devices can be impacted by echoes from hard structures, such as wind turbines, meteorological towers, or forests. Although such effects can be mitigated by careful placement of the sodar, this approach can also have the effect that the sodar unit must be repositioned further away from a wind turbine than a vertically profiling lidar.

The international wind energy industry has taken steps to develop recommended practices for the use of sodars (and other ground-based remote-sensing devices) for wind energy applications. Recommended practices for resource assessment and a summary of other relevant standards can be found in Clifton et al. (2013a).

Monostatic sodars, which are typically used for measuring winds in the lower $500 \mathrm{~m}$ of the atmospheric boundary layer, have a TRL of 9 and have been commercially available for the last 40 years or more.

\subsubsection{Scanning Radar}

Like lidar, radar exploits the Doppler effect: a short pulse of energy is emitted from a radar, and when the pulse strikes an object, the backscattered energy is measured to identify the object, its location, and how it is moving along the direction of the radar beam. A network of Next Generation Radar (NEXRAD) systems provides precipitation and wind observations across the United States, but the resolution of the winds and accuracy of the wind retrievals do not offer the same benefits as typical instrumentation like radar wind profilers (Fast et al. 2007) and are not generally considered useful for wind energy applications.

However, other types of radars do offer substantial advantages for observations for wind energy applications. Texas Tech University (TTU) maintains research-grade mobile Ka-band (35 gigahertz GHz) Doppler radar systems that provide an along-beam range resolution of $15 \mathrm{~m}$ and a half-power beam width of $0.49^{\circ}$ (Hirth et al. 2012). In one test case, a complete set of 10 scans (at 10 different elevation angles) across a $30^{\circ}$ sector required $45 \mathrm{~s}$. The TTUKa radars can provide continuous radial velocity measurements by relying on distributed meteorological targets (e.g., water droplets and ice crystals) to scatter their signal. Clear air signals can sometimes be returned, but with intermittent coverage in low-humidity environments. Comparisons of dualDoppler retrievals of wind speed and direction from the TTUKa radars with tower-based anemometers suggest that retrievals of mean wind speed and direction profiles in both clear-air (nonprecipitating) and precipitating environments agree well at altitudes above approximately 50 m. At lower altitudes, radar-based estimates were slightly higher than in situ measurements. Further, bulk turbulence parameters were also slightly underestimated by the dual-Doppler Kaband radar retrievals (Gunter et al. 2015). Examples of dual-Doppler retrievals in a wind farm are shown in Figure 9. 

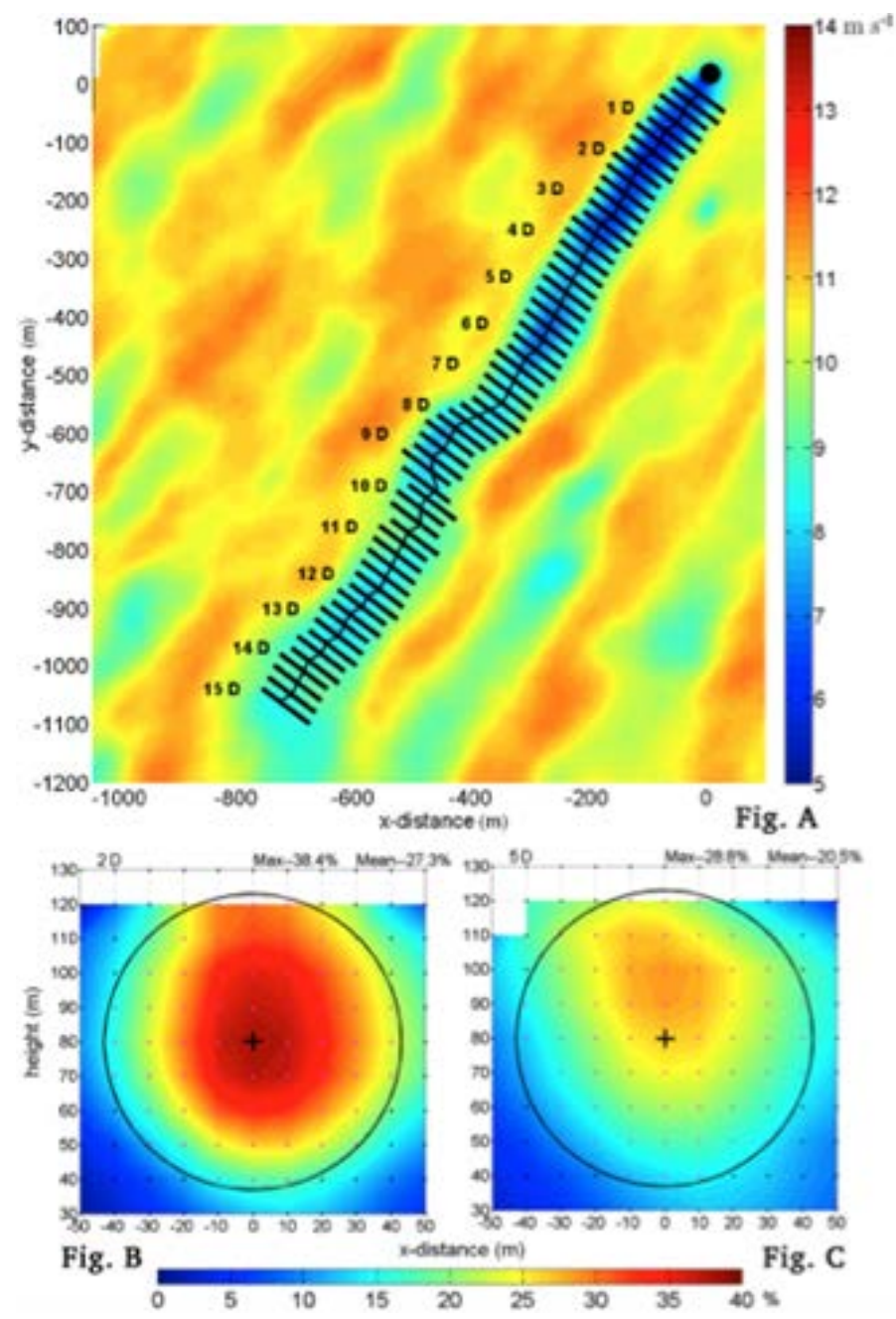

Figure 9. A dual-Doppler-synthesized horizontal wind speed at hub height (A) with an algorithmdefined wake centerline and cross-section lines. Vertical cross sections within the wake of horizontal wind speed reduction from the free-stream wind profile are shown in (B) two rotor diameters (2D) and (C) five rotor diameters (5D) downwind. The black circle describes the projected rotor sweep.

Source: Sandia National Laboratories (2015)

Recent developments in the X-band (8-12 GHz) radar, which is similar to the Ka-band radar, are promising. The main objective for the development of the X-band technology was to improve clear air (i.e., nonprecipitating) data availability, and early tests demonstrate a substantial increase in data availability in every atmospheric condition, whereas the X-band technology provides for data from a larger maximum range (J. Schroeder, personal communication, Nov. 2016). The change in wavelength and increase in sensitivity of the receiver chain enables the $X$ band systems to rely on Bragg scattering from temperature gradients in the atmosphere. The range resolution is as small as $9 \mathrm{~m}$, and the maximum range can be up to $37.5 \mathrm{~km}$, assuming a pulse repetition frequency of 4,000 Hz. Scanning is very fast: for a 65 -degree-sector volume with 14 elevation tilts, a measurement volume is acquired every minute. Validation efforts are underway as of 2017. 


\subsubsection{Radar Wind Profilers}

Radar wind profilers (RWPs) also rely on the Doppler effect as they transmit pulses of electromagnetic radiation vertically and in at least two slightly off-vertical ( 75-degree elevation) directions to resolve the three components of the wind (Ecklund et al. 1988). RWPs sample backscatter returns from atmospheric features, such as turbulence, clouds, or precipitation, but they also measure returns from nonatmospheric features, notably insects and birds. Signal processing software enables a proper focus on the atmospheric returns (Wilczak et al. 1995).

Just as with DBS lidar scans, line-of-sight velocities for each of the transmitted beam directions (three in this case) are assumed to represent horizontally homogeneous winds so that the three components of the flow can be reconstructed. For an RWP, a single wind profile is produced over an averaging period of 30 to $90 \mathrm{~s}$, but these individual profiles are typically averaged together into a larger averaging period of 15-60 min. Depending on the frequency of the radio emission, RWP have different vertical resolutions and lowest measurement altitudes. $915 \mathrm{MHz}$ wind profilers usually have nominally 60 -m vertical resolution, with the lowest level approximately $100 \mathrm{~m}$ above the surface. $449 \mathrm{MHz}$ wind profilers usually have nominally $100-\mathrm{m}$ vertical resolution, with the lowest level approximately $200 \mathrm{~m}$ above the surface. RWP technology is commercially-available at TRL $>8$ and has been commercially available for the last 20 years or more.

High-resolution RWPs can provide information on the height of the daytime convective atmospheric boundary layer (Angevine et al. 1994; Cohn and Angevine 2000). Because clear-air radars of this sort rely on inhomogeneities in the radio refractive index structure parameter $C_{N}^{2}$, and that parameter is a maximum at the inversion atop the convective boundary layer, the peak in the range-corrected SNR ratio of the RWP identifies the top of the inversion. Of course, the resolution of the height of the boundary layer is limited by the vertical resolution of the radar. Further, nocturnal stable boundary layer heights tend to be much lower than daytime convective boundary layers, often below the lowest measurement height of an RWP.

\subsubsection{Acoustic Tomography}

Acoustic tomography is a method of measuring wind fields by making multiple simultaneous samples of the wind field from different directions using sound, and then finding the single wind field that best fits those observations. Acoustic tomography systems simultaneously measure velocity and temperature. Originally used for measuring currents in the ocean on mesoscales, acoustic tomography has since been applied to the atmosphere and extended into multiple dimensions and different scales (Barth and Raabe 2011; Holstein et al. 2004). Ostashev et al. (2009) provides a useful summary of measurements in the atmospheric boundary layer and demonstrates the ability to measure winds in an 80 -m square grid with errors of less than $10 \%$, temporal resolution of $1.5 \mathrm{~s}$, and horizontal resolution of a few meters, albeit it in a plane a few meters thick. Acoustic tomography in the atmosphere has not been commercialized and should be considered a TRL of 6 .

\subsubsection{Particle Image Velocimetry}

Particle image velocimetry (PIV) is a velocity measurement technique that offers a highresolution instantaneous measurement capable of capturing coherent turbulent structures across a 
field of view smaller than more widely used velocity measurement technologies in atmospheric science and wind energy applications, such as lidar, sodar, and radar.

PIV is based on measuring the displacement of tracer particles entrained in a flow field between image pairs over a known change in time, thus providing the velocity of the flow field (Tropea and Yarin 2007; Adrian and Westerweel 2011). A thin laser sheet is normally used to illuminate the tracer particles with a pulsed laser while a camera resolves the tracer particles in subsequent image frames/pulses to capture image pairs (Figure 10). Powerful LEDs or spotlights can also be used to form the light sheet (Hong et al. 2014). PIV uses a cross-correlation analysis to find the average displacement between small subdomains, or interrogation regions, in the image pairs (Figure 11), while particle tracking velocimetry uses computational methods to track individual particles within the image pairs (Nemes et al. 2017). Velocity is calculated from the displacement vectors between image pairs using the image magnification, measurement plane

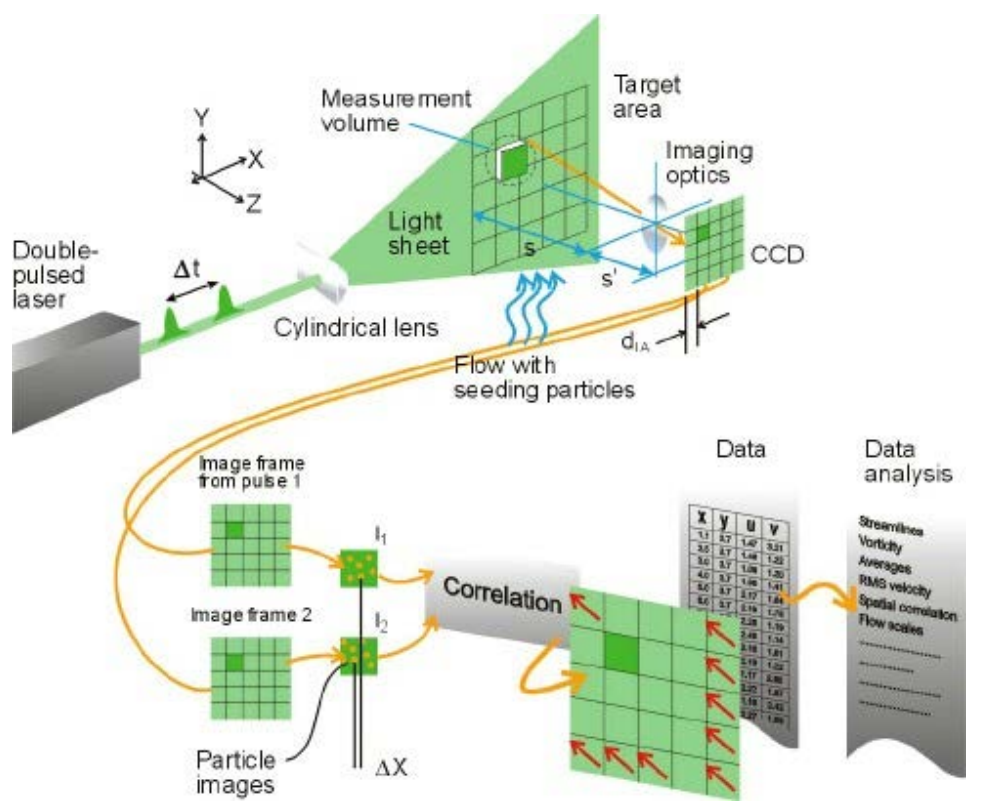

Figure 10. Schematic of PIV setup and processing (left) Source: Dantec Dynamics (2017)

position, and time delay between light pulses.

Planar PIV measures the velocity components normal to the light-sheet plane using a single camera, whereas stereoscopic PIV uses two cameras to measure three components of the flow field within the planar field of the laser sheet. Tomographic PIV uses multiple cameras to measure three velocity components within an illuminated volume (Adrian and Westerweel 2011).

The ability to use PIV for wind energy or atmospheric science applications is driven by the particulate seeding of the flow field. As scales increase, a trade-off exists between resolving the particles across multiple image pixels and adequately capturing enough light to image each particle (Tropea and Yarin 2007; Adrian and Westerweel 2011). High-resolution cameras help to adequately resolve the particles in the imaging plane, whereas shorter working distances (or 
stand-off distances), high-powered lasers, large-diameter particles, and intensified cameras amplify the amount of scattered light acquired (Herges et al. 2015).

Presently, the largest PIV scales have been achieved by seeding large-diameter tracer particles into the flow because the amount of scattered light scales by the square of the particle diameter and only linearly with laser power (Bosbach et al. 2009; Pol and Balakumar 2013; Scarano et al. 2015). Successful PIV measurements of the atmospheric boundary layer (Toloui et al. 2014) and utility-scale wind-turbine tip vortices (Hong et al. 2014) have been achieved at scales not previously possible using snowflakes as the tracer particles. These measurements have provided insight into the unsteady flow structures, but they are limited by the conditions on which data can be acquired and the fidelity at which snowflakes can adequately track the flow (Herges et al. 2015).

These limitations are why PIV has been more suitable for wind tunnel applications. Outdoor applications require the use of extremely large tracer particles that need to be safe for outdoor dispersion. It is difficult to seed an atmospheric inflow with changing wind direction, and camera working distances become challenging for wind turbine investigations (cameras mounted on aerial lifts or towers).

Wind tunnel PIV has a TRL ranging between 6 to 8 depending on the size of the field of view, whereas a field test PIV system has a TRL of 5-6. The key area of research to enable field test use of PIV is particle seeding generation.

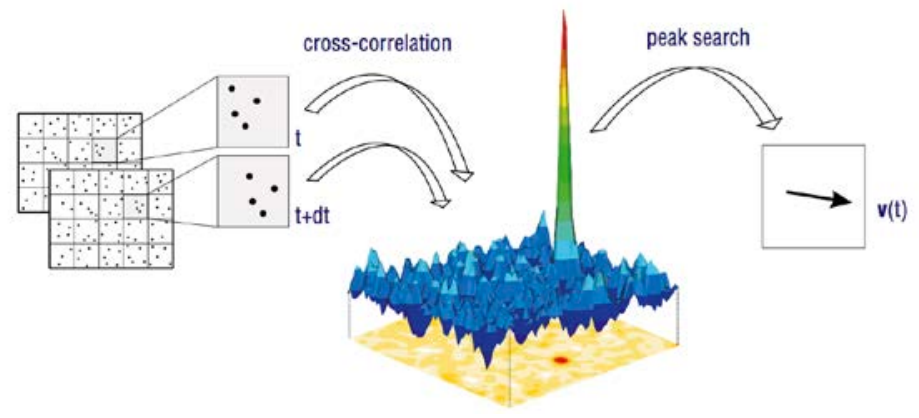

Figure 11. Example cross-correlation interrogation region processing for PIV

Source: Lavision (2017)

\subsubsection{Sandia Wake Imaging System}

The Sandia Wake Imaging System (SWIS) has undergone development to improve the precision of velocity measurements within the inflow and wake of wind turbines through DOE funding. SWIS development began with a goal to capture instantaneous coherent turbulent structures within the tip-vortex region (Figure 12) of the near wake for the purpose of validating highfidelity models. SWIS operates using the Doppler global velocimetry (DGV) method, also referred to as planar Doppler velocimetry, because of its ability to scale to large fields of view while capturing instantaneous coherent structures, or velocity images, of the flow field. Doppler 
global velocimetry scales to larger fields of view because individual particles are not resolved, though particulate seeding does improve the SNR ratio of the measurement (McKenzie 1996; Meyers et al. 2001; Herges et al. 2015, 2016; Tropea and Yarin 2007).

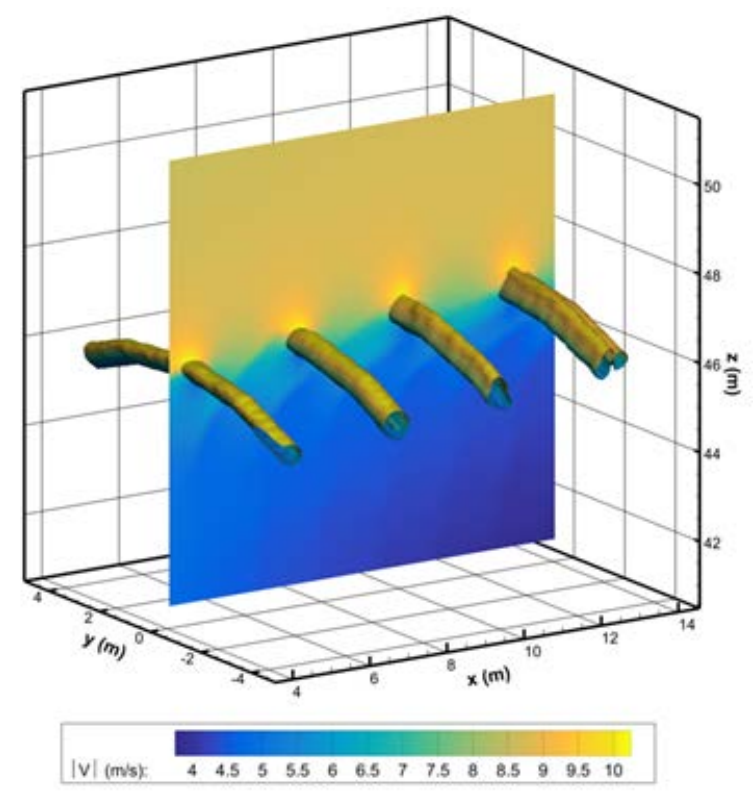

Figure 12. Representative flow field simulating the wind turbine tip vortex region

Other velocity measurement technologies, such as lidar, radar, and PIV, were considered. Lidar and radar instrumentation are limited in their capability to instantaneously acquire coherent turbulent structures at short spatial and temporal scales (Sjöholm et al. 2013a; Hirth et al. 2015), whereas PIV has extreme challenges with scaling to large fields of view because individual particles need to be resolved by the imaging device (Tropea and Yarin 2007; Bosbach et al. 2009; Adrian and Westerweel 2011; Pol and Balakumar 2013; Scarano et al. 2015).

DGV measures the velocity by capturing the Doppler shift frequency of light scattered from aerosol particles within a flow field illuminated by a narrow line width laser sheet. The scattered light is collected through a molecular iodine absorption filter contained within an optical cell (glass cylinder with optical windows) to convert the Doppler shift frequency into an intensity variation measureable by cameras to produce a velocity image (Elliott and Beutner 1999; Mosedale et al. 2000). The Doppler shift of the seeded and naturally occurring particles is calculated at each pixel of the imaging device using the Doppler shift equation, the measured intensity and camera observation unit vector, the iodine transmission profile, and the incident light-sheet-laser frequency and unit vector (Mosedale et al. 2000). The measured velocity component is the result of the system layout, wherein the bisector angle between the observation and incident laser light unit vector defines the direction of the velocity sensitivity, thus, multiple velocity components can be measured with additional observation vectors (Elliott and Beutner 1999). An example of the velocity sensitivity component relative to the laser sheet and observation vector is shown in Figure 13 for a possible SWIS configuration to measure one velocity component of the wind turbine tip vortex region at the SWiFT site. The SWIS acquires velocity images with a spatial resolution of 256-by-256 pixels at a rate of $15 \mathrm{~Hz}$. 


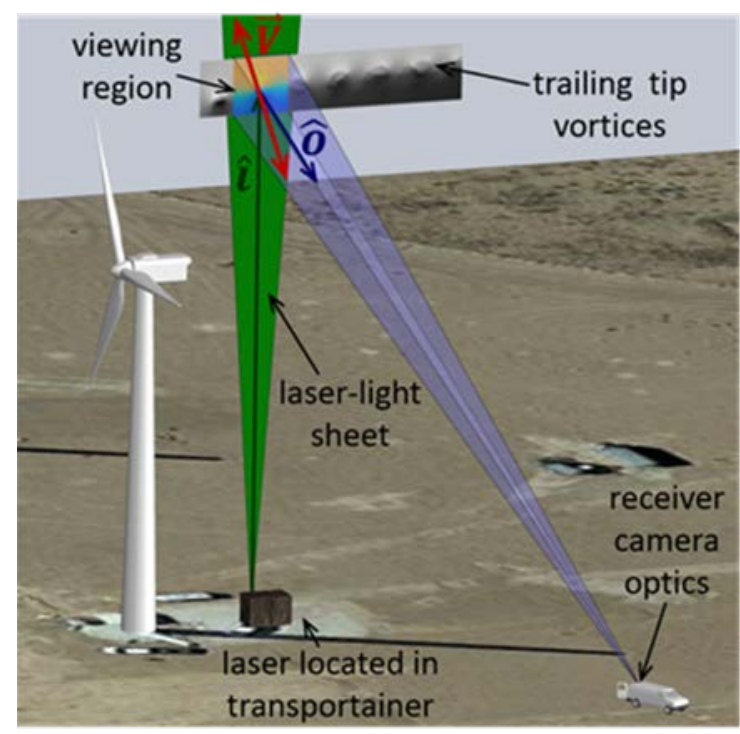

Figure 13. Example of a possible SWIS setup

The SWIS system has undergone development from an initial laboratory viewing area of $15 \mathrm{~cm}$ by $15 \mathrm{~cm}$, to a system characterization experiment with a 2-m-by-2-m viewing area (Herges et al. 2015 ) and finally a field demonstration viewing area of $3.5 \mathrm{~m}$ by $3.5 \mathrm{~m}$ centered at a height of $9.8 \mathrm{~m}$ from the ground to demonstrate safe operation of the laser and aerosol system outdoors (Herges et al. 2016). During this process, a SWIS modeling tool was created and calibrated to facilitate further system development, optimization, and experimental planning at the SWiFT facility (Herges et al. 2016). The modeling tool calculates measurement quality based on a specific experimental configuration and flow field of interest. As an example, Figure 12 and Figure 13 show the representative flow field from a simulation of the wind turbine tip vortex and the system layout, respectively, whereas Figure 14 (left) provides the velocity image captured with the current SWIS configuration, and Figure 14 (right) displays the velocity image acquired with a proposed upgraded SWIS system.

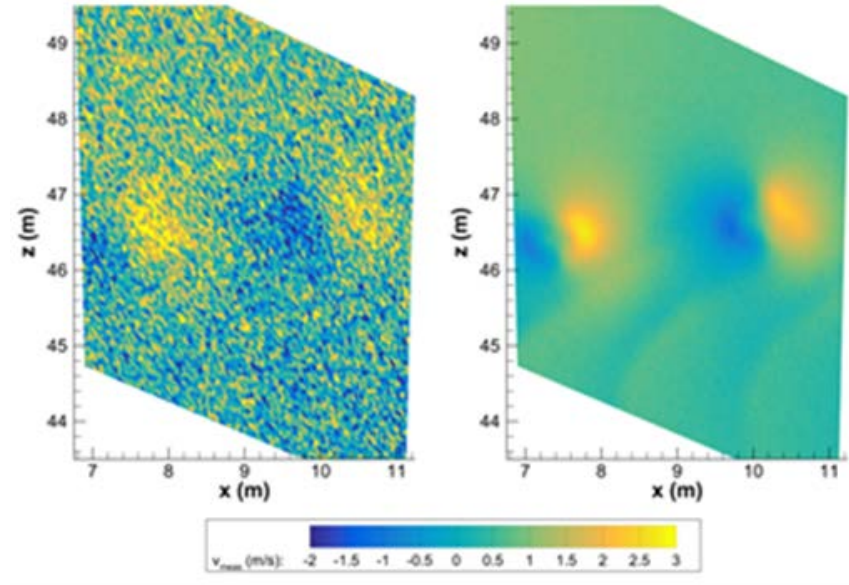

Figure 14. Comparison of (left) expected SWIS measurement with current equipment, and (right) anticipated measurement with upgraded system; results predicted using the SWIS modeling tool 
The upgraded system improvements include a new pulse-burst laser, modified iodine cell, and an adjusted aerosol generation system with a larger coverage area. The SWIS has a TRL of 6.

\subsubsection{Temperature Profiles}

Temperature profiling is important for wind energy research given the well-known impact of atmospheric stability on power performance (Sumner and Masson 2006; Wharton and Lundquist 2012; Vanderwende and Lundquist 2012), turbine wake characteristics (Magnusson and Smedman 1994; Aitken et al. 2014; Dörenkämper et al. 2015), and on turbine loads (Sathe et al. 2013). Although profiles of temperature measurements along towers are often used to assess atmospheric stability, or temperature differences between two levels used to assess a bulk Richardson number, profiles of temperature from remote-sensing instrumentation can also be used to assess atmospheric stability. Some of these methods provide adequate vertical resolution across a turbine rotor disk to assess the stability of fine layers of the atmosphere.

A radio-acoustic sounding system (RASS) combines radio and acoustic techniques to sense profiles of virtual temperature. A high-power acoustic source emits a signal, and the radar senses the signal backscattered from variations in atmospheric refractive index to estimate the speed of sound (May et al. 1989). RASS is at a TRL $>8$. Numerous studies have evaluated the accuracy of RASS measurements by comparing to radiosonde and in situ tower observations. Root-meansquare differences are less than $1{ }^{\circ} \mathrm{C}$ in virtual temperature (May et al. 1989; Lundquist et al. 2017; Bianco et al. 2016). Vertical resolution of a RASS is identical to that of the wind-profiling radar system with which the RASS is coupled: usually the wind-profiling radar/RASS system operates in wind-measurement mode for a large fraction of each hour and operates in temperature-measurement mode for the remaining small fraction of the hour. A RASS is associated with $915-\mathrm{MHz}$ wind profilers, which usually have a nominal 60-m vertical resolution, with the lowest level approximately $100 \mathrm{~m}$ above the surface. RASSs associated with $449-\mathrm{MHz}$ wind profilers usually have a nominal 100-m vertical resolution, with the lowest level approximately $200 \mathrm{~m}$ above the surface.

Microwave radiometers provide regular and automated measurements of temperature and moisture profiles up to altitudes of approximately $10 \mathrm{~km}$ (Ware et al. 2003; Bianco et al. 2005; Cimini et al. 2011; Friedrich et al. 2012). By observing atmospheric brightness temperature in the K-band (22-30 GHz) and in the V-band (51-59 GHz) and applying radiative transfer equations and neural network retrievals, these instruments can provide estimates of profiles of temperature, liquid water, humidity, integrated water vapor, and cloud liquid water path. The neural network retrievals rely on historical soundings from the vicinity (Ware et al. 2013) as a basis. Multiple commercial systems are available at a TRL of $>8$ (Figure 15 shows one example). The Radiometrics microwave radiometer vertical retrieval intervals are $50 \mathrm{~m}$ between the surface and $500 \mathrm{~m}$ above ground level, $100-\mathrm{m}$ intervals from $500 \mathrm{~m}$ to $2 \mathrm{~km}$, and $250-\mathrm{m}$ intervals from $2 \mathrm{~km}$ to $10 \mathrm{~km}$, all with a temporal resolution of 1 minute. Microwave radiometers, as they measure profiles of temperature and moisture, should be able to provide an assessment of boundary layer height. Based on 1 year of comparisons between microwave radiometers and radiosonde profiles, Collaud Coen et al. (2014) found reasonable agreement between boundary-layer height estimates. 


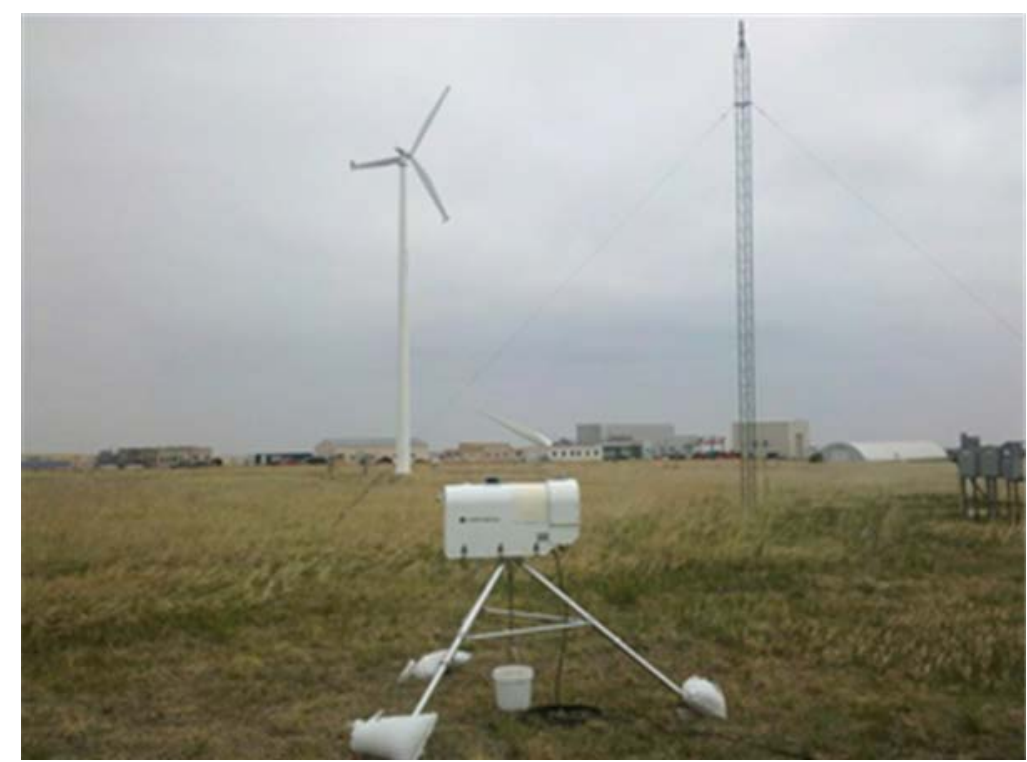

Figure 15. Microwave radiometer deployed at the National Wind Technology Center at the National Renewable Energy Laboratory in 2011. Photo by Julie Lundquist. Data presented in Friedrich et al. (2012)

\section{As mentioned earlier, acoustic tomography systems can also measure temperature at the same} time as velocity fields.

Finally, radiosonde launches can also provide profiles of temperature, pressure, humidity, as well as wind speed and direction. Radiosondes are small, expendable packages attached to a balloon that provides lift to carry the instrument aloft. By maintaining a radio connection to a groundbased receiver at the location of the launch, data from the ascent of the balloon are transmitted to the base. Additionally, these data are often used in evaluation studies of remote-sensing instrumentation (Lundquist et al. 2017; Bianco et al. 2016), although they are not ideal, considering that they drift with the winds and do not provide a strictly vertical profile. Studies of horizontal drift of radiosondes in the lowest $5 \mathrm{~km}$ of the atmosphere suggest median drift is less than $10 \mathrm{~km}$ below an altitudes of $5 \mathrm{~km}$ (Houchi et al. 2010). The ascent rate of radiosondes is typically between 4.5 and $6 \mathrm{~m} \mathrm{~s}^{-1}$; lower ascension rates can result in erroneous data high in the atmosphere as the temperature and relative humidity sensors are not aspirated properly. Radiosondes are generally considered a TRL of $>8$.

Radiosondes, and their profiles of virtual potential temperature, are usually considered the most reliable approach for defining the height of the atmospheric boundary layer. Most investigations that assess whether remote-sensing platforms can quantify boundary-layer height evaluate the new approach by conducting a comparison of those platforms to soundings.

\subsubsection{Turbulence Metrics}

Historically, turbulence measurements for wind energy purposes have been based on variances of horizontal wind speed observed with cup anemometers (Brower 2012; Emeis 2012), usually based on an average over 10-minute intervals, as documented in IEC standards. In contrast, atmospheric scientists, micrometeorologists, and boundary-layer meteorologists usually consider "turbulence" to be based on variation in three directions, including vertically (Panofsky and Dutton 1984; Stull 1988; Arya 2001; Wallace and Hobbs 2006; Foken 2008), and quantify 
turbulence using an eddy-correlation approach. The eddy-correlation approach usually relies on the use of a sonic anemometer recording fluctuations of the three components of the flow measured at $10 \mathrm{~Hz}$ or faster. A Reynolds decomposition is applied to a time series to separate the fluctuating or turbulent component from a slowly varying or stationary mean component considered to be representative of mesoscale variability. The time interval over which this Reynolds decomposition is applied varies, but is usually on the order of 20-30 minutes (Lenschow et al. 1994; de Franceschi et al. 2009). Further, other parameters defining turbulence, such as the rate of turbulence destruction or the turbulence dissipation rate, can also be employed to define turbulence.

The quantification of turbulence is closely tied to the instruments used to estimate it and therefore the effective measurement volume of the instruments. When remote-sensing devices, such as lidars, are used, variances of wind speed can be calculated. However, these variances are subject to spatial averaging from the pulse length of the laser as well as the sampling frequency of the return signal, and so turbulence statistics measured from lidar are distinct from those that would have been measured from cup or sonic anemometers and should not be considered interchangeable (Sathe et al. 2011). Some researchers refer specifically to "lidar turbulence" (e.g., Rhodes and Lundquist 2013). Recent approaches have suggested methods that might adjust lidar measurements to more closely approximate what may have been measured by a co-located sonic anemometer, but these developments are ongoing (Brugger et al. 2016; Newman and Clifton 2017). Information on turbulence, such as turbulence dissipation rate or structure functions, may also be extracted from analysis of the Doppler spectra from scanning lidars (Frehlich et al. 1998; Smalikho et al. 2005; Smalikho and Banakh 2013; Smalikho et al. 2013) and profiling lidars (O'Connor et al. 2010; Bodini et al. 2018).

Comprehensive reviews on approaches for measuring turbulence with lidars are presented in Engelbart et al. (2007), Sathe et al. (2011), and Sathe and Mann (2013). Recent work has suggested that a six-beam approach (Sathe et al. 2015) may be useful. Numerous intercomparisons of measurement approaches (Pauscher et al. 2016; Lundquist et al. 2017) have also been addressed recently or are ongoing.

\subsubsection{Hot Wire, Cold Wire, Hot Film, Cold Film}

Hot wires and hot films are used for constant temperature anemometry. Constant temperature anemometry uses an electronic circuit to maintain the resistance (and thus temperature) of a heated probe that is being cooled by flow. The amount of power required to maintain the temperature of the probe is a measure of the wind speed across the probe. The circuit is designed to have very high gain, which allows for rapid response to changes in cooling. By using very small and thin probes that resemble wires, wedges, or films of conductive material on a ceramic body, it is possible to obtain meaningful wind speed data at several kilohertz. These systems require calibration and are often used in wind tunnel studies. Combining three sensors orthogonally allows the three components of turbulence to be measured. More details of hot wire anemometry can be found in Bruun (1995). The high-frequency, three-dimensional turbulence information can be used to determine turbulent kinetic energy or dissipation rates using an inertial estimation method or a direct dissipation method (Champagne 1978; Oncley et al. 1996; Piper and Lundquist 2004). 
Cold wires and cold films are a slightly different implementation of constant temperature anemometry that use low mass sensors and high gain circuits to measure temperature fluctuations. Combining hot and cold wires allows heat fluxes to be measured at very high sampling rates.

Because of their extreme sensitivity and delicacy, hot or cold wires or films are rarely used for long duration measurements in the atmosphere, but they can deliver valuable information for short periods of time. Examples include the hot wire systems that were deployed on the CIRES tethered lifting system at the National Wind Technology Center (NWTC) (Figure 16) to measure conditions in the wake of the GE 1.5-megawatt (MW) turbine (Lundquist and Bariteau 2015). Extended campaigns can incur significant costs because of damage to the sensors, which can cost from a few hundred to a few thousand dollars. Hot or cold wires or films are commercially

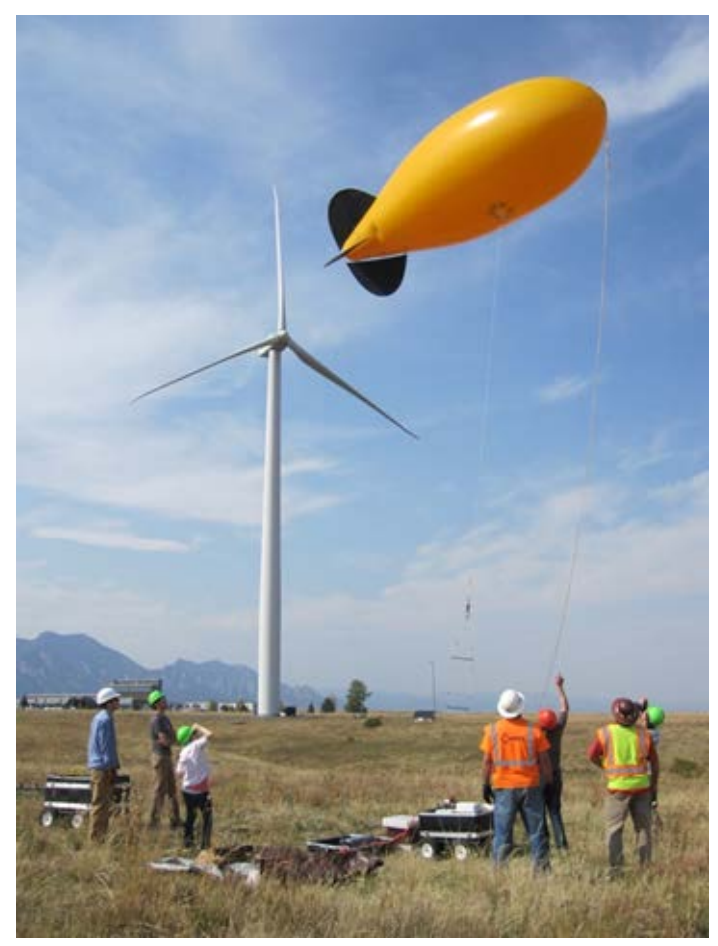

available with a TRL $>8$.

Figure 16. Deployment of the CIRES tethered lifting system at the NWTC in September 2012. Photo courtesy of Julie Lundquist

\subsubsection{Moisture}

Measurements of relative and absolute humidity are helpful in wind energy studies when considering downwind impacts of wind farms and wind turbines. Several of the instruments mentioned earlier that measure temperature via measuring the speed of sound (e.g., sonic anemometers, RASS) actually measure a temperature influenced by humidity measurements. Further, when measurements of atmospheric stability are desired, the contribution of moisture to stability can be important (Friedrich et al. 2012) as a situation may be conditionally unstable if moisture is considered but neutral or stable if the effects of moisture are neglected. Measurements of moisture profiles are possible with microwave profiling radiometers, as discussed in Section 2.2.5. 
Further, satellite observations of moisture can be useful. The Global Positioning System (GPS) consists of 31 satellites and a small number of ground stations. The large number of satellites and the different viewing angles from a detector to each satellite allow the delay in the GPS signal because of the atmosphere to be estimated. This delay can be related to the water content of the atmosphere above the detector, providing the total amount of water in a column from the ground to space (Bevis et al. 1992). Because most of this moisture is concentrated in the lower part of the atmosphere (the troposphere), the data can be used as input to atmospheric models.

\subsubsection{Boundary-Layer Height}

The height of the atmospheric boundary layer is a fundamental parameter in boundary-layer studies, including those conducted for wind energy applications. Unfortunately, it can often be a difficult parameter to measure. During daytime conditions with strong solar heating of the surface, the boundary-layer height is driven by convection from the surface. In midlatitudes with little cloud cover, the boundary-layer height typically ranges between 1 and $3 \mathrm{~km}$ (Stull 1988; Wallace and Hobbs 2006). In contrast, nocturnal boundary layers are much more shallow (20$300 \mathrm{~m}$ ), driven by mechanical forcing and buoyant suppression of turbulence. Unfortunately, observations of stable boundary layer height are rarely straightforward, as a result of the low levels of turbulence and frequent intermittency in the stable boundary layer (Steeneveld et al. 2007). In one study based on the CASES-99 stable boundary layer experiment, a classical stable boundary layer height could be defined only $22 \%$ of the time (Vickers and Mahrt 2004).

The standard approach to directly measuring the boundary-layer height is to assess a profile of potential temperature (or virtual potential temperature) from a radiosonde (or tethered airborne system [remotely piloted aircraft system]), recognizing that the boundary layer is topped by a strong inversion (Schmid and Niyogi 2012). Other remote-sensing instruments, such as radar wind profilers (Angevine et al. 1994; Coulter and Holdridge 1998; Cohn and Angevine 2000) can be used to identify the inversion height (and therefore the boundary-layer top) via a maximum in range-corrected SNR ratio. A comparison of the radiosonde and radar wind profile approach appears in Figure 17.

If the instruments have suitable range, lidars may be used to identify the top of the boundary layer. Because lidars rely on the presence of aerosols in the atmosphere for backscatter, and aerosols usually have a source at the surface, a strong contrast in aerosol density would indicate the entrainment zone separating the convective boundary layer from the free troposphere (Cohn and Angevine 2000). At night, the height of the stable boundary layer is often (but not always) coincident with the nocturnal low-level jet (when it forms) (Banta et al. 2002), and so wind profiles from lidar could potentially be used to identify the depth of the stable boundary layer.

Microwave radiometers, as they measure profiles of temperature and moisture, should be able to provide an assessment of boundary layer height. Based on 1 year of comparisons between microwave radiometers and radiosonde profiles, Collaud Coen et al. (2014) found reasonable agreement between all of the boundary-layer height estimates.

Ceilometers (otherwise not discussed in this document) measure aerosol backscatter, and can also be used to identify the entrainment zone and the top of the daytime convective boundary layer. Based on 40 profiles and comparison between radiosondes and ceilometer-based aerosol methods, reasonable agreement was found (Caicedo et al. 2016). Ceilometers struggle with 
identifying the top of the stable boundary layer because there is no expectation of aerosol gradient at the top of the stable boundary layer.
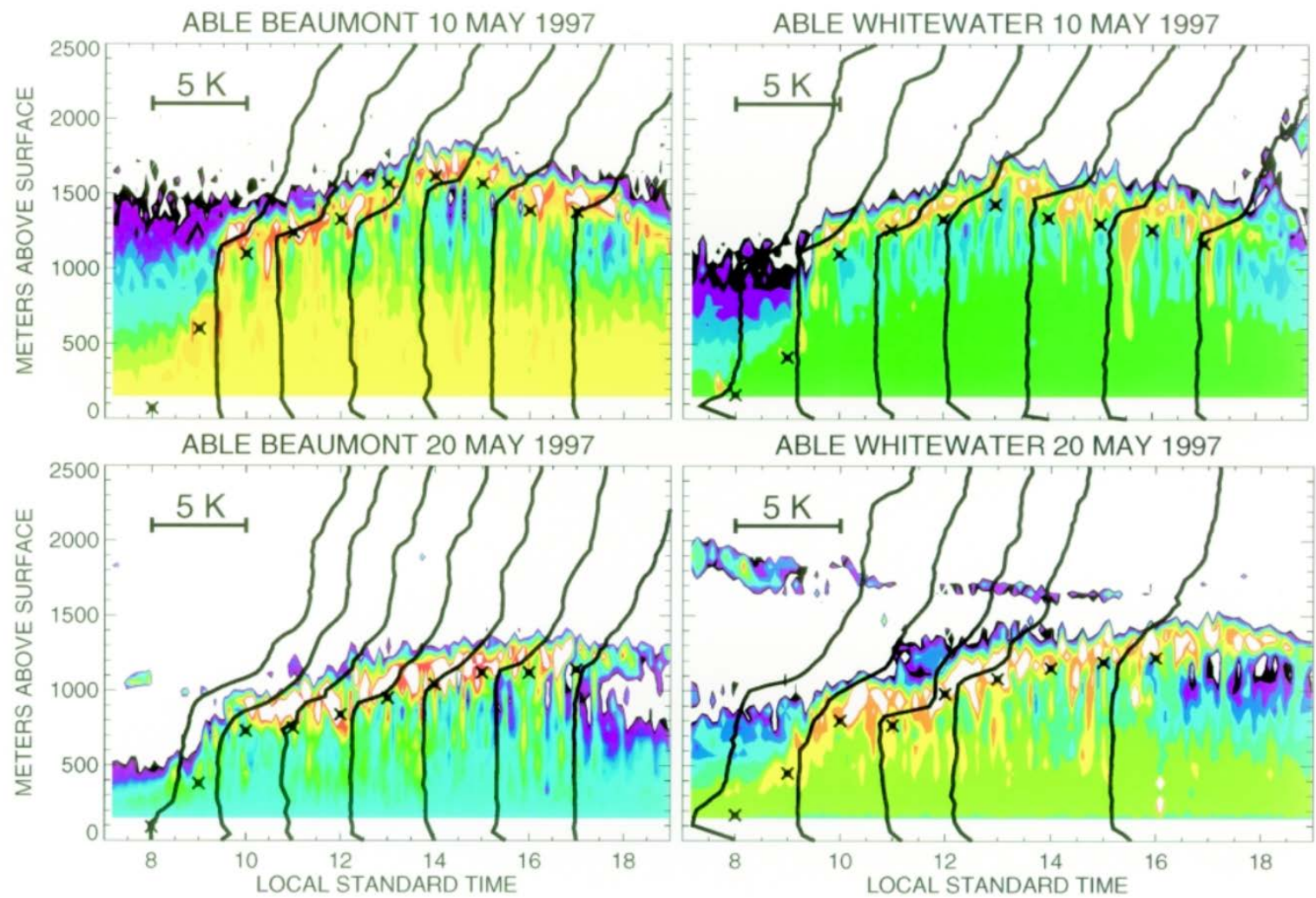

ABLE WHITEWATER 20 MAY 1997

Figure 17. Growth of the convective boundary layer at two locations in southeastern Kansas (Beaumont and Whitewater) on two different days. Colored contours are range-corrected, 915-MHz radar SNR profiles (colors, from weak to strong SNR: white, black, violet, dark blue, blue-green, green, light green, yellow, orange, red, and white). Solid black lines represent radiosonde potential temperature profiles with the scale of 5 kelvin $(K)$ indicated in the upper-left corner of each plot. Symbols indicate a mixed-layer top as defined by Coulter and Holdridge (1998). From LeMone et al. (2000)

\subsection{Auxiliary Systems}

Although the emphasis in this report thus far has been on equipment making measurements, a coherent plan to ensure adequate support of the sensor and data archival is critical for field measurements. Power supplies for many of these instruments are critical, and ensuring real-time or near-real-time communications for data transfer and performance monitoring is usually required. Further details are discussed in Foken (2008) and Brower (2012).

\subsection{Platforms}

\subsubsection{Masts and Towers}

The words "mast" and "tower" are often used interchangeably. Both structures can be used to support instrumentation, such as anemometers at multiple heights or temperature sensors. Instruments to measure wind speed and direction must be carefully mounted on long booms that are often 4-6 times the tower cross-sectional width from the center of the tower to ensure minimum interference between the tower and sensors, even when the booms are upwind of the 
tower structure. This tower interference effect is documented in IEC 61400-12-1 (2017). Care must also be taken to avoid using data that are gathered when the sensors are in the shadow of the tower. This waked sector can be $30-60^{\circ}$ wide, depending on tower size and porosity. Wake effects from towers have been documented in several studies, most recently McCaffrey et al. (2017). It is also important to design booms according to the types of instrumentation that they will carry. Because temperature sensors are relatively insensitive to vertical or horizontal vibration, booms used to mount those sensors can be relatively flexible, as long as the motion of the sensor is slow. By comparison, large vertical vibrations can impact the performance of cup anemometers, and sonic anemometers will measure any boom motion as a velocity superimposed on the true wind speed. For this reason, booms designed for sonic anemometers must be very stiff compared to those for cups, which increases their weight and can make the booms too heavy for tubular masts, and instead a lattice tower may be required (Figure 18). Lattice towers are also beneficial when "research" equipment is installed that may need frequent or unplanned maintenance, as the tower can support elevators for the booms or for personnel to access the instrumentation.

A complication of masts is the need to install guy lines. These lines can extend approximately one-half of the mast height out from the mast base in three or four directions, and may be a hazard to other site users and birds. Also, masts or towers require Federal Aviation Administration approval when installed near runways or airfields. They require power for lighting systems when they exceed 200 feet in height.

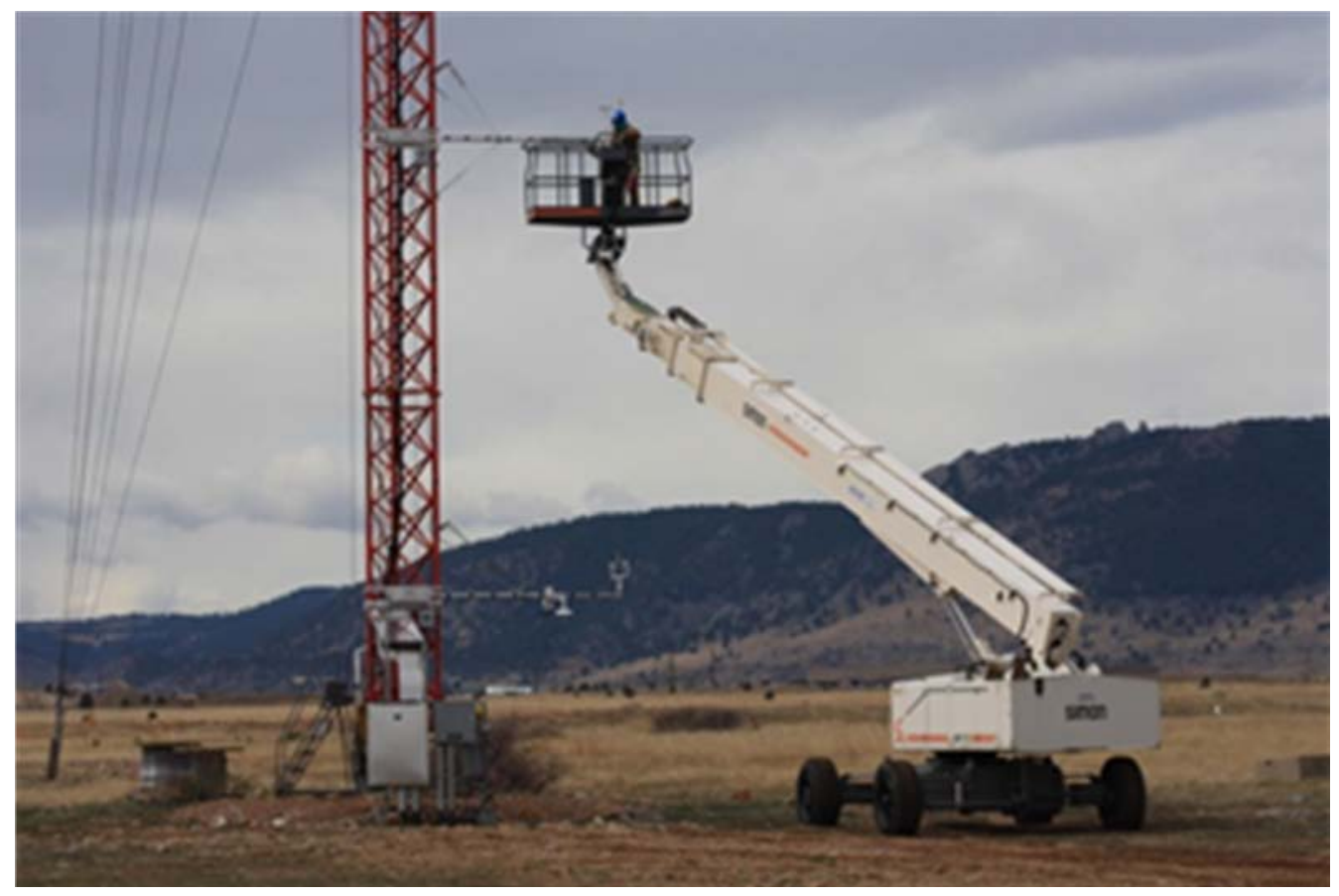

Figure 18. A technician uses a manlift to service a sensor mounted on a boom on one of the NWTC's 135-m lattice masts. Photo courtesy of Andrew Clifton, National Renewable Energy Laboratory (NREL)

Tubular and lattice masts and towers up to $100 \mathrm{~m}$ in height are "off-the-shelf" items, and complete wind resource measurement systems can be bought online. Although a tower or mast up to $100 \mathrm{~m}$ in height may only cost $\$ 50,000-\$ 100,000$ to purchase and equip, annual costs for 
equipment maintenance and calibration may add $20 \%$ or more per year to overall costs, depending on the number and type of sensors. Furthermore, the type of terrain and weather that the mast is deployed in may impact costs. For example, a remote mast that can only be accessed by helicopter is considerably more expensive to operate than a mast on a wind power plant. Also, masts and towers are at risk of lightning strikes and should be designed with devices that protect electronics and power supplies. Additionally, ice buildup can cause masts or towers to collapse, or make the area around the mast dangerous because of ice shedding after a freezing event.

Examples of towers designed for wind energy research include the 60-m inflow masts at the SWiFT facility, and the NWTC's 135-m inflow towers. The NWTC towers are documented in Clifton et al. (2013b). Taller towers have been built for atmospheric research, such as the 300-m Boulder Atmospheric Observatory (Kaimal and Gaynor 1983), which was used in the XPIA study (Lundquist et al. 2017), although these tall towers are very difficult to keep operational and require a high level of funding commitment (Wolfe and Lataitis 2018).

Masts and towers for wind energy resource assessment and meteorological studies have also been deployed offshore on fixed and floating platforms. Although most of these have been selfsupporting towers, there have been some masts deployed that use guy lines attached to the bottom and top of the masts and have intermediate bracing back to the mast. Offshore towers have been found to cost several million dollars to install and several hundred thousand dollars per year to operate.

Although numerical weather prediction models show promise for use in predicting offshore wind resources, a 2014 study by the Crown Estate in the United Kingdom showed that numerical weather prediction models were not as accurate as direct observations on site by instruments on towers (Crown Estate 2014). Since that report was published, floating lidar systems have been found to perform well if correctly deployed and operated, but at a considerably lower cost than towers; this cost advantage has contributed to the rapid adoption of floating lidar technology.

\subsubsection{Floating Systems}

To support the development of wind energy offshore, several different types of floating lidar systems have been developed. These systems measure wind speed and direction at the turbine hub height from the surface, making offshore wind resource prospecting much easier and faster. They are also potentially much less expensive than offshore towers.

Floating lidar systems are complex and include communications, energy generation and storage, and various methods to mitigate the effect of the lidar motion on the data obtained by the lidar. These motion mitigation systems (often referred to as motion compensation systems) are a combination of software and hardware, and may reduce the physical motion of the lidar while controlling the lidar or data processing to reduce the effect of motion. Floating lidar systems are considered a TRL 8 at this time as they are currently used widely, but questions remain about their accuracy and long-term performance.

These systems have been used extensively in Europe (particularly in the United Kingdom), the United States, and Asia. At the time of writing, floating lidar systems have been deployed at least 20 times in the United States, and many more times in the United Kingdom and Europe. The first 
offshore deployments took place in the late 2000s and since then around 10 different lidar and platform designs have been developed.

The type of platform and lidar device are usually optimized for a particular deployment, although at this time the same lidar systems dominate both the offshore and land-based markets. This parallel development stems partly from the fact that offshore lidar users require confidence in the technology that they are deploying, and using an existing and tested design is one way to reduce risk. IEA Wind Task 32 developed a recommended practice for floating lidar systems in 2016 that documents the process of deploying floating lidar systems for offshore wind energy applications (Bischoff et al. 2016).

One major concern about floating lidar systems is the effect of sea conditions and motion on the accuracy and uncertainty of the device. The effect of motion on lidar accuracy was explored in the XPIA experiment (Lundquist et al. 2017). Because the floating lidar system and lidar motion compensation system are limited by the geometry of the system, it can be assumed that there will be some amount or type of motion beyond which the motion compensation system will not be able to function. This performance boundary may impact the accuracy and uncertainty of the floating lidar system when used at two different sites, if the amount of time when the motion exceeds the boundary changes between the sites (Figure 19).

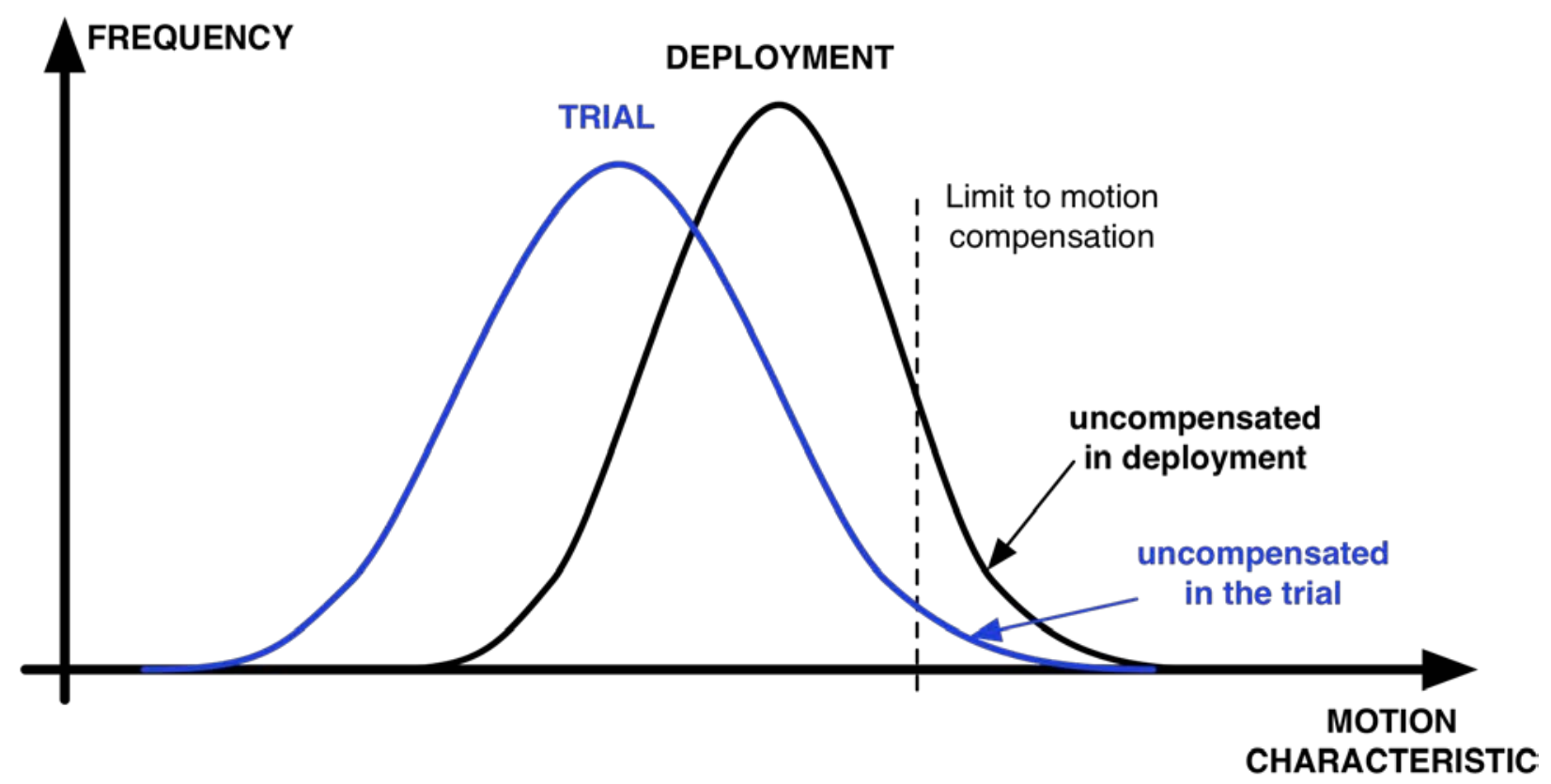

Figure 19. Different motion characteristics at deployment sites can lead to changes in uncertainty

\subsubsection{Tethered Lifting Systems}

Kites and balloon-borne systems have been used for atmospheric research since 1749, and Balsley (2008) provides a comprehensive review of this history. These platforms can transport probes aloft to sample the lowest atmosphere. Even though weather balloons typically carry radiosondes that measure average values of temperature, pressure, winds, and humidity, tethered systems can carry five-hole and seven-hole pitot tubes as well as hot wire and cold wire anemometers. 
Such platforms have enabled important fundamental insights into boundary-layer dynamics, especially stable boundary layers, because of the ability to sample vertical profiles of thin layers in the atmosphere (Frehlich et al. 2003; Muschinski et al. 2004; Frehlich et al. 2006; Balsley et al. 2006, 2007). As discussed here and shown in Figure 16, in "Hot wire, cold wire, hot film, cold film anemometers," tethered systems have been used to sample turbulence dissipation rates as well as wind speed deficits in wind turbine wakes (Lundquist and Bariteau 2015).

\subsubsection{Remotely Piloted Aircraft System}

The rapid development of remotely piloted aircraft systems during the last decade has provided new airborne sensor platforms for atmospheric boundary layer research as summarized by Elston et al. (2015). Typically, these systems can provide measurements of wind speed, temperature, pressure, and some humidity variables. Depending on the rate of the probe mounted on the remotely piloted aircraft system, many of these platforms have documented capabilities for measuring atmospheric turbulence parameters (Båserud et al. 2016), usually a temperature structure parameter (Thomas et al. 2012; Kroonenberg et al. 2012; Reineman et al. 2013; Wildmann et al. 2013, 2014, 2015; Braam et al. 2016). These systems have been used to measure the wind speed deficits in wind turbine wakes (Kocer et al. 2012; Båserud et al. 2014).

\subsubsection{Satellite-Based Measurements}

Wind speed and direction can be measured from satellites over water surfaces by satellites using lidars, microwave scatterometers, and synthetic aperture radars. Satellite lidar systems are similar to the systems that are used for wind speed and direction measurements on the ground or from turbines. They typically leverage the movement of the satellite to obtain multiple viewing angles for use in wind field reconstruction, rather than having any ability to adjust their beam's trajectory. An ultraviolet Doppler wind lidar system was launched by the European Space Agency as the Aladin instrument on the Aeolus satellite in late 2018. ${ }^{3}$ This instrument has the capability to measure wind speeds in the atmosphere at altitudes up to $30 \mathrm{~km}$ with an approximate 500-m vertical resolution and 3-km horizontal resolution, with errors less than $1 \mathrm{~m}$ $\mathrm{s}^{-1}$ in the lower $2 \mathrm{~km}$ of the atmosphere. Some horizontal and vertical aggregation should be expected.

Microwave scatterometers measure the amount of microwave energy reflected by the ocean surface and relate that to surface wind speed using empirical relationships. Wind direction is derived from the wind speed vectors using a fitting method. Scatterometers deliver wind speeds at the surface over pixels that are several tens of kilometers on a side, therefore they cannot be used near the shore. Wind speeds are measured at or near the surface. As a result, wind speeds can only be estimated at wind turbine hub heights by extrapolation.

The European Space Agency, National Aeronautics and Space Administration (NASA), and the National Space Development Agency of Japan have all flown microwave scatterometers on several satellites. NASA operated a scanning scatterometer called SeaWinds on the QuikSCAT satellite from 1999 to 2009, and then operated an almost-identical scatterometer on the international space station from 2014 on. Data from the QuikSCAT satellite have been used to estimate wind resources in offshore regions (Karagali et al. 2014). Biases compared to surface stations are around zero but the standard deviation is around $1 \mathrm{~m} \mathrm{~s}^{-1}$ or more. Together with

\footnotetext{
${ }^{3}$ See http://www.esa.int for details.
} 
coarse temporal and spatial resolution, this large standard deviation renders data from the current generation of scatterometers unsuitable for use for validating wind estimates from models in coastal regions. Despite their limitations, the data provided by scatterometers can be used as boundary conditions to global and mesoscale weather models.

Synthetic aperture radars use two radar beams with identical or different polarization to detect the wind speed near the surface. Wind directions are retrieved by analyzing features, such as streaks, and are not directly observed. The spatial resolution is around $1 \mathrm{~km}$ or less, and although it is a better resolution than what can be obtained using microwave scatterometers, it is still relatively coarse. A summary of the use of synthetic aperture radars for wind measurements can be found in Dagestad et al. (2013) and a recent application at the Anholt wind farm is discussed by Ahsbahs et al. (2018).

Satellite measurements are also employed for measuring solar radiation. The amount of energy received from the sun at the ground cannot be measured by satellites directly. Instead, a satellite can observe the distribution, structure, and opacity of clouds, which are the primary way in which the top-of-atmosphere irradiance from the sun is modified. Combining simple models of the top-of-atmosphere irradiance with cloud masks, aerosol data, and radiative transfer models such as FARMS (Xie et al. 2016) allows the global horizontal irradiance and direct normal irradiance to be estimated to within a few percent of the values obtained by high-quality surface stations. Such single-column methods have been commercialized and are the basis of some solar energy resource forecasting products.

\subsubsection{Turbine Response}

Wind turbines themselves respond to atmospheric conditions through mechanical loads or power production, and thus data streams from turbines can be used as sensors of the atmosphere. Guidelines and recommendations for measuring mechanical loads and turbine power are documented in IEC standards (IEC 61400-11 2012; IEC 61400-12-1 2005, 2017; IEC 61400-122 2013; IEC 61400-13 2015; IEC 61400-21 2008). These methods may be adapted to meet specific testing needs as needed. For example, when higher accuracy is required, researchers can make modifications to instrumentation or the turbine to obtain higher SNR ratios.

Measurement uncertainties are determined by using uncertainty estimation techniques provided in the ISO/IEC Guide 98-3:2008 (2008). Examples of test reports following IEC standards can be found in Mendoza et al. (2015b, a); Santos and van Dam (2015); Roadman and Huskey (2015). The following sections provide details on the measurement techniques used for specific signals.

\subsubsection{Mechanical Loads Measurements}

Strain gages are one of the most common and proven technologies for measuring many different static and dynamic loads (Hannah and Reed 1992; IEC 61400-13 2015). Strain gages come in a large variety of sizes, patterns, sensitivities, and backing materials. They commonly consist of a foil grid (sensing element), with organic or metal backing material. Further, they allow the user to measure highly localized strain with a single gage. Many gages must be placed to measure strains over a large area. For turbine response measurements, strain gages can be used to acquire bending moments (for the blades, tower, main shaft, and/or bedplate) and torque (for the blades, tower, main shaft, and high-speed shaft). 
Fiber Bragg gratings allow the user to measure high-fidelity strains by means of the Bragg wavelength shift, a perturbation of the refractive index in the core of an optical fiber (Rao 1997). The fiber Bragg gratings consist of single-mode fiber that reflects and transmits particular wavelengths of light when an ultraviolet or broadband light is applied to the fiber and an optical interrogator or charge-coupled device to observe the Bragg wavelengths. Common measurement ranges of $\sim 5$ microstrain to $>10,000$ microstrain can be measured. Typical strain levels of wind turbine components are in the range of 100 to several thousand (Rao 1997; Kreuzer 2006). In regard to turbine response measurements, a fiber Bragg grating can be used to measure loads of various turbine systems and components. It can also be used to determine blade loads (in plane, out of plane, and torque), tower loads (bending moments and torque), and main shaft loads (bending moments and torque).

Digital image correlation is a noncontact optical method and technology used to measure deformations, strains, and displacements of a material or object using precision stereoscopic imaging to accurately track two-dimensional and three-dimensional changes in images (Pan et al. 2009). Digital image correlation has a wide measurement range, with fields of view from 500 microns to $100+$ meters (Winstroth et al. 2014). Further, it can be used to acquire the following turbine response parameters:

- Blade loads. Using spanwise targets applied to the outside of a blade, the following blade loads can be measured (Niezrecki et al. 2010; Winstroth et al. 2014): in plane, out of plane, and rotor torque.

- Surface strain. Using a stochastic pattern applied to a component surface, digital image correlation can be used to measure surface strains.

- Blade displacements. Spanwise targets applied to the exterior of a blade can be used to measure the following displacements (Niezrecki et al. 2010; Winstroth et al. 2014): in plane and out of plane.

Accelerations are also critical turbine measurements. Measured turbine accelerations include the tower-top and blade accelerations (IEC 61400-13 2015). Accelerations are typically measured with devices called accelerometers. These instruments use piezoelectric or capacitive sensing technologies to measure static and dynamic accelerations. Accelerometers are capable of measuring a wide range of accelerations and frequencies, from $0 \mathrm{~g}$ (gravitational accelerations) to $10,000 \mathrm{~g}$ at peak and $0.05 \mathrm{~Hz}$ to $10,000 \mathrm{~Hz}$, respectively.

Load cells allow for the measurement of tensile and compressive static and dynamic loads. Load cells are less commonly used in wind turbine applications due to the difficulty of placing a load cell in the load path (IEC 61400-13 2015). Load cells are most commonly used in calibration procedures. However, in turbine response applications, a load cell can be used to measure tower anchor rod tension and blade pitch actuation loads.

\subsubsection{Blade Measurements}

\section{Local inflow angle measurements}

Flow angle flags are simple mechanical devices similar to wind vanes that measure local inflow angle in the plane orthogonal to the blade axis, and typically are positioned a significant chord fraction ahead of the blade leading edge. Such devices are well-suited to provide average flow 
angles over long periods of time, but are dynamically active, meaning they provide erroneous data in response to turbulent or impulsive stimulation because of the presence and interaction of inertial and unsteady aerodynamic effects. Such stimulation can cause flow angle flags to oscillate around the true flow angle, severely limiting their effective trustworthy bandwidth (Simms et al. 1999).

Multihole probes use a measurement of pressure at several holes on the tip of a conical, biconical, or spherical tip to determine inflow angle, inflow speed, and local static and total pressure, depending on calibration regimen. A three-hole probe can determine flow angle in one plane, and a five or seven-hole probe can determine flow angle in two planes. Five-hole probes can generally acquire reliable measurements through a conical half-angle range of approximately 40 degrees, whereas a seven-hole probe widens this range to approximately 60 degrees (Zilliac 1989; Hand et al. 2001). Such probes do not suffer from the dynamic effects of the flow angle flags because they do not possess any mass, and unsteady aerodynamic effects are limited by tip size and geometry. However, calibration and processing of the data from these probes can be difficult and slow, depending on the calibration and reduction methodology. Once these problems are overcome, these devices provide a highly reliable measure of the local flow angle at the probe tip with a bandwidth comparable to that of the pressure system used to measure the port pressures, and to angular resolution of approximately 0.1 degree.

\subsubsection{Flow Visualization}

\section{Tufts}

Tufts are pieces of string or yarn that are used to indicate the local flow angle, usually in the blade boundary layer. If the tuft is offset from the surface by a thin rod, it can be used to indicate the flow angle above the surface and outside the boundary layer, but this is less common. Flow intrusion caused by the presence of the tufts depends on tuft size and location, but in most cases these effects do not represent an overriding impediment (Pope and Rae 1984).

Used at the surface, an array of tufts can indicate local surface flow direction. Flow angle and/or flow state at the tufts can be very different between the attached and separated flow regimes. For example, tufts might sit smoothly against the surface pointing in the mean flow direction for attached flow, but shake violently and point in more random directions in separated or reattaching flow.

\section{Oil flow}

Oil flow visualization can be used in several ways to determine flow qualities in the surface boundary layer. The simplest approach is to track how oil flows in the presence of local blade surface boundary layer shear stresses. Photos are taken before and after the flow condition is realized, and in some cases, photos are taken during the experiment. The processing is done on the pictures later (Squire et al. 1962). It must be noted that practical considerations inherent in this technique make it a challenging and costly undertaking.

\section{Full-field techniques}

Full field techniques include qualitative smoke or particle visualization of structures (e.g., vortices) or events (separation), or quantitative interrogation of seeded flows (i.e., PIV, see Section 2.2.4.10). It should be noted that these techniques are well-suited to wind tunnel 
experiments, but are generally infeasible in the field environment because of difficulties with achieving threshold densities in visualization or seeding, and with providing illumination intensities that sufficiently exceed background levels.

\subsubsection{Surface Pressure Measurements}

Surface pressure measurements are usually used to determine local airfoil performance, including local dynamic pressure at the stagnation point, and local normal and tangential force coefficients. An advantage of this approach over something like strain gauges is that it is very specific to a local area, rather than integrated across a whole section, and that it can be very fast because it does not have a mass to be moved to make the measurement. Bandwidths can range from about $1 \mathrm{~Hz}$ if pressure tubes between sensor and airfoil surface are long to upwards of 1 kilohertz if surface sensors are employed directly (Boorsma and Schepers 2011). With short tubes, effective bandwidths are often in the 10-100 Hz range (Butterfield et al. 1992). If long tube lengths cannot be avoided, then inverse filtering techniques can be applied to partially compensate for nonlinear dispersion effects (Whitmore 2006).

\section{Pitch angle}

Pitch angle is typically measured by installing an absolute rotary encoder on the pitch gear. This allows measurement of the pitch angle within $0.1^{\circ}$ (typically the uncertainty is determined by the amount of backlash in the setup). For a wind turbine with a hydraulic pitch system, a linear encoder can be used. Oftentimes the turbine controller signal can be split, in which case the latency and accuracy of the signal needs to be evaluated.

\section{Pitch actuation loads}

Depending on the pitch system, the pitch actuation load can either be measured through strain on a linear actuator (e.g., hydraulic pitch ram), by measuring pressure in a hydraulic actuator, by measuring the torque on the shaft of the pitch drives, or it can be estimated from the power consumption of an electric pitch drive. Note that all these methods will include loads caused by the friction in the pitch bearing.

\section{Pitch rate}

The pitch rate is usually derived from the pitch angle. This calculation requires evaluating the pitch angle resolution and sample frequency and implementation of a multisample derivative of the pitch angle signal.

\section{Rotor azimuth}

Rotor azimuth is typically measured by installing a rotary quadrature encoder at the end of the shaft, having a rotary quadrature encoder ride on the main shaft, or by creating quadrature pulses by counting targets (bolt heads or other targets). Typically (unless an end of shaft encoder is used), a separate reset pulse is provided to reset the azimuth signal. The same sensor can often be used to derive rotor speed. Alternatively, an inertial measurement unit or accelerometer can be used in the rotating frame. 


\subsubsection{Nacelle}

\section{Drivetrain displacement}

Rigid body motion of the drivetrain is typically measured relative to the bedplate/nacelle frame using proximity sensors, linear variable differential transformers, or optical sensors.

Measurements are typically taken from the main bearing housing to the main shaft and from the gearbox trunnion mounts to the torque arms.

\section{Stray currents}

A Rogowski coil is an electrical device for measuring AC or high-speed current pulses. It consists of a helical coil of wire with the lead from one end returning through the center of the coil to the other end, so that both terminals are at the same end of the coil. The whole assembly is then wrapped around a straight conductor whose current is to be measured (Webster and Eren 2014). Rigowsky coils have been used by industry to measure so-called "stray currents" through main shafts and bearings (Marinov and Rahman 2005). This technique can measure stray currents on main shaft and high-speed-shaft bearings in wind turbines.

\section{Six-degree-of-freedom inertial measurement unit}

A six-degree-of-freedom inertial measurement unit is a sensor designed to provide translational movement in three perpendicular axes and rotational movement about three perpendicular axes, for a total of six independent degrees of freedom. These sensors can be used to measure nacelle or tower-top accelerations, displacements, and rotations.

\subsubsection{Performance}

\section{Power (rotor, stator, and consumption)}

Generally, power output of a wind turbine is three-phase $50 / 60 \mathrm{~Hz}$. The generator range should adequately cover the instantaneous minimum and maximum power output, i.e. $-50 \%$ to $150 \%$ of the rated power of the wind turbine. Measuring net power may require measuring power in more than one location to include the wind turbine's consumption as well as output. Power can be measured by different instrumentation including a power transducer or a current and voltage transducers. Other characteristics may also be measured including phase voltage, phase current, frequency, and reactive power.

\section{Acoustic emissions}

Acoustic emissions from a wind turbine can be affected by turbine operating and atmospheric conditions. The acoustic emissions can be measured using a microphone, preamplifier, and acoustic data acquisition system. The IEC 61400-11 standard provides guidelines to measuring acoustic emissions from wind turbines (IEC 61400-11 2012).

\section{Nacelle anemometer}

Wind turbines typically have a cup anemometer installed on the nacelle to measure the wind speed. The measured wind speed is read by the wind turbine controller to assist in determining the operation. The wind speed may determine if the wind turbine should start idling or to shut down at cut-out wind speeds. Because the anemometer is mounted on the nacelle behind the wind turbine blades, the flow is obstructed and has less accuracy than an anemometer on a meteorological tower or which is measured by a remote-sensing device. The IEC 61400-12-2 
standard provides a method to determine a transfer function between a meteorological-towermounted anemometer to a nacelle anemometer to determine a wind turbine power curve (IEC 61400-12-2 2013). Research investigations have begun to use nacelle anemometers to assess turbine performance (Vanderwende and Lundquist 2012; St. Martin et al. 2016) as well as provide data to improve atmospheric modeling.

\section{Nacelle wind vane}

Wind turbines typically have a wind vane installed on the nacelle to measure the wind direction. The measured wind direction is read by the wind turbine controller to assist in keeping the wind turbine aligned with the wind. The nacelle yaw position is determined based on the wind direction measured by the wind vane. In wake steering projects, an offset can be applied to execute a yaw offset.

\section{Turbine status}

A signal or signals from the wind turbine controller indicate if the wind turbine is on standby, operating, producing power, shutdown, or faulted. For more detail, see the section on supervisory control and data acquisition signals.

\section{Rotor speed}

The rotor speed indicates the rotational speed of the rotor that is measured by an absolute rotary encoder or proximity sensor, similar to azimuth. This measurement range is $0-360$ degrees and requires a position reset when passing from 360 to 0 degrees.

\section{Yaw position}

The yaw position indicates the position of the nacelle that is measured by an absolute rotary encoder or proximity sensor, similar to azimuth. This measurement range is $0-360$ degrees and requires a position reset when passing from 360 to 0 degrees or the other direction. The yaw position is determined by the wind turbine controller using the wind direction measurement from the wind vane.

\section{Yaw rate}

The yaw rate is usually derived from the yaw position. It requires evaluation of the yaw position resolution and sample frequency and implementation of a multisample derivative of the yaw position signal.

\section{Supervisory control and data acquisition signals}

The wind turbine will have an anemometer, wind vane, rotor speed sensor, electrical power sensor, pitch angle sensor, limit switches, vibration sensors, temperature sensors, operator switches, yaw position sensor, and other sensors to control and determine the state of the wind turbine. The signals from these sensors, switches, and controls can be made available for data acquisition or the data can be made available.

\subsubsection{Gaps}

Great progress has been made in the past 20 years in developing observational capabilities relevant for boundary-layer meteorology and wind energy field experiments, but it is clear that there is still room for improvement. For example, scanning radar and lidar systems may provide 
volumetric measurements of winds, but the capability of measuring turbulence relevant for the volumes of numerical modeling (either large-eddy simulation or mesoscale simulation) is still preliminary, especially in complex terrain, for both model validation and wind turbine tests. Further, uncertainty quantification for such measurements is at an early stage. Increased temporal (especially for lidar) and spatial resolution would be beneficial, as would be the ability to "see" in all air conditions. Particularly for evaluation modeling formulations, simultaneous measurements of vertical fluxes of heat, momentum, and moisture over the area of interest (perhaps $10 \mathrm{~km}$ by $10 \mathrm{~km}$, the size of a wind farm) at vertical resolution on the order of $10 \mathrm{~m}$ would provide key parameters for initializing and evaluating simulations. Large-eddy simulations also require estimates of surface roughness. The aerodynamic roughness length, usually denoted as $z$, is a mathematical construct based on the wind shear in the surface layer resulting from roughness elements on the surface such as vegetation, buildings, or wave heights. Smaller roughness elements create a smaller roughness length. Stull (1988) summarizes methods for estimating roughness length from the size, silhouette, and spacing of roughness elements. Offshore, it is often assumed that the roughness is a function of wind speed and the resulting surface stress $u_{*}^{2}$ using Charnock's relation:

$z_{0}=0.015 \frac{u_{*}^{2}}{g}$

On land, the heights of roughness elements can be measured with lidar, but the direct calculation of roughness length from those roughness elements depends on the horizontal extent of the area covered by those roughness elements.

Evaluating large-eddy simulation capabilities for representing turbines is still challenging, especially when evaluating how actuator line and actuator disk models represent the evolution of the near-wake region of a turbine. Such measurements would require spatial resolution on the order of $5 \mathrm{~m}$ or even finer to consider turbine blade tip vortices. Similarly, the ability to more accurately and dynamically measure blade-tip deflection would be useful.

Fundamentally, the need to generalize specific observations, collected over a short period of time, to a longer climatological time series, impacts numerous facets of wind energy, from the annual or interannual time scales of wind resource assessment to the short temporal scales of wake steering projects. Formulation of dynamic uncertainty models could be useful, especially as simulation-in-the-loop is incorporated into more and more studies. 


\section{Recent Experiments}

\section{1 eXperimental Planetary boundary layer Instrumentation Assessment}

To assess capabilities for quantifying features of the complex flow in and near wind farms, DOE sponsored the eXperimental Planetary boundary layer Instrumentation Assessment (XPIA) campaign (Lundquist et al. 2017). The experiment was conducted from March 2 to May 31, 2015 at the Boulder Atmospheric Observatory (BAO), located $\sim 25 \mathrm{~km}$ east of the eastern slopes of the Rocky Mountains, $\sim 25 \mathrm{~km}$ north of downtown Denver, Colorado, and $\sim 20 \mathrm{~km}$ east northeast of Boulder, Colorado, at an elevation of 1,584 meters above sea level. The spring season offers a range of wind speed, direction, and precipitation conditions to challenge the instrumentation. XPIA was supplemented by the National-Science-Foundation-sponsored "Characterizing the Atmospheric Boundary Layer" educational outreach project, which provided in situ sensors such as radiosonde launches, 12 sonic anemometers deployed on the 300-m tower, and two surface flux stations, as well as opportunities to engage students from middle school through graduate studies. In addition to deploying state-of-the-art wind scanning remote-sensing technology, such as Ka-band radars and scanning lidars, the XPIA team developed and tested multi-Doppler scanning techniques for comparison to the in situ instrumentation. To quantify the uncertainty of these new types of measurements, results of these scans and retrievals are compared to standard measurements as well as to profiles from profiling lidars. In addition, radiosonde launches, along with temperature and moisture profiles from the tower, provide verification data for assessing microwave radiometer estimates of atmospheric stability. The collected data are archived for public use at the A2e Data Archive and Portal (https://a2e.energy.gov/data).

Line-of-sight velocities measured by scanning lidars and radars exhibit close agreement with tower measurements, despite differences in measurement volumes. Virtual towers of wind measurements, from multiple lidars or radars, also agree well with tower and profiling lidar measurements. Estimates of winds over volumes from scanning lidars and radars are in close agreement, enabling assessment of spatial variability. Strengths of the radar systems used here include high scan rates, large domain coverage, and availability during most precipitation events, but they struggle at times to provide data during periods with limited atmospheric scatterers. In contrast, for the deployment geometry tested here, the lidars have slower scan rates and less range, but provide more data during nonprecipitating atmospheric conditions. Microwave radiometers provide temperature profiles with approximately the same uncertainty as RASS. Using a motion platform, motion-compensation algorithms for lidars to be mounted on offshore platforms were assessed. Cases for validation of mesoscale or large-eddy simulations were identified, providing information on accessing the archived data set. Modern remote-sensing systems provide a generational improvement in observational capabilities, enabling resolution of fine-scale processes critical to understanding inhomogeneous boundary-layer flows. 


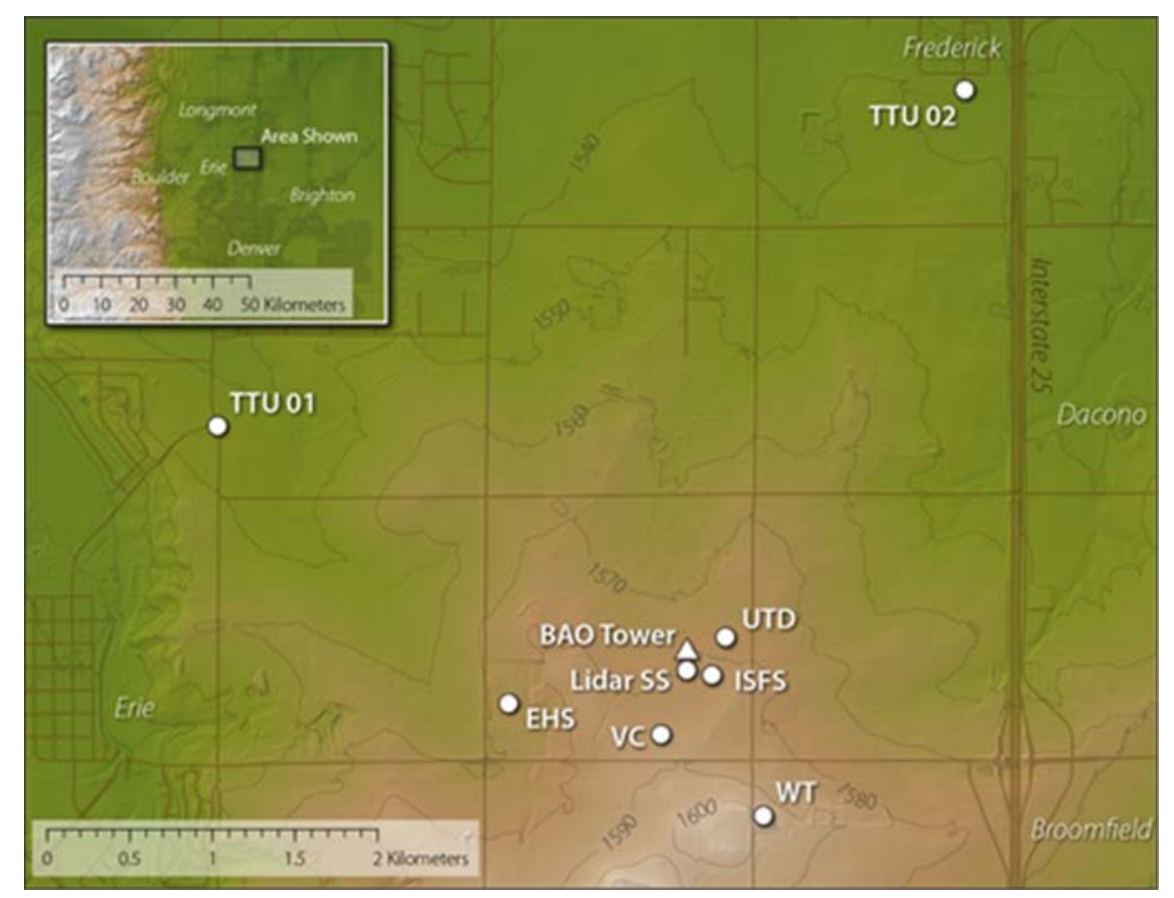

Figure 20. Schematic diagram of the XPIA deployment. Inset: the location of the XPIA measurement site in northern Colorado. Main figure: the location of the BAO $300-\mathrm{m}$ tower (BAO Tower); the lidar supersite (Lidar SS); the Visitor Center (VC), location of National Oceanic and Atmospheric Administration (NOAA) Dalek 02, the radar wind profiler/RASSs, the NOAA and CU microwave radiometers, and several radiosonde launches); the water tank (WT), location of the NOAA HRDL, the UMBC lidar and radiometer, and some radiosonde launches; Erie High School (EHS), location of the NOAA Dalek 01; UTD, the location of the UTD 2005 lidar, and the locations of the two TTU Ka-band Doppler radars (TTU 01 and TTU 02). Contours show elevation in meters above sea level. From Lundquist et al. (2017)

\subsection{SWiFT}

Sandia National Laboratories and NREL will jointly execute a two-phase experimental campaign on wind farm controls and wake characterization at the SWiFT facility in 2016 and 2017. The goal of the experiment is to demonstrate the capability of wake steering control to improve total wind turbine array power production.

In Phase I, an offset controller is applied to the SWiFT turbine WTGa1. This controller applies an offset to a nacelle-based wind direction sensor used to align the turbine to the wind direction to achieve a prescribed misalignment to the wind. Wake position data will be collected under multiple yaw misalignment angles and inflow conditions as simulated prior to the experiment using the Simulator fOr Wind Farm Applications (SOWFA) code. These data will be used to both verify the ability to steer the turbine wake at the SWiFT facility and to develop a look-up table for the FLOw Redirection and Induction in Steady-State (FLORIS) control model to be implemented in the Phase II controller.

In Phase II, the offset controller on WTGa1 is replaced by a wake steering controller that operates in a similar fashion to the offset controller. However, it uses a look-up table based on the FLORIS model to prescribe offsets to produce a desired wake steering amount based on the inflow parameters. The wake deflection will be verified by the scanning lidar along with turbine performance data (loads and power) for both the WTGa1 and WTGa2 turbines. The collected 
data will be used to improve wind farm simulation codes, and will be archived for public use in the A2e Data Archive and Portal. ${ }^{4}$

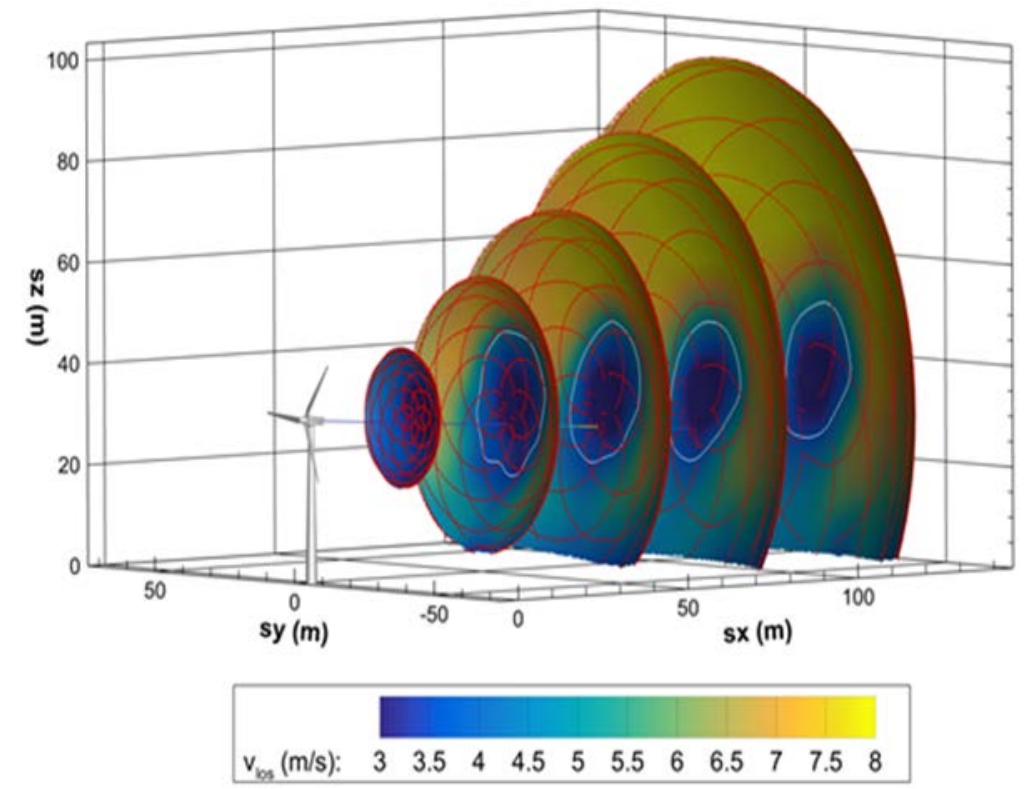

Figure 21. Configuration and example measurements of the SWiFT turbine with the lidar measuring the velocity $1-5$ rotor diameters $(D)(D=27 \mathrm{~m})$ downstream; the yellow portion of the laser schematic depicts the probe volume

The following GPS time-synchronized instrumentation supported this experiment:

- SWiFT wind turbines. The research-grade turbines known as WTGa1 and WTGa2 will be the primary instrumented research turbines to collect power and loads data. The upwind WTGal turbine will be enabled with the yaw-based wake steering controller.

- SWiFT meteorological tower. Upwind from the WTGal turbines is the meteorological tower METa1 with instrumentation that characterizes the inflow at multiple heights from below the rotor to above the rotor plane.

- DTU SpinnerLidar. A customized scanning lidar that is installed in the upwind WTGa1 turbine nacelle and faces downwind to characterize the wake at multiple ranges (Figure 21).

- Pentalum SpiDARs. Six vertical profiling lidars measuring the flow at 10 heights ranging between 20 and $65 \mathrm{~m}$ deployed in multiple configurations near the METa1 tower and in the wake of the WTGal turbine.

- Windar 4-beam Lidar. A nacelle-mounted lidar with four beams focused $40 \mathrm{~m}$ downwind of the WTGa1 turbine.

\footnotetext{
${ }^{4}$ https://a2e.energy.gov/projects/wake
} 


\subsection{National Rotor Testbed}

The National Rotor Testbed (NRT) is an experimental platform that is used to study wind turbine wake physics at a scale that is both affordable and relevant to utility-size turbines. The rotor creates a scaled wake by having the same dimensionless circulation, induction, and thrust coefficient as a GE 1.5sle rotor. Instrumentation planned for the NRT include a suite of aerodynamic and structural sensors including five-hole pitot probes, pressure taps, tufts, strain gauges, and accelerometers.

Five-hole pitot probes will be used to measure relative flow angles and inflow velocities across the blade span during operation. From these probes, axial induction and tangential induction can be calculated to verify that the NRT blade performs consistently with its design. Induction is also important for describing the near-wake of a wind turbine. From the measured inflow angle and the known blade twist, the angle of attack at any blade station can be calculated. Angle of attack is useful to verify two-dimensional airfoil performance of the design, and for validation of simulation codes.

Pressure taps at a few blade stations will be used to measure the static pressure around the airfoil sections. From pressure, lift and form drag can be directly calculated. These measurements are important for validating blade-resolved simulations, in which the flow around the blade surface is modeled. The pressure coefficient can also be calculated from the pressure taps and will be used to verify the airfoil polars used in the NRT design.

Tufts of string will be adhered to the root region of the blade and used as a qualitative flow visualization technique. Tufts lying parallel to the blade surface show an attached boundary layer, and oscillating, lifted tufts indicate the boundary layer has separated. This spatial distribution of tufts will be used to verify the separation and stall characteristics of the NRT design. The tufts can also be used to validate codes because the extent of separation is difficult for simulation codes to ensure accurate predictions, especially in three-dimensional and rotating flows.

Strain gages were installed to measure the flap and edge strains in the blade skin $200 \mathrm{~mm}$ from the blade root. At three additional blade stations $(3,250 \mathrm{~mm}, 6,500 \mathrm{~mm}$, and $9,750 \mathrm{~mm})$ strains are only measured in the flap-wise bending direction. This configuration allows for integrated loads and torques to be quantified in the NRT blade. Strain gages are prone to temperature drift, therefore temperature sensors are included and located at 200, 4,875, and 9,750 $\mathrm{mm}$.

Two accelerometers measure NRT blade acceleration in three orthogonal directions at $8,060 \mathrm{~mm}$ and $11,440 \mathrm{~mm}$ locations relative to the blade root. The first and second derivative of acceleration is blade velocity and displacement, respectively, which can also be calculated to understand the dynamic and elastic behavior of the blade. Modal analysis of the beam structure showed that these two sensor locations best capture the highest energy and lowest frequency structural modes of vibration.

\subsection{Crop-Wind Energy Experiments}

The series of Crop-Wind Energy Experiments (CWEX) (Rajewski et al. 2013; Rhodes and Lundquist 2013; Lundquist et al. 2014; Rajewski et al. 2014; Takle et al. 2014; Vanderwende et 
al. 2015; Rajewski et al. 2016, Bodini et al. 2017), which took place in a 200-MW wind farm in central Iowa, sought to measure interactions between wind turbines, the atmosphere, and the microclimate of intensive agriculture. The Story County I and II wind farms experience strong diurnal cycles of atmospheric stability and frequent nocturnal low-level jets. The area has flat topography, primarily devoted to large fields of corn (height 1-2 m) and soybeans (height 0.3-0.8 $\mathrm{m})$. The region also has four small villages, some riparian areas, and a few trees and buildings associated with farmsteads.

The CWEX-10 experiment, highlighted in Rajewski et al. (2013) and discussed in detail in Rajewski et al. (2016) primarily consisted of surface flux station measurements taken between 2.5D upwind and 20D downwind of two rows of turbines to investigate impacts of wind turbine wakes on surface wind speed, temperature, fluxes, and turbulence. The CWEX-11 again employed surface flux stations between 2D and 10D from a row of turbines, but also employed wind-profiling lidars (Windcube v1 lidars) upwind and downwind from the row of turbines to quantify turbine wakes (Rajewski et al. 2013; Rhodes and Lundquist 2013). CWEX-13 expanded the scope of interest by including a scanning lidar (Windcube 200S), a microwave radiometer, several profiling lidars, and surface flux stations to explore the role of stability-driven phenomena like nocturnal low-level jets on wake interactions with the atmosphere and with each other (Lundquist et al. 2014; Takle et al. 2014; Vanderwende et al. 2015). Scanning lidar measurements suggest that the wakes from turbines at the outer edge of a row are fundamentally different from wakes from inner turbines because outer wakes expand faster and have smaller velocity deficits (Bodini et al. 2017), as shown in Figure 22.

a)

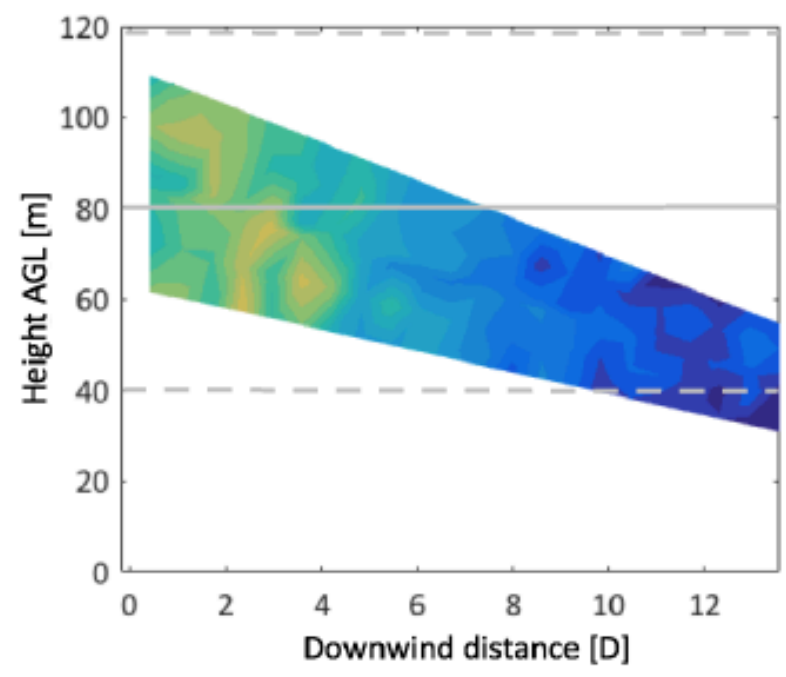

b)

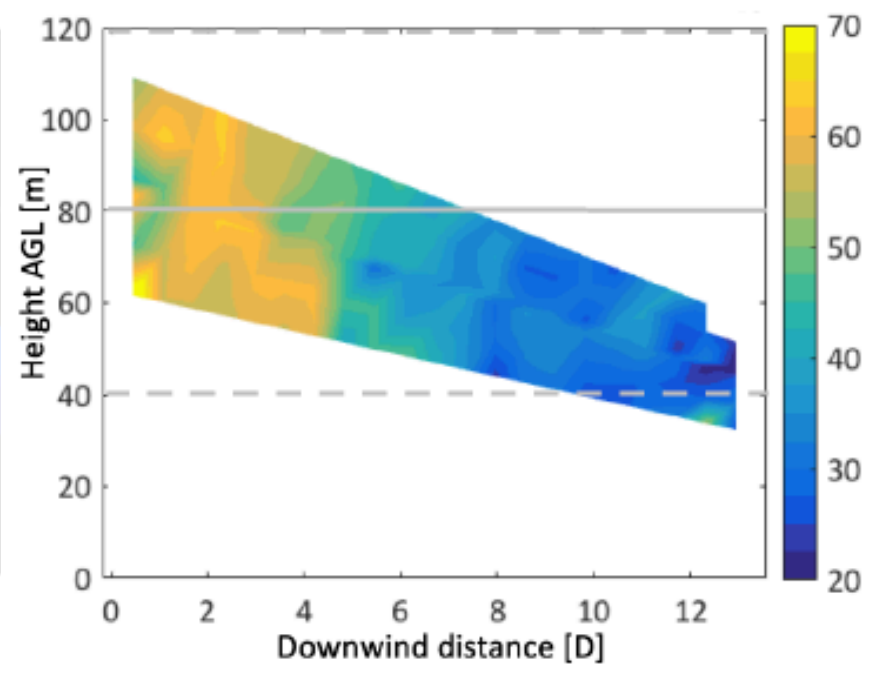

Figure 22. Velocity deficit (\%) vs. downwind distance at different vertical positions for wakes from a) an outer turbine and b) an inner turbine. Gray horizontal dashed lines represent the vertical limits of the rotor disk of the turbines; the horizontal continuous gray line shows the hub height of the turbines. Data collected from 5:31 to 5:42 Coordinated Universal Time (from 00:31 to 00:42 Central Daylight Time), August 26, 2013, from a succession of six PPI scans performed at six different elevation angles. From Bodini et al. (2017) 


\subsection{Full-Scale Wake Testing}

Numerous entities worldwide are engaged in full-scale wake testing using different technologies. Researchers have used ground-based research-grade lidars to observe turbine wakes (Aitken et al. 2014), whereas others have used ground-based commercial lidars (Rajewski et al. 2013), radar systems (Hirth et al. 2012), nacelle-mounted lidars (Aitken and Lundquist 2014; Gallacher and More 2014) advanced optical techniques (Hong et al. 2014), and even unmanned aerial vehicles (Kocer et al. 2012). The goal of each of these studies is to gain a better understanding of wind turbine wakes that greatly influence wind farm performance and reliability.

Recently, DOE funded tests on a single 1.5-MW wind turbine located at the NWTC through a partnership between NREL and the University of Stuttgart. NREL and DOE are providing the turbine testing platform and control access, while the University of Stuttgart is providing their scanning lidar and analysis capabilities (see Figure 23). In this study, researchers are interested primarily in the wake behavior influenced by different atmospheric and turbine operating conditions. In particular, researchers are interested in the difference between wind turbine wakes when the turbine is operating under normal operating settings, versus those in which the turbine is yawed relative to the incoming flow, up to 25 degrees from the predominant wind direction (Fleming et al. 2017). It has been shown that yawing a turbine steers the wake away from downstream turbines and can be an effective control method for improving wind farm performance. The data are also useful for validating modeling tools of varying fidelity and testing the similarity of subscale wake tests, such as those performed at SWiFT, that are being used to better understand wake interactions under the DOE A2e program.

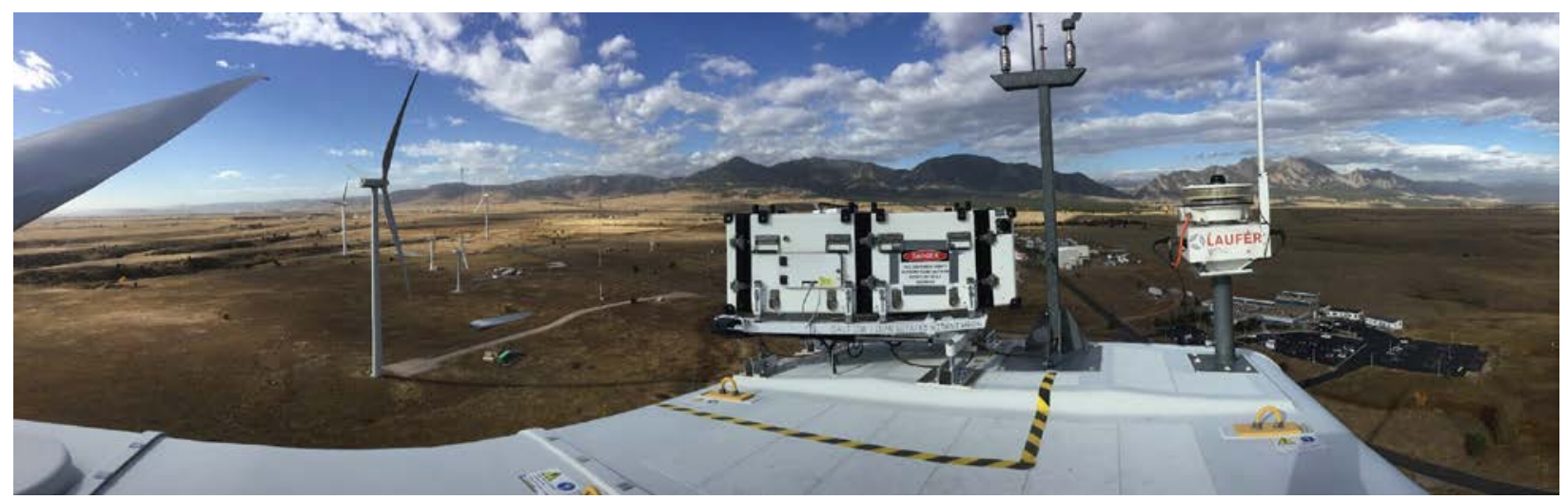

Figure 23. Photo of the University of Stuttgart lidar installed on the nacelle of the DOE 1.5-MW turbine. The lidar faces backwards to measure wakes and can rotate with yaw angles to capture the changing wake direction. Photo by Andrew Scholbrook, NREL

Observations of wind speeds and other atmospheric quantities are performed through researchgrade instrumentation installed on a 135-m meteorological tower at the NWTC (Clifton et al. 2013b). Wakes are tracked using the Stuttgart lidar at four different ranges, from 1 to 3D downstream of the operating turbine. Turbine operating conditions are observed through an augmented suite of sensors. Tests ran through the spring of 2018, with validation studies and comparisons to similar measurements at SWiFT to be published thereafter. 


\subsection{Wind Forecasting Improvement Project}

The Wind Forecasting Improvement Projects are collaborations between DOE, the National Oceanic and Atmospheric Administration (NOAA), and awardees of competitive funding. The projects were intended to foster improvement in the foundational forecasts prepared by NOAA and used by the wind energy industry either directly or incorporated into third-party products.

The first Wind Forecasting Improvement Project (WFIP) ran from 2011 to 2012 and focused on the initialization problem by examining the impact that assimilating enhanced observations has on the accuracy of wind turbine hub-height forecasts in Texas and the northern U.S. Great Plains (North and South Dakota) (Wilczak et al. 2015). Three data sets were assimilated: special WFIP remote-sensing observations (including RWP and lidar data), tall tower wind speed measurements, and turbine nacelle anemometer observations. The combination of these three datasets reduced the root mean-squared error (RMSE) for wind power forecasts averaged over the first 6 forecast hours by 3\% (Wilczak et al. 2015).

In 2015, observations commenced for the second Wind Forecast Improvement Project (WFIP2). WFIP2 sought to improve the representation of complex terrain boundary-layer physics and related processes in mesoscale models for improved wind power forecasts. The WFIP2 integrated observational and modeling study involved the wind industry, universities, NOAA, and DOE's national laboratories. Observations spanned 18 months in and around the Columbia Basin of eastern Washington and Oregon; the observations are archived at the DOE A2e DAP (https://a2e.energy.gov/projects/wfip2). Telescoping nests of observational systems captured important atmospheric scales from the mesoscale $(\sim 400 \mathrm{~km})$ to the numerical weather prediction model subgrid scale (the 2-km-by-2-km "Physics Site"). The WFIP2 study region extended from the mouth of the Columbia River around $200 \mathrm{~km}$ to the north and south, and $400 \mathrm{~km}$ west. Model improvements were tested in NOAA's High-Resolution Rapid Refresh (HRRR) model. This focus facilitated the rapid WFIP2 model improvements into operational forecast models. More detail on the WFIP2 is provided in an overview (Shaw et al. forthcoming) and a focused discussion of the observational campaign (Wilczak et al. forthcoming).

\subsection{Askervein Hill}

The Askervein Hill experiments (Taylor and Teunissen 1987), conducted in 1982 and 1983, documented flow on and around the Askervein Hill, a 116-m elevation hill on the west coast of the island of South Uist in the Outer Hebrides, Scotland. The hill was isolated in all wind directions except the northeast-east sector. To the southwest, the fetch was flat and uniform for 3-4 km toward the coastline, with sand dunes and low cliffs. The hill had a uniform surface roughness of $0.03 \mathrm{~m}$. The Askervein Hill project collected velocity and turbulence data, using over 50 meteorological towers with a total of 28 sonic anemometers, thereby providing a unique data set for comparison to numerical simulations. At the time, Askervein represented a significant advancement in measurements of flow over a hill: 35 of the masts were 10-m masts equipped with a cup anemometer to measure the mean flow. Vertical profiles were measured with taller masts at a reference point upstream, at the hill top, and at the center point.

Askervein Hill has become a standard test case for flow modeling (Raithby et al. 1987; Kim and Patel 2000; Lopes and Palma 2002; Castro et al. 2003; Undheim et al. 2006; Lopes et al. 2007; Chow and Street 2009). 


\subsection{New European Wind Atlas and Perdigão}

The New European Wind Atlas is an ongoing multiyear (2014-2019), €13M project to reduce the uncertainty in wind resource assessment. Several field campaigns contribute to the New European Wind Atlas, sampling a range of flow conditions from complex terrains (mountains and forests), offshore, large changes in surface characteristics (roughness change), and cold climates (Mann et al. 2017).

One of the complex terrain campaigns, the Perdigão experiment in eastern Portugal, occurred from late 2016 through midsummer 2017 in the Vale Cobrão, a picturesque valley nestled within a double ridge located in central Portugal. The U.S. National Science Foundation's Physical and Dynamical Meteorology Program sponsored a U.S.-based counterpart campaign. The pooled, coordinated measurement and modeling capabilities of European Union and U.S. investigators provided a holistic view of multiscale microscale processes in complex terrain to best capture diurnal flow variability, thermal circulation, turbine wake, and topographic effects (Fernando et al. 2019).

Perdigão collected a massive data set on microscales, covering an approximately 6-km-long, 2km-wide swath of the Cobrão valley (Fernando et al. 2019). Vertically, the measurements extend to tens of kilometers, with dense measurements up to several kilometers above the ridge height of about $500 \mathrm{~m}$ measured from the plain. An important design consideration was to collect a rich set of data extending from the surface to $300 \mathrm{~m}$ above ground level, which is particularly relevant for wind turbines. The instrument array was unprecedentedly dense (Figure 24), including 50 flux towers with heights of 10-100 m mounted with sonic anemometers (for mean flow, turbulence, and fluxes), thermistor arrays, rapid measurements of carbon dioxide and water vapor, and radiometers (incoming, outgoing, and net radiation); remote sensors for flow (sodars, lidars, and wind profilers) and temperature and/or humidity (microwave radiometers, RASS, atmospheric emitted radiance interferometer, water-vapor differential absorption lidar (DIAL), ceilometers, and radar wind profilers); tethered lifting (profiling) systems for fine-scale turbulence; micro- and nano-barographs; microphones for acoustics; and radiosonde launches. The lidar coverage is unique, with 28 scanning and profiling units operating to map the valley atmosphere in coordinated or autonomous modes. In a major shift from previous field studies, the mean and turbulent velocity fields were measured by six triumvirates of scanning Doppler lidars between a $25-$ and $75-\mathrm{m}$ resolution over $\sim 2-5-\mathrm{km}$ hemispherical volumes. The scanning lidar datasets have already yielded insights into turbine wake behavior in complex terrain (Menke et al. 2018; Wildmann et al. 2018) as well as atmospheric recirculations in complex terrain (Menke et al. 2019). Perdigão publications will be collected at https://www.atmos-chemphys.net/special issue636 946.html.

In summary, the Perdigão project was a giant step forward in gathering massive data sets in complex terrain at the microscale using cutting-edge measurement platforms, probing down to a spatial resolution of $100 \mathrm{~m}$ and frequencies of tens of $\mathrm{Hz}$. The outcomes will include improved wind energy and microscale physics in complex terrain, new model-usable parameterizations, and a "gold standard" data set for high-fidelity microscale simulations and forecasting. For more information, including data access, see: https://www.eol.ucar.edu/field_projects/perdigao. 

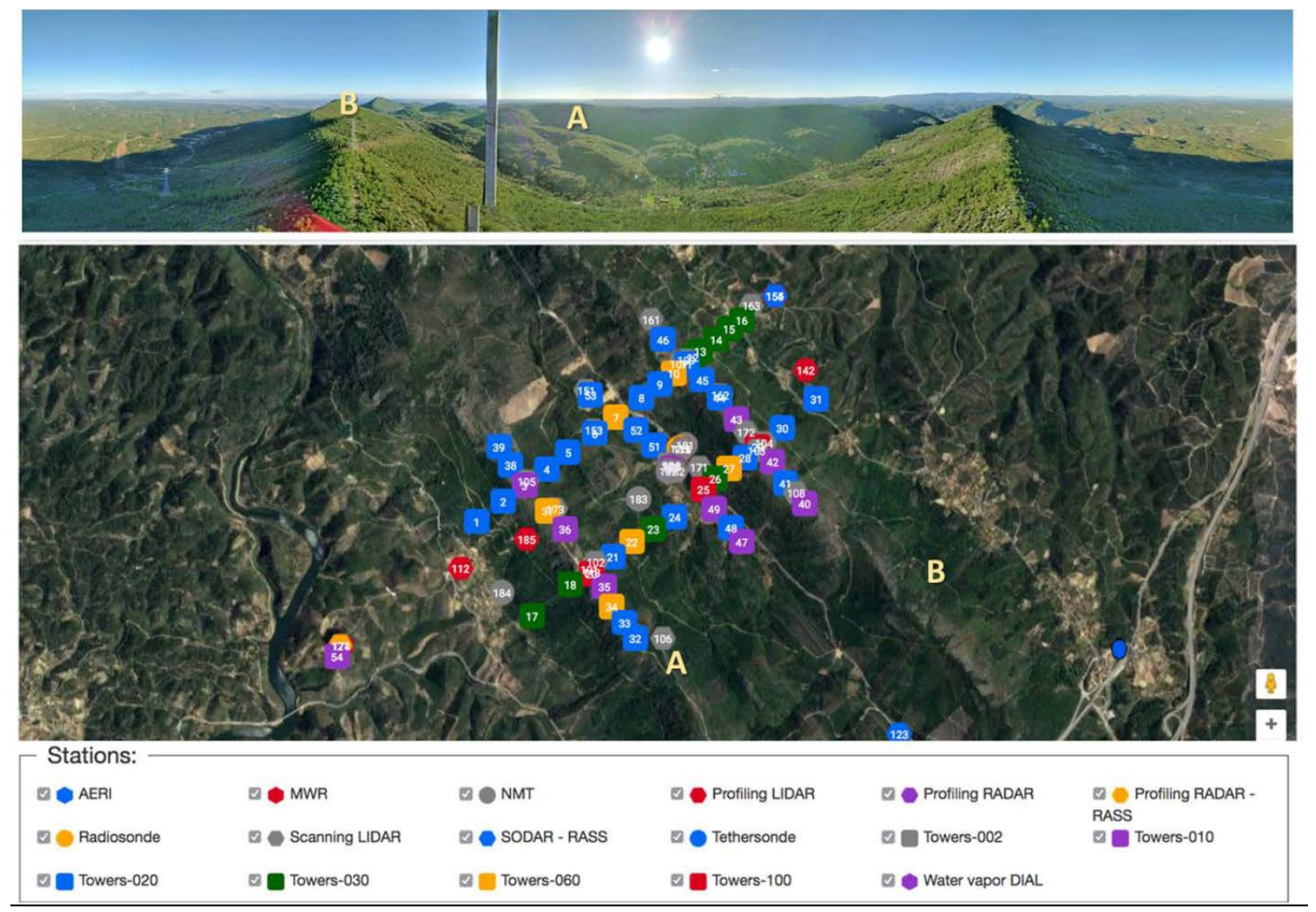

Figure 24. (Top) A panoramic view of Vale Cobrão, as viewed from \#13 (30-m tower) in the lower figure. The wind turbine is between \#18 and \#21, on the ridge. (Bottom) A screenshot of the instrumentation placement map for Perdigão campaign IOP. Most of the instrument towers have been erected and other instrumentation is currently arriving at the site. Each instrument is identified by a number and color coding. From Fernando, Lundquist, and Oncley (2017)

Acronyms in the key include: atmospheric emitted radiance interferometer (AERI), microwave radiometer (MWR), and noise measurement terminal (NMT). Tower heights are indicated (in meters) after a dash.

\subsection{WIPAFF}

More than $12 \mathrm{GW}$ of wind turbines are currently deployed offshore, in European waters, often in close proximity to each other. Due to close proximity, wind farms can induce large wind farm wakes that result in power deficits (Nygaard et al. 2014) or odd accelerations (Nygaard and Hansen 2016). Using a specially equipped research aircraft, the WIPAFF team conducted in situ measurements of large wind farm wakes in 2016 and 2017. They measured wind, turbulence, temperature, and moisture impacts from large wind farms. In stable atmospheric conditions, the found wake lengths with wind speed deficits of $40 \%$ in excess of tens of kilometers downwind The first direct in situ measurements of the existence and shape of large wind farm wakes by a specially equipped research aircraft in 2016 and 2017 confirm wake lengths of more than tens of kilometres under stable atmospheric conditions, with maximum wind speed deficits of $40 \%$, and enhanced turbulence (Platis et al. 2018, Siedersleben et al. 2018). These measurements were the first step in a large research project to describe and understand the physics of large offshore wakes using direct measurements, together with the assessment of satellite imagery and models. 


\section{Conclusions}

To develop the next generation of predictive tools that can better understand wind power plant performance and help the industry lower the overall cost of energy, a diverse set of accurate observations of atmospheric forcing and wind power plant response must be collected. This report is intended to serve as a reference to help with the planning, design, and execution of field experiments. Herein, we provide detail on the capability, accuracy, and resolution of existing and developing measurement technologies to observe quantities of interest for wind power plant model validation. We also explain how observations are used in initializing and carrying out simulations. Finally, we summarize recent, upcoming, and benchmark data sets that may be useful for evaluating simulation capabilities.

We emphasize those instruments commonly used in boundary-layer meteorology to measure the flow field and atmosphere around and within a wind power plant (of tens of kilometers on a side) as well as those instruments that measure the operational behavior of individual turbines within the wind plant. The A2e validation team may use this catalog of instrument capability in conjunction with the validation plan to choose the optimal set of instruments to be deployed, inform instrument placement and operation, and suggest the types of validation that may be gathered through new field campaigns. Of great emphasis is the concept of "simulation-in-theloop" to intimately couple measurements and modeling studies to optimize instrument type and placement as well as maximize the utility of the limited sets of observations (Figure 1).

Gaps in existing instrumentation are also highlighted. For most instrumentation, uncertainty quantification (beyond simple calibration metrics of instrument accuracy or precision) is at a nascent stage. Therefore, a more sophisticated understanding of how to generalize limited observations should be developed. Numerous facets of wind energy, from the annual or interannual time scales of wind resource assessment, to the short temporal scales of wake steering projects, all suffer from the need to generalize specific observations collected over a short period of time to achieve a longer climatological understanding.

Specific measurement needs are discussed. Although scanning radar and lidar systems provide volumetric measurements of winds, the capability of measuring turbulence that is relevant for the volumes of numerical modeling (either large-eddy simulation or mesoscale simulation) is still preliminary, especially in complex terrain, for both model validation and wind turbine tests. Increased temporal (especially for lidar) and spatial resolution would be beneficial, as would the ability to "see" in all air conditions. Particularly for evaluation modeling formulations, simultaneous measurements of vertical fluxes of heat, momentum, and moisture over the area of interest (perhaps $10 \mathrm{~km}$ by $10 \mathrm{~km}$, the size of a wind farm) at vertical resolution on the order of $10 \mathrm{~m}$ would be helpful (https://www.eol.ucar.edu/observing_facilities/centnet). Reliable automated routines for estimating boundary-layer height in all stability regimes would also be useful. 


\section{References}

Adrian, R. J., and J. Westerweel, 2011: Particle Image Velocimetry. Cambridge University Press, 585 pp.

Ahsbahs, T., M. Badger, P. Volker, K. S. Hansen, and C. B. Hasager, 2018: Applications of satellite winds for the offshore wind farm site Anholt. Wind Energy Sci., 3, 573-588, doi:10.5194/wes-3573-2018.

Aitken, M. L., and J. K. Lundquist, 2014: Utility-Scale Wind Turbine Wake Characterization Using Nacelle-Based Long-Range Scanning Lidar. J. Atmospheric Ocean. Technol., 31, 1529-1539, doi:10.1175/JTECH-D-13-00218.1.

—, M. E. Rhodes, and J. K. Lundquist, 2012: Performance of a Wind-Profiling Lidar in the Region of Wind Turbine Rotor Disks. J. Atmospheric Ocean. Technol., 29, 347-355, doi:10.1175/JTECHD-11-00033.1.

— , R. M. Banta, Y. L. Pichugina, and J. K. Lundquist, 2014: Quantifying Wind Turbine Wake Characteristics from Scanning Remote Sensor Data. J. Atmospheric Ocean. Technol., 31, 765 787, doi:10.1175/JTECH-D-13-00104.1.

Allaerts, D., and J. Meyers, 2018: Gravity Waves and Wind-Farm Efficiency in Neutral and Stable Conditions. Bound.-Layer Meteorol., 166, 269-299, doi:10.1007/s10546-017-0307-5.

American Institute of Aeronautics and Astronautics, 1988: Guide for the Verification and Validation of Computational Fluid Dynamics Simulations (AIAA G-077-1998(2002)). Guide for the Verification and Validation of Computational Fluid Dynamics Simulations, American Institute of Aeronautics and Astronautics, Inc. http://arc.aiaa.org/doi/abs/10.2514/4.472855.001 (Accessed July 14, 2016).

Angelou, N., and M. Sjöholm, 2015: UniTTe WP3/MC1: Measuring the inflow towards a Nordtank $500 \mathrm{~kW}$ turbine using three short-range WindScanners and one SpinnerLidar. DTU Wind Energy.

Angevine, W. M., A. B. White, and S. K. Avery, 1994: Boundary-layer depth and entrainment zone characterization with a boundary-layer profiler. Bound.-Layer Meteorol., 68, 375-385, doi:10.1007/BF00706797.

Arnold, C. P., and C. H. Dey, 1986: Observing-Systems Simulation Experiments: Past, Present, and Future. Bull. Am. Meteorol. Soc., 67, 687-695, doi:10.1175/15200477(1986)067<0687:OSSEPP $>2$.0.CO;2.

Arya, S. P., 2001: Introduction to Micrometeorology. Academic Press, 448 pp.

Balsley, B., 2008: The CIRES Tethered Lifting System: a survey of the system, past results and future capabilities. Acta Geophys., 56, 21-57, doi:10.2478/s11600-007-0045-z.

Balsley, B. B., R. G. Frehlich, M. L. Jensen, and Y. Meillier, 2006: High-resolution in situ profiling through the stable boundary layer: examination of the SBL top in terms of minimum shear, maximum stratification, and turbulence decrease. J. Atmospheric Sci., 63, 1291-1307.

Balsley, B. B., G. Svensson, and M. Tjernström, 2007: On the Scale-dependence of the Gradient Richardson Number in the Residual Layer. Bound.-Layer Meteorol., 127, 57-72, doi:10.1007/s10546-007-9251-0. 
Banta, R. M., L. D. Olivier, E. T. Holloway, R. A. Kropfli, B. W. Bartram, R. E. Cupp, and M. J. Post, 1992: Smoke-Column Observations from Two Forest Fires Using Doppler Lidar and Doppler Radar. J. Appl. Meteorol., 31, 1328-1349, doi:10.1175/15200450(1992)031<1328:SCOFTF>2.0.CO;2.

—, R. K. Newsom, J. K. Lundquist, Y. L. Pichugina, R. L. Coulter, and L. Mahrt, 2002: Nocturnal low-level jet characteristics over Kansas during CASES-99. Bound.-Layer Meteorol., 105, 221252.

Banta, R. M., and Coauthors, 2015: 3D Volumetric Analysis of Wind Turbine Wake Properties in the Atmosphere Using High-Resolution Doppler Lidar. J. Atmospheric Ocean. Technol., 32, 904 914, doi:10.1175/JTECH-D-14-00078.1.

Barth, M., and A. Raabe, 2011: Acoustic tomographic imaging of temperature and flow fields in air. Meas. Sci. Technol., 22, 35102, doi:10.1088/0957-0233/22/3/035102.

Båserud, L., M. Flügge, A. Bhandari, and J. Reuder, 2014: Characterization of the SUMO Turbulence Measurement System for Wind Turbine Wake Assessment. Energy Procedia, 53, 173-183, doi:10.1016/j.egypro.2014.07.226.

Båserud, L., J. Reuder, M. O. Jonassen, S. T. Kral, M. B. Paskyabi, and M. Lothon, 2016: Proof of concept for turbulence measurements with the RPAS SUMO during the BLLAST campaign. Atmos Meas Tech, 9, 4901-4913, doi:10.5194/amt-9-4901-2016.

Berg, J., N. Vasiljević, M. Kelly, G. Lea, and M. Courtney, 2015: Addressing Spatial Variability of Surface-Layer Wind with Long-Range WindScanners. J. Atmospheric Ocean. Technol., 32, 518 527, doi:10.1175/JTECH-D-14-00123.1.

Berg, J., A. Natarajan, J. Mann, and E. G. Patton, 2016: Gaussian vs non-Gaussian turbulence: impact on wind turbine loads. Wind Energy, 19, 1975-1989, doi:10.1002/we.1963.

Bevis, M., S. Businger, T. A. Herring, C. Rocken, R. A. Anthes, and R. H. Ware, 1992: GPS meteorology: Remote sensing of atmospheric water vapor using the global positioning system. $J$. Geophys. Res. Atmospheres, 97, 15787-15801, doi:10.1029/92JD01517.

Bianco, L., D. Cimini, F. S. Marzano, and R. Ware, 2005: Combining microwave radiometer and wind profiler radar measurements for high-resolution atmospheric humidity profiling. J. Atmospheric Ocean. Technol., 22, 949-965.

—, K. Friedrich, J. M. Wilczak, D. Hazen, D. E. Wolfe, R. Delgado, and J. K. Lundquist, 2016: Assessing atmospheric profiles from microwave radiometers and radio acoustic sounding systems for wind energy applications. Atmos Meas Tech, in review.

Bischoff, O., I. Würth, J. Gottschall, B. Gribben, J. Hughes, D. Stein, and H. Verhoef, 2016:

Recommended Practices for Floating Lidar Systems. https://www.ieawind.org/index_page_postings/whatsNEW/IEA_Wind_Task32_StateOfArtFloati ngLIDAR_Feb2016.pdf (Accessed March 26, 2017).

Bodini, N., D. Zardi, and J. K. Lundquist, 2017: Three-dimensional structure of wind turbine wakes as measured by scanning lidar. Atmos Meas Tech, 10, 2881-2896, doi:10.5194/amt-10-2881-2017. 
Bodini, N., J. K. Lundquist, and R. K. Newsom, 2018: Estimation of turbulence dissipation rate and its variability from sonic nemometer and wind Doppler lidar during the XPIA field campaign. Atmospheric Meas. Tech., 11, 4291-4308, doi:https://doi.org/10.5194/amt-11-4291-2018.

Boorsma, K., and J. G. Schepers, 2011: Description of experimental setup MEXICO measurements. ECN.

Bosbach, J., M. Kühn, and C. Wagner, 2009: Large scale particle image velocimetry with helium filled soap bubbles. Exp. Fluids, 46, 539-547, doi:10.1007/s00348-008-0579-0.

Braam, M., F. Beyrich, J. Bange, A. Platis, S. Martin, B. Maronga, and A. F. Moene, 2016: On the Discrepancy in Simultaneous Observations of the Structure Parameter of Temperature Using Scintillometers and Unmanned Aircraft. Bound.-Layer Meteorol., 158, 257-283, doi:10.1007/s10546-015-0086-9.

Bradley, S., 2007: Atmospheric Acoustic Remote Sensing: Principles and Applications. CRC Press, 304 pp.

Brower, M., 2012: Wind Resource Assessment: A Practical Guide to Developing a Wind Project. John Wiley \& Sons, 298 pp.

Brugger, P., K. Träumner, and C. Jung, 2016: Evaluation of a Procedure to Correct Spatial Averaging in Turbulence Statistics from a Doppler Lidar by Comparing Time Series with an Ultrasonic Anemometer. J. Atmospheric Ocean. Technol., 33, 2135-2144, doi:10.1175/JTECH-D-150136.1.

Bruun, H. H., 1995: Hot-wire Anemometry: Principles and Signal Analysis. Oxford University Press, 534 pp.

Burns, S. P., T. W. Horst, L. Jacobsen, P. D. Blanken, and R. K. Monson, 2012: Using sonic anemometer temperature to measure sensible heat flux in strong winds. Atmos Meas Tech, 5, 2095-2111, doi:10.5194/amt-5-2095-2012.

Butterfield, C. P., W. P. Musial, and D. A. Simms, 1992: Combined Experiment Phase 1. Final Report. National Renewable Energy Laboratory, Golden, CO (United States), https://www.osti.gov/scitech/biblio/10105837 (Accessed March 30, 2017).

Caicedo, V., B. Rappenglueck, B. Lefer, G. Morris, D. Toledo, and R. Delgado, 2016: Comparison of aerosol lidar retrieval methods for boundary layer height detection using ceilometer backscatter data. Atmos Meas Tech Discuss, 2016, 1-24, doi:10.5194/amt-10-1609-2017.

Campbell Scientific, Inc. 2018a. "41303-5A 6-Plate Solar Radiation Shield." https://www.campbellsci.com/41303-shield.

Campbell Scientific, Inc. 2018b. "CSAT3B 3-D Sonic Anemometer with Integrated Electronics." https://www.campbellsci.com/csat3b

Carbajo Fuertes, F. C., G. V. Iungo, and F. Porté-Agel, 2014: 3D Turbulence Measurements Using Three Synchronous Wind Lidars: Validation against Sonic Anemometry. J. Atmospheric Ocean.

Technol., 31, 1549-1556, doi:10.1175/JTECH-D-13-00206.1. 
Castro, F. A., J. M. L. M. Palma, and A. S. Lopes, 2003: Simulation of the Askervein Flow. Part 1: Reynolds Averaged Navier-Stokes Equations ( $\mathrm{k} \in$ Turbulence Model). Bound.-Layer Meteorol., 107, 501-530, doi:10.1023/A:1022818327584.

Champagne, F. H., 1978: The fine-scale structure of the turbulent velocity field. J. Fluid Mech., 86, 67108.

Chang, J. C., and S. R. Hanna, 2004: Air quality model performance evaluation. Meteorol. Atmospheric Phys., 87, 167-196, doi:10.1007/s00703-003-0070-7.

Charnock, H., 1955: Wind stress on a water surface. Q. J. R. Meteorol. Soc., 81, 639.

Chehbouni, A., and Coauthors, 2000: Estimation of heat and momentum fluxes over complex terrain using a large aperture scintillometer. Agric. For. Meteorol., 105, 215-226, doi:10.1016/S01681923(00)00187-8.

Chow, F. K., and R. L. Street, 2009: Evaluation of Turbulence Closure Models for Large-Eddy Simulation over Complex Terrain: Flow over Askervein Hill. J. Appl. Meteorol. Climatol., 48, 1050-1065, doi:10.1175/2008JAMC1862.1.

Churchfield, M., Q. Wang, A. Scholbrock, T. Herges, T. Mikkelsen, and M. Sjöholm, 2016: Using HighFidelity Computational Fluid Dynamics to Help Design a Wind Turbine Wake Measurement Experiment. J. Phys. Conf. Ser., 753, 32009, doi:10.1088/1742-6596/753/3/032009.

Churchfield, M. J., S. Lee, J. Michalakes, and P. J. Moriarty, 2012: A numerical study of the effects of atmospheric and wake turbulence on wind turbine dynamics. J. Turbul., 13, N14, doi:10.1080/14685248.2012.668191.

Cimini, D., and Coauthors, 2011: Thermodynamic Atmospheric Profiling During the 2010 Winter Olympics Using Ground-Based Microwave Radiometry. IEEE Trans. Geosci. Remote Sens., 49, 4959-4969, doi:10.1109/TGRS.2011.2154337.

Clifton, A., D. Elliott, and M. Courtney, 2013a: Ground-based Vertically-profiling remote sensing for Wind Resource Assessment. https://www.ieawind.org/index_page_postings/RP/RP\%2015_RemoteSensing_1stEd_8March201 3.pdf (Accessed March 26, 2017).

—, S. Schreck, G. Scott, N. Kelley, and J. K. Lundquist, 2013b: Turbine Inflow Characterization at the National Wind Technology Center. J. Sol. Energy Eng., 135, 31017-031017-11, doi:10.1115/1.4024068.

Cohn, S. A., and W. M. Angevine, 2000: Boundary Layer Height and Entrainment Zone Thickness Measured by Lidars and Wind-Profiling Radars. J. Appl. Meteorol., 39, 1233-1247, doi:10.1175/1520-0450(2000)039<1233:BLHAEZ>2.0.CO;2.

Collaud Coen, M., C. Praz, A. Haefele, D. Ruffieux, P. Kaufmann, and B. Calpini, 2014: Determination and climatology of the planetary boundary layer height above the Swiss plateau by in situ and remote sensing measurements as well as by the COSMO-2 model. Atmos Chem Phys, 14, 1320513221, doi:10.5194/acp-14-13205-2014. 
Coulter, R. L., and D. J. Holdridge, 1998: A Procedure for the Automatic Estimation of Mixed Layer Height. Proceedings of the Eight ARM Science Team Meeting, Eighth ARM Science Team Meeting, Tucson, AZ https://www.arm.gov/publications/proceedings/conf08/extended_abs/coulter_rl.pdf(Accessed March 31, 2017).

Courtney, M., R. Wagner, and P. Lindelöw, 2008: Commercial lidar profilers for wind energy. A comparative guide. Proceedings of EWEC 2008, 9 https://www.renewablenrgsystems.com/assets/resources/Commercial-Lidar-Profilers-for-WindEnergy-Whitepaper.

The Crown Estate, 2014: UK MERRA Validation With Offshore Meteorological Data. https://www.thecrownestate.co.uk/media/389807/ei-uk-merra-validation-with-offshoremeteorological-data.pdf (Accessed March 26, 2017).

Cui, Y. Y., and Coauthors, 2015: Top-down estimate of methane emissions in California using a mesoscale inverse modeling technique: The South Coast Air Basin. J. Geophys. Res. Atmospheres, 120, 2014JD023002, doi:10.1002/2014JD023002.

Dagestad, K.-F., and Coauthors, 2013: WIND RETRIEVAL FROM SYNTHETIC APERTURE RADAR - AN OVERVIEW. Proceedings of SEASAR 2012, Vol. 709 of, SEASAR 2012 Advances in SAR Oceanography, European Space Agency - SP, 23 https://www.researchgate.net/publication/274248910_WIND_RETRIEVAL_FROM_SYNTHETI C_APERTURE_RADAR_-_AN_OVERVIEW (Accessed March 26, 2017).

Dantec Dynamics. 2017. https://www.dantecdynamics.com/measurement-principles-of-piv

Debnath, M., and Coauthors, 2017a: Assessment of virtual towers performed with scanning wind lidars and Ka-band radars during the XPIA experiment. Atmos Meas Tech, 10, 1215-1227, doi:10.5194/amt-10-1215-2017.

— lidars performing triple range-height-indicator scans. Atmos Meas Tech, 10, 431-444, doi:10.5194/amt-10-431-2017.

Dérian, P., C. F. Mauzey, and S. D. Mayor, 2015: Wavelet-Based Optical Flow for Two-Component Wind Field Estimation from Single Aerosol Lidar Data. J. Atmospheric Ocean. Technol., 32, 1759-1778, doi:10.1175/JTECH-D-15-0010.1.

Dörenkämper, M., B. Witha, G. Steinfeld, D. Heinemann, and M. Kühn, 2015: The impact of stable atmospheric boundary layers on wind-turbine wakes within offshore wind farms. J. Wind Eng. Ind. Aerodyn., 144, 146-153, doi:10.1016/j.jweia.2014.12.011.

Ecklund, W. L., D. A. Carter, and B. B. Balsley, 1988: A UHF Wind Profiler for the Boundary Layer: Brief Description and Initial Results. J. Atmospheric Ocean. Technol., 5, 432-441, doi:10.1175/1520-0426(1988)005<0432:AUWPFT>2.0.CO;2.

Elliott, G. S., and T. J. Beutner, 1999: Molecular filter based planar Doppler velocimetry. Prog. Aerosp. Sci., 35, 799-845, doi:10.1016/S0376-0421(99)00008-1. 
Elston, J., B. Argrow, M. Stachura, D. Weibel, D. Lawrence, and D. Pope, 2015: Overview of Small Fixed-Wing Unmanned Aircraft for Meteorological Sampling. J. Atmospheric Ocean. Technol., 32, 97-115, doi:10.1175/JTECH-D-13-00236.1.

Emeis, S., 2010: Surface-Based Remote Sensing of the Atmospheric Boundary Layer. Springer Science \& Business Media, 181 pp.

—_, 2012: Wind Energy Meteorology: Atmospheric Physics for Wind Power Generation. Springer Science \& Business Media, 202 pp.

Engelbart, D. A. M., M. Kallistratova, and R. Kouznetsov, 2007: Determination of the turbulent fluxes of heat and momentum in the ABL by ground-based remote-sensing techniques (a Review).

Meteorol. Z., 16, 325-335, doi:10.1127/0941-2948/2007/0224.

Fast, J. D., R. K. Newsom, K. J. Allwine, Q. Xu, P. Zhang, J. H. Copeland, and Sun, 2007: Development of NEXRAD Wind Retrievals as Input to Atmospheric Dispersion Models - PNNL-16399.pdf. Pacific Northwest National Laboratory, Richland, WA, https://www.pnl.gov/main/publications/external/technical_reports/PNNL-16399.pdf (Accessed March 29, 2017).

Fernando, H.J.S., J. K. Lundquist, and S. Oncley, 2017: Monitoring wind in Portugal's mountains down to microscales. Eos, 98, https://doi.org/10.1029/2017EO074745. Published on 31 May 2017.

— Bulletin of the American Meteorological Society, in review.

Fitch, A. C., J. B. Olson, J. K. Lundquist, J. Dudhia, A. K. Gupta, J. Michalakes, and I. Barstad, 2012: Local and Mesoscale Impacts of Wind Farms as Parameterized in a Mesoscale NWP Model. Mon. Weather Rev., 140, 3017-3038, doi:10.1175/MWR-D-11-00352.1.

Fleming, P., Annoni, J., Scholbrock, A., Quon, E., Dana, S., Schreck, S., ... \& Schlipf, D., 2017:. Fullscale field test of wake steering. In Journal of Physics: Conference Series(Vol. 854, No. 1, p. 012013). IOP Publishing.

Foken, T., 2008: Micrometeorology. Springer Science \& Business Media, 320 pp.

de Franceschi, M., D. Zardi, M. Tagliazucca, and F. Tampieri, 2009: Analysis of second-order moments in surface layer turbulence in an Alpine valley. Q. J. R. Meteorol. Soc., 135, 1750-1765, doi:10.1002/qj.506.

Frehlich, R., S. M. Hannon, and S. W. Henderson, 1998: Coherent Doppler Lidar Measurements of Wind Field Statistics. Bound.-Layer Meteorol., 86, 233-256, doi:10.1023/A:1000676021745.

—, Y. Meillier, M. L. Jensen, and B. Balsley, 2003: Turbulence Measurements with the CIRES Tethered Lifting System during CASES-99: Calibration and Spectral Analysis of Temperature and Velocity. J. Atmospheric Sci., 60, 2487-2495, doi:10.1175/15200469(2003)060<2487:TMWTCT>2.0.CO;2.

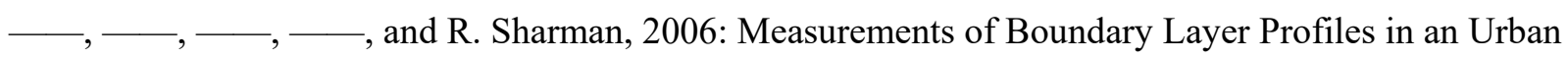
Environment. J. Appl. Meteorol. Climatol., 45, 821-837, doi:10.1175/JAM2368.1. 
Friedrich, K., J. K. Lundquist, M. Aitken, E. A. Kalina, and R. F. Marshall, 2012: Stability and turbulence in the atmospheric boundary layer: A comparison of remote sensing and tower observations. Geophys. Res. Lett., 39, L03801, doi:10.1029/2011GL050413.

Gallacher, D., and G. More, 2014: Lidar Measurements and Visualisations of Turbulence and Wake Decay Length. EWEA 2014 http://www.sgurrenergy.com/wp/wpcontent/uploads/2016/05/EWEA-2014-Poster-ID-175-Lidar-Measured-Wakes-B3.pdf (Accessed March 27, 2017).

Grund, C. J., R. M. Banta, J. L. George, J. N. Howell, M. J. Post, R. A. Richter, and A. M. Weickmann, 2001: High-Resolution Doppler Lidar for Boundary Layer and Cloud Research. J. Atmospheric Ocean. Technol., 18, 376-393, doi:10.1175/1520-0426(2001)018<0376:HRDLFB >2.0.CO;2.

Gunter, W. S., J. L. Schroeder, and B. D. Hirth, 2015: Validation of Dual-Doppler Wind Profiles with in situ Anemometry. J. Atmospheric Ocean. Technol., 32, 943-960, doi:10.1175/JTECH-D-1400181.1.

Hand, M. M., D. A. Simms, L. J. Fingersh, D. W. Jager, J. R. Cotrell, S. Schreck, and S. M. Larwood, 2001: Unsteady Aerodynamics Experiment Phase VI: Wind Tunnel Test Configurations and Available Data Campaigns - 29955.pdf. National Renewable Energy Laboratory, Golden, CO, http://www.nrel.gov/docs/fy02osti/29955.pdf (Accessed March 30, 2017). - please check the link to the document -having trouble getting to the file

Hannah, R. L., and S. E. Reed, 1992: Strain Gage Users' Handbook. Springer Science \& Business Media, $506 \mathrm{pp}$.

Herges, T., D. C. Maniaci, D. Bossert, R. Schmitt, and B. Naughton, 2015: Preliminary Field Test of the Wind Turbine Wake Imaging System. 33rd Wind Energy Symposium, American Institute of Aeronautics and Astronautics https://arc.aiaa.org/doi/abs/10.2514/6.2015-0219 (Accessed March $27,2017)$.

Herges, T. G., D. Bossert, R. Schmitt, M. Johnson, D. C. Maniaci, C. Glen, and B. Naughton, 2016: Field Demonstration of the Sandia Wake Imaging System Capabilities at the Scaled Wind Farm Technology Facility. 34th Wind Energy Symposium, American Institute of Aeronautics and Astronautics https://arc.aiaa.org/doi/abs/10.2514/6.2016-1524 (Accessed March 27, 2017).

D. C. Maniaci, B. Naughton, K. Hansen, M. Sjoholm, N. Angelou, and T. Mikkelsen, 2017: Scanning Lidar Spatial Calibration and Alignment Method for Wind Turbine Wake Characterization. 35th Wind Energy Symposium, American Institute of Aeronautics and Astronautics https://arc.aiaa.org/doi/abs/10.2514/6.2017-0455 (Accessed March 27, 2017).

Hill, M., R. Calhoun, H. J. S. Fernando, A. Wieser, A. Dörnbrack, M. Weissmann, G. Mayr, and R. Newsom, 2010: Coplanar Doppler Lidar Retrieval of Rotors from T-REX. J. Atmospheric Sci., 67, 713-729, doi:10.1175/2009JAS3016.1.

Hills, R. G., D. C. Maniaci, and Naughton, 2015: V\&V Framework. Sandia National Laboratories, Albuquerque, New Mexico, http://prod.sandia.gov/techlib/access-control.cgi/2015/157455.pdf (Accessed March 26, 2017). 
Hirth, B. D., J. L. Schroeder, W. S. Gunter, and J. G. Guynes, 2012: Measuring a Utility-Scale Turbine Wake Using the TTUKa Mobile Research Radars. J. Atmospheric Ocean. Technol., 29, 765-771, doi:10.1175/JTECH-D-12-00039.1.

,,--- , and -2015 : Coupling Doppler radar-derived wind maps with operational turbine data to document wind farm complex flows. Wind Energy, 18, 529-540, doi:10.1002/we.1701.

Holstein, P., A. Raabe, R. Müller, M. Barth, D. Mackenzie, and E. Starke, 2004: Acoustic tomography on the basis of travel-time measurement. Meas. Sci. Technol., 15, 1420, doi:10.1088/09570233/15/7/026.

Hong, J., M. Toloui, L. P. Chamorro, M. Guala, K. Howard, S. Riley, J. Tucker, and F. Sotiropoulos, 2014: Natural snowfall reveals large-scale flow structures in the wake of a 2.5-MW wind turbine. Nat. Commun., 5, 4216, doi:10.1038/ncomms5216.

Houchi, K., A. Stoffelen, G. J. Marseille, and J. De Kloe, 2010: Comparison of wind and wind shear climatologies derived from high-resolution radiosondes and the ECMWF model. J. Geophys. Res. Atmospheres, 115, D22123, doi:10.1029/2009JD013196.

IEC 61400-11, 2012: International Standard 61400-11: Acoustic noise measurement techniques, Edition 3.0 - Part 11: Measurement of mechanical loads.

IEC 61400-12-1, 2005: Wind Turbines - Part 12-1: Power Performance Measurements of Electricity Producing Wind Turbines.

— 2017: International Standard 61400-12-1: Wind Energy Generation Systems - Part 12-1: Power Performance Measurements of Electricity Producing Wind Turbines; Edition 2.0.

IEC 61400-12-2, 2013: International Standard 61400-12-2: Wind Energy Generation Systems - Part 12-2: Power Performance Measurements of Electricity Producing Wind Turbines Based on Nacelle Anemometry; Edition 1.0.

IEC 61400-13, 2015: International Standard 61400-13: Wind Turbines - Part 13: Measurement of Mechanical Loads.

IEC 61400-21, 2008: International Standard 61400-21: Wind Turbines - Part 21: Measurement and Assessment of Power Quality Characteristics of Grid Connected Wind Turbines, Edition 2.0.

ISO/IEC Guide 98-3:2008, 2008: Uncertainty of Measurement -- Part 3: Guide to the Expression of Uncertainty in Measurement.

Kaimal, J. C., and J. A. Businger, 1963: A Continuous Wave Sonic Anemometer-Thermometer. J. Appl. Meteorol., 2, 156-164, doi:10.1175/1520-0450(1963)002<0156:ACWSAT>2.0.CO;2.

_ and J. E. Gaynor, 1983: The Boulder Atmospheric Observatory. J. Clim. Appl. Meteorol., 22, 863880, doi:10.1175/1520-0450(1983)022<0863:TBAO $>2.0 . \mathrm{CO} ; 2$.

— J. C. Wyngaard, and D. A. Haugen, 1968: Deriving Power Spectra from a Three-Component Sonic Anemometer. J. Appl. Meteorol., 7, 827-837. 
Karagali, I., A. Peña, M. Badger, and C. B. Hasager, 2014: Wind characteristics in the North and Baltic Seas from the QuikSCAT satellite. Wind Energy, 17, 123-140, doi:10.1002/we.1565.

Kim, H. G., and V. C. Patel, 2000: Test Of Turbulence Models For Wind Flow Over Terrain With Separation And Recirculation. Bound.-Layer Meteorol., 94, 5-21, doi:10.1023/A:1002450414410.

Klein, P., and Coauthors, 2015: LABLE: A Multi-Institutional, Student-Led, Atmospheric Boundary Layer Experiment. Bull. Am. Meteorol. Soc., 96, 1743-1764, doi:10.1175/BAMS-D-13-00267.1.

Kleissl, J., J. Gomez, S.-H. Hong, J. M. H. Hendrickx, T. Rahn, and W. L. Defoor, 2008: Large Aperture Scintillometer Intercomparison Study. Bound.-Layer Meteorol., 128, 133-150, doi:10.1007/s10546-008-9274-1.

Kocer, G., N. Chokani, and R. Abhari, 2012: Wake Structure of a 2MW Wind Turbine Measured Using an Instrumented UAV. 50th AIAA Aerospace Sciences Meeting including the New Horizons Forum and Aerospace Exposition, American Institute of Aeronautics and Astronautics https://arc.aiaa.org/doi/abs/10.2514/6.2012-231 (Accessed March 27, 2017).

Kreuzer, M., 2006: Strain Measurement with Fiber Bragg Grating Sensors. http://www.ae.metu.edu.tr/seminar/strain-gage/FBG.pdf (Accessed March 26, 2017).

Kroonenberg, A. C. van den, S. Martin, F. Beyrich, and J. Bange, 2012: Spatially-Averaged Temperature Structure Parameter Over a Heterogeneous Surface Measured by an Unmanned Aerial Vehicle. Bound.-Layer Meteorol., 142, 55-77, doi:10.1007/s10546-011-9662-9.

Kumar, V., G. Svensson, A. A. M. Holtslag, C. Meneveau, and M. B. Parlange, 2010: Impact of Surface Flux Formulations and Geostrophic Forcing on Large-Eddy Simulations of Diurnal Atmospheric Boundary Layer Flow. J. Appl. Meteorol. Climatol., 49, 1496-1516, doi:10.1175/2010JAMC2145.1.

Lagouarde, J.-P., J.-M. Bonnefond, Y. H. Kerr, K. J. McAneney, and M. Irvine, 2002: Integrated Sensible Heat Flux Measurements of a Two-Surface Composite Landscape using Scintillometry. Bound.Layer Meteorol., 105, 5-35, doi:10.1023/A:1019631428921.

Lavision. 2017. https://www.lavision.de/en/download.php?id=317

LeMone, M. A., and Coauthors, 2000: Land-atmosphere interaction research, early results, and opportunities in the Walnut River Watershed in southeast Kansas: CASES and ABLE. Bulletin of the American Meteorological Society, 81, 757-779.

Lenschow, D. H., J. Mann, and L. Kristensen, 1994: How Long Is Long Enough When Measuring Fluxes and Other Turbulence Statistics? J. Atmospheric Ocean. Technol., 11, 661-673, doi:10.1175/1520-0426(1994)011<0661:HLILEW>2.0.CO;2.

Loescher, H. W., and Coauthors, 2005: Comparison of temperature and wind statistics in contrasting environments among different sonic anemometer-thermometers. Agric. For. Meteorol., 133, 119-139, doi:10.1016/j.agrformet.2005.08.009. 
Lopes, A. S., and J. M. L. M. Palma, 2002: Large Eddy Simulation of the Flow Around the Askervein Hill. 3rd Theoretical Fluid Mechanics Meeting, American Institute of Aeronautics and Astronautics https://arc.aiaa.org/doi/abs/10.2514/6.2002-3085 (Accessed March 28, 2017).

,-- , and F. A. Castro, 2007: Simulation of the Askervein flow. Part 2: Large-eddy simulations. Bound.-Layer Meteorol., 125, 85-108, doi:10.1007/s10546-007-9195-4.

Lundquist, J. K., and L. Bariteau, 2015: Dissipation of Turbulence in the Wake of a Wind Turbine. Bound.-Layer Meteorol., 154, 229-241, doi:10.1007/s10546-014-9978-3.

Lundquist, J. K., and Coauthors, 2014: Lidar observations of interacting wind turbine wakes in an

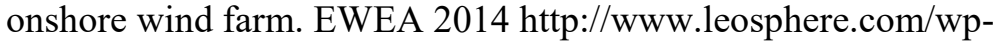
content/uploads/2014/03/Lundquist_Boquet_EWEA_2014_CWEX13_final.pdf (Accessed March $30,2017)$.

Lundquist, J. K., M. J. Churchfield, S. Lee, and A. Clifton, 2015: Quantifying error of lidar and sodar Doppler beam swinging measurements of wind turbine wakes using computational fluid dynamics. Atmos Meas Tech, 8, 907-920, doi:10.5194/amt-8-907-2015.

Lundquist, J. K., and Coauthors, 2017: Assessing State-of-the-Art Capabilities for Probing the Atmospheric Boundary Layer: The XPIA Field Campaign. Bull. Am. Meteorol. Soc., 98, 289314, doi:10.1175/BAMS-D-15-00151.1.

Lundquist, J. K., K. K. DuVivier, D. Kaffine, and J. M. Tomaszewski, 2019: Costs and consequences of wind turbine wake effects arising from uncoordinated wind energy development. Nat. Energy, 4, 26-34, doi:10.1038/s41560-018-0281-2.

Machefaux, E., G. C. Larsen, N. Troldborg, K. S. Hansen, N. Angelou, T. Mikkelsen, and J. Mann, 2016: Investigation of wake interaction using full-scale lidar measurements and large eddy simulation. Wind Energy, 19, 1535-1551, doi:10.1002/we.1936.

Magnusson, M., and A.-S. Smedman, 1994: Influence of Atmospheric Stability on Wind Turbine Wakes. Wind Eng., 18, 139-151.

Mann, J., and Coauthors, 2017: Complex terrain experiments in the New European Wind Atlas. Phil Trans R Soc A, 375, 20160101, doi:10.1098/rsta.2016.0101.

Marinov, P., and M. M. Rahman, 2005: Measuring Bearing Currents. Chalmers University of Technology, 146 pp. http://webfiles.portal.chalmers.se/et/MSc/Marinov\&RahmanMSc.pdf (Accessed March 30, 2017).

May, P. T., K. P. Moran, and R. G. Strauch, 1989: The Accuracy of RASS Temperature Measurements. J. Appl. Meteorol., 28, 1329-1335, doi:10.1175/1520-0450(1989)028<1329:TAORTM>2.0.CO;2.

Mayor, S. D., and S. M. Spuler, 2004: Raman-shifted eye-safe aerosol lidar. Appl. Opt., 43, 3915-3924, doi:10.1364/AO.43.003915.

Mazzaro, L. J., D. Muñoz-Esparza, J. K. Lundquist, and R. R. Linn, 2017: Nested Mesoscale-to-LES Modeling of the Atmospheric Boundary Layer in the Presence of Under-Resolved Convective Structures. J. Adv. Model. Earth Syst., in review. 
McCaffrey, K., and Coauthors, 2017: Identification of tower-wake distortions using sonic anemometer and lidar measurements. Atmos Meas Tech, 10, 393-407, doi:10.5194/amt-10-393-2017.

McKenzie, R. L., 1996: Measurement capabilities of planar Doppler velocimetry using pulsed lasers. Appl. Opt., 35, 948-964, doi:10.1364/AO.35.000948.

Meijninger, W. M. L., F. Beyrich, A. Lüdi, W. Kohsiek, and H. A. R. D. Bruin, 2006: ScintillometerBased Turbulent Fluxes of Sensible and Latent Heat Over a Heterogeneous Land Surface - A Contribution to Litfass-2003. Bound.-Layer Meteorol., 121, 89-110, doi:10.1007/s10546-0059022-8.

Mendoza, I., J. Hur, and S. Thao, 2015a: Power Quality Test Report for the U.S. Department of Energy 1.5-Megawatt Wind Turbine - 63686.pdf. National Renewable Energy Laboratory, Golden, CO, http://www.nrel.gov/docs/fy15osti/63686.pdf (Accessed March 30, 2017).

,,--- , and A. Curtis, 2015b: Power Performance Test Report for the U.S. Department of Energy 1.5-Megawatt Wind Turbine - 63684.pdf. National Renewable Energy Laboratory, http://www.nrel.gov/docs/fy15osti/63684.pdf (Accessed March 30, 2017).

Menke, R., N. Vasiljević, K. S. Hansen, A. N. Hahmann, and J. Mann, 2018: Does the wind turbine wake follow the topography? A multi-lidar study in complex terrain. Wind Energy Sci., 3, 681-691, doi:https://doi.org/10.5194/wes-3-681-2018.

,$--\frac{}{-}$ J. Mann, and J. K. Lundquist, 2019: Characterization of flow recirculation zones at the Perdigão site using multi-lidar measurements. Atmospheric Chem. Phys., 19, 2713-2723, doi:https://doi.org/10.5194/acp-19-2713-2019.

Meyers, J. F., J. W. Lee, and R. J. Schwartz, 2001: Characterization of measurement error sources in Doppler global velocimetry. Meas. Sci. Technol., 12, 357, doi:10.1088/0957-0233/12/4/301.

Mikkelsen, T., and Coauthors, 2013: A spinner-integrated wind lidar for enhanced wind turbine control. Wind Energy, 16, 625-643, doi:10.1002/we.1564.

Mirocha, J. D., and B. Kosović, 2009: A Large-Eddy Simulation Study of the Influence of Subsidence on the Stably Stratified Atmospheric Boundary Layer. Bound.-Layer Meteorol., 134, 1-21, doi:10.1007/s10546-009-9449-4.

Monin, A. S., and A. M. Obukhov, 1954: Basic laws of turbulent mixing in the surface layer of the atmosphere. Tr Akad Nauk SSSR Geophiz Inst, 24, 163-187.

Mosedale, A. D., G. S. Elliott, C. D. Carter, and T. J. Beutner, 2000: Planar Doppler Velocimetry in a Large-Scale Facility. AIAA J., 38, 1010-1024, doi:10.2514/2.1085.

Muñoz-Esparza, D., B. Kosović, J. Mirocha, and J. van Beeck, 2014: Bridging the Transition from Mesoscale to Microscale Turbulence in Numerical Weather Prediction Models. Bound.-Layer Meteorol., 153, 409-440, doi:10.1007/s10546-014-9956-9.

Muschinski, A., R. G. Frehlich, and B. B. Balsley, 2004: Small-scale and large-scale intermittency in the nocturnal boundary layer and the residual layer. J. Fluid Mech., 515, 319-351, doi:10.1017/S0022112004000412. 
Nemes, A., T. Dasari, J. Hong, M. Guala, and F. Coletti, 2017: Snowflakes in the atmospheric surface layer: observation of particle-turbulence dynamics. J. Fluid Mech., 814, 592-613, doi:10.1017/jfm.2017.13.

Newman, J. F., and A. Clifton, 2017: An error reduction algorithm to improve lidar turbulence estimates for wind energy. Wind Energy Sci., 2, 77-95, doi:10.5194/wes-2-77-2017.

Newsom, R., R. Calhoun, D. Ligon, and J. Allwine, 2008: Linearly Organized Turbulence Structures Observed Over a Suburban Area by Dual-Doppler Lidar. Bound.-Layer Meteorol., 127, 111-130, doi:10.1007/s10546-007-9243-0.

Niezrecki, C., P. Avitabile, C. Warren, P. Pingle, and M. Helfrick, 2010: A Review of Digital Image Correlation Applied to Structura Dynamics. Vol. 1253 of, American Institute of Physics Conference Series, 219-232 http://adsabs.harvard.edu/abs/2010AIPC.1253..219N (Accessed March 26, 2017).

NRG Systems. "NRG 40C Anemometer." Accessed [include full date accessed]. https://www.renewablenrgsystems.com/products/met-sensors/anemometers/detail/40canemometer.

O’Connor, E. J., A. J. Illingworth, I. M. Brooks, C. D. Westbrook, R. J. Hogan, F. Davies, and B. J. Brooks, 2010: A Method for Estimating the Turbulent Kinetic Energy Dissipation Rate from a Vertically Pointing Doppler Lidar, and Independent Evaluation from Balloon-Borne In Situ Measurements. J. Atmospheric Ocean. Technol., 27, 1652-1664, doi:10.1175/2010JTECHA1455.1.

Oncley, S. P., C. A. Friehe, J. C. Larue, J. A. Businger, E. C. Itsweire, and S. S. Chang, 1996: SurfaceLayer Fluxes, Profiles, and Turbulence Measurements over Uniform Terrain under Near-Neutral Conditions. J. Atmospheric Sci., 53, 1029-1044.

OpenLidar. Undated. OpenLidar website. https://www.openlidar.net/

Ostashev, V. E., S. N. Vecherin, K. D. Wilson, A. Ziemann, and G. H. Goedecke, 2009: Recent progress in acoustic travel-time tomography of the atmospheric surface layer. Meteorol. Z., 125-133, doi:10.1127/0941-2948/2009/0364.

Pan, B., K. Qian, H. Xie, and A. Asundi, 2009: Two-dimensional digital image correlation for in-plane displacement and strain measurement: a review. Meas. Sci. Technol., 20, 62001, doi:10.1088/0957-0233/20/6/062001.

Panofsky, H. A., and J. A. Dutton, 1984: Atmospheric turbulence: models and methods for engineering applications. Wiley, $432 \mathrm{pp}$.

Pauscher, L., and Coauthors, 2016: An Inter-Comparison Study of Multi- and DBS Lidar Measurements in Complex Terrain. Remote Sens., 8, 782, doi:10.3390/rs8090782.

Pindado, S., J. Cubas, and F. Sorribes-Palmer, 2014: The Cup Anemometer, a Fundamental Meteorological Instrument for the Wind Energy Industry. Research at the IDR/UPM Institute. Sensors, 14, 21418-21452, doi:10.3390/s141121418. 
Piper, M., and J. K. Lundquist, 2004: Surface layer turbulence measurements during a frontal passage. $J$. Atmospheric Sci., 61, 1768-1780.

Platis, A., and Coauthors, 2018: First in situ evidence of wakes in the far field behind offshore wind farms. Sci. Rep., 8, 2163, doi:10.1038/s41598-018-20389-y.

Pol, S. U., and B. J. Balakumar, 2013: Design considerations for large field particle image velocimetery (LF-PIV). Meas. Sci. Technol., 24, 25302, doi:10.1088/0957-0233/24/2/025302.

Pope, A., and W. H. Rae, 1984: Low-speed wind tunnel testing. Wiley, 558 pp.

Post, M. J., and R. E. Cupp, 1990: Optimizing a pulsed Doppler lidar. Appl. Opt., 29, 4145-4158, doi:10.1364/AO.29.004145.

Poulos, G. S., and Coauthors, 2002: CASES-99: A Comprehensive Investigation of the Stable Nocturnal Boundary Layer. Bull. Am. Meteorol. Soc., 83, 555-581, doi:10.1175/15200477(2002)083<0555:CACIOT>2.3.CO;2.

Raithby, G. D., G. D. Stubley, and P. A. Taylor, 1987: The Askervein hill project: A finite control volume prediction of three-dimensional flows over the hill. Bound.-Layer Meteorol., 39, 247-267, doi:10.1007/BF00116121.

Rajewski, D. A., and Coauthors, 2013: CROP WIND ENERGY EXPERIMENT (CWEX): Observations of Surface-Layer, Boundary Layer, and Mesoscale Interactions with a Wind Farm. Bull. Am. Meteorol. Soc., 94, 655-672.

, E. S. Takle, J. K. Lundquist, J. H. Prueger, R. L. Pfeiffer, J. L. Hatfield, K. K. Spoth, and R. K. Doorenbos, 2014: Changes in fluxes of heat, H2O, and CO2 caused by a large wind farm. Agric. For. Meteorol., 194, 175-187, doi:10.1016/j.agrformet.2014.03.023.

- — - J. H. Prueger, and R. K. Doorenbos, 2016: Toward understanding the physical link between turbines and microclimate impacts from in situ measurements in a large wind farm. J. Geophys. Res. Atmospheres, 2016JD025297, doi:10.1002/2016JD025297.

Rao, Y.-J., 1997: In-fibre Bragg grating sensors. Meas. Sci. Technol., 8, 355, doi:10.1088/09570233/8/4/002.

Reineman, B. D., L. Lenain, N. M. Statom, and W. K. Melville, 2013: Development and Testing of Instrumentation for UAV-Based Flux Measurements within Terrestrial and Marine Atmospheric Boundary Layers. J. Atmospheric Ocean. Technol., 30, 1295-1319, doi:10.1175/JTECH-D-1200176.1.

Rhodes, M. E., and J. K. Lundquist, 2013: The Effect of Wind-Turbine Wakes on Summertime US Midwest Atmospheric Wind Profiles as Observed with Ground-Based Doppler Lidar. Bound.Layer Meteorol., 149, 85-103, doi:10.1007/s10546-013-9834-x.

Rieker, G. B., and Coauthors, 2014: Frequency-comb-based remote sensing of greenhouse gases over kilometer air paths. Optica, 1, 290-298, doi:10.1364/OPTICA.1.000290. 
Roadman, J., and A. Huskey, 2015: Acoustic Noise Test Report for the U.S. Department of Energy 1.5Megawatt Wind Turbine. National Renewable Energy Laboratory, Golden, CO, http://www.nrel.gov/docs/fy15osti/63681.pdf (Accessed March 30, 2017).

Sandia National Laboratories. "TTU Advanced Doppler Radar." Accessed [include date accessed]. http://energy.sandia.gov/energy/renewable-energy/wind-power/wind plant opt/ttu-advanceddoppler-radar/

Santos, R., and J. van Dam, 2015: Mechanical Loads Test Report for the U.S. Department of Energy 1.5Megawatt Wind Turbine. National Renewable Energy Laboratory, Golden, CO, http://www.nrel.gov/docs/fy15osti/63679.pdf. (Accessed March 30, 2017).

Sathe, A., and J. Mann, 2013: A review of turbulence measurements using ground-based wind lidars. Atmospheric Meas. Tech., 6, 3147-3167, doi:10.5194/amt-6-3147-2013.

,-- J. Gottschall, and M. S. Courtney, 2011: Can Wind Lidars Measure Turbulence? J. Atmospheric Ocean. Technol., 28, 853-868, doi:10.1175/JTECH-D-10-05004.1.

,-- T. Barlas, W. A. A. M. Bierbooms, and G. J. W. van Bussel, 2013: Influence of atmospheric stability on wind turbine loads. Wind Energy, 16, 1013-1032, doi:10.1002/we.1528.

,-- N. Vasiljevic, and G. Lea, 2015: A six-beam method to measure turbulence statistics using ground-based wind lidars. Atmos Meas Tech, 8, 729-740, doi:10.5194/amt-8-729-2015.

Scarano, F., S. Ghaemi, G. C. A. Caridi, J. Bosbach, U. Dierksheide, and A. Sciacchitano, 2015: On the use of helium-filled soap bubbles for large-scale tomographic PIV in wind tunnel experiments. Exp. Fluids, 56, 42, doi:10.1007/s00348-015-1909-7.

Schmid, P., and D. Niyogi, 2012: A Method for Estimating Planetary Boundary Layer Heights and Its Application over the ARM Southern Great Plains Site. J. Atmospheric Ocean. Technol., 29, 316322, doi:10.1175/JTECH-D-11-00118.1.

Sengupta, M., and Coauthors, 2015: Best Practices Handbook for the Collection and Use of Solar Resource Data for Solar Energy Applications. National Renewable Energy Laboratory, Golden, CO, http://www.nrel.gov/docs/fy15osti/63112.pdf. (Accessed March 28, 2017).

Siedersleben, S. K., and Coauthors, 2018: Micrometeorological impacts of offshore wind farms as seen in observations and simulations. Environ. Res. Lett., 13, 124012, doi:10.1088/1748-9326/aaea0b.

Simms, D. A., M. M. Hand, L. J. Fingersh, and D. W. Jager, 1999: Unsteady Aerodynamics Experiment Phases II-IV Test Configurations and Available Data Campaigns. National Renewable Energy Laboratory, Golden, CO, http://www.nrel.gov/docs/fy99osti/25950.pdf. (Accessed March 30, 2017).

Shaw, W. J., L. K. Berg, J. Cline, C. Draxl, I. Djalalova, E. P. Grimit, J. K. Lundquist, M. Marquis, J. McCaa, J. Olson, C. Sivaraman, J. Sharp, J. M. Wilczak. Forthcoming. The Second Wind Forecast Improvement Project (WFIP 2): General Overview. Bulletin of the American Meteorological Society, in review.

Sjöholm, M., N. Angelou, P. Hansen, K. H. Hansen, T. Mikkelsen, S. Haga, J. A. Silgjerd, and N. Starsmore, 2013a: Two-Dimensional Rotorcraft Downwash Flow Field Measurements by Lidar- 
Based Wind Scanners with Agile Beam Steering. J. Atmospheric Ocean. Technol., 31, 930-937, doi:10.1175/JTECH-D-13-00010.1.

, A. T. Pedersen, N. Angelou, F. Foroughi Abari, T. Mikkelsen, M. Harris, C. Slinger, and S. Kapp, 2013b: Full two-dimensional rotor plane inflow measurements by a spinner-integrated wind lidar.

Smalikho, I., F. Köpp, and S. Rahm, 2005: Measurement of Atmospheric Turbulence by 2- $\mu$ m Doppler Lidar. J. Atmospheric Ocean. Technol., 22, 1733-1747, doi:10.1175/JTECH1815.1.

Smalikho, I. N., and V. A. Banakh, 2013: Accuracy of estimation of the turbulent energy dissipation rate from wind measurements with a conically scanning pulsed coherent Doppler lidar. Part I. Algorithm of data processing. Atmospheric Ocean. Opt., 26, 404-410, doi:10.1134/S102485601305014X.

,-- Y Y. L. Pichugina, W. A. Brewer, R. M. Banta, J. K. Lundquist, and N. D. Kelley, 2013: Lidar Investigation of Atmosphere Effect on a Wind Turbine Wake. J. Atmospheric Ocean. Technol., 30, 2554-2570, doi:10.1175/JTECH-D-12-00108.1.

Spuler, S. M., K. S. Repasky, B. Morley, D. Moen, M. Hayman, and A. R. Nehrir, 2015: Field-deployable diode-laser-based differential absorption lidar (DIAL) for profiling water vapor. Atmos Meas Tech, 8, 1073-1087, doi:10.5194/amt-8-1073-2015.

Squire, L., R. Maltby, R. Keating, and A. Stanbrock, 1962: The Surface Oil Flow Technique. NATO.

St. Martin, C. M., J. K. Lundquist, A. Clifton, G. S. Poulos, and S. J. Schreck, 2016: Atmospheric turbulence affects wind turbine nacelle transfer functions. Wind Energy Sci. Discuss., 1-22, doi:10.5194/wes-2016-45.

Steeneveld, G. J., B. J. H. van de Wiel, and A. a. M. Holtslag, 2007: Diagnostic Equations for the Stable Boundary Layer Height: Evaluation and Dimensional Analysis. J. Appl. Meteorol. Climatol., 46, 212-225, doi:10.1175/JAM2454.1.

Strauch, R. G., V. E. Derr, and R. E. Cupp, 1971: Atmospheric water vapor measurement by Raman Lidar. Remote Sens. Environ., 2, 101-108, doi:10.1016/0034-4257(71)90083-6.

Stull, R. B., 1988: An Introduction to Boundary Layer Meteorology. Springer Science \& Business Media, $688 \mathrm{pp}$.

Sumner, J., and C. Masson, 2006: Influence of Atmospheric Stability on Wind Turbine Power Performance Curves. J. Sol. Energy Eng., 128, 531-538, doi:10.1115/1.2347714.

Takle, E. S., D. A. Rajewski, J. K. Lundquist, W. A. G. Jr, and A. Sharma, 2014: Measurements in support of wind farm simulations and power forecasts: The Crop/Wind-energy Experiments (CWEX). J. Phys. Conf. Ser., 524, 12174, doi:10.1088/1742-6596/524/1/012174.

Taylor, P. A., and H. W. Teunissen, 1987: The Askervein Hill project: Overview and background data. Bound.-Layer Meteorol., 39, 15-39, doi:10.1007/BF00121863.

Thomas, R. M., K. Lehmann, H. Nguyen, D. L. Jackson, D. Wolfe, and V. Ramanathan, 2012: Measurement of turbulent water vapor fluxes using a lightweight unmanned aerial vehicle system. Atmos Meas Tech, 5, 243-257, doi:10.5194/amt-5-243-2012. 
Toloui, M., S. Riley, J. Hong, K. Howard, L. P. Chamorro, M. Guala, and J. Tucker, 2014: Measurement of atmospheric boundary layer based on super-large-scale particle image velocimetry using natural snowfall. Exp. Fluids, 55, 1737, doi:10.1007/s00348-014-1737-1.

Tropea, C., and A. L. Yarin, 2007: Springer Handbook of Experimental Fluid Mechanics. Springer Science \& Business Media, 1570 pp.

Undheim, O., H. I. Andersson, and E. Berge, 2006: Non-Linear, Microscale Modelling of the Flow Over Askervein Hill. Bound.-Layer Meteorol., 120, 477-495, doi:10.1007/s10546-006-9065-5.

US EPA, 2000: Meteorological Monitoring Guidance for Regulatory Modeling Applications. US EPA, Research Triangle Park, NC, https://www3.epa.gov/scram001/guidance/met/mmgrma.pdf (Accessed March 1, 2017).

Vanderwende, B. J., and J. K. Lundquist, 2012: The modification of wind turbine performance by statistically distinct atmospheric regimes. Environ. Res. Lett., 7, 34035.

Vanderwende, B. J., J. K. Lundquist, M. E. Rhodes, E. S. Takle, and S. L. Irvin, 2015: Observing and Simulating the Summertime Low-Level Jet in Central Iowa. Mon. Weather Rev., 143, 2319-2336, doi:10.1175/MWR-D-14-00325.1.

Vickers, D., and L. Mahrt, 2004: Evaluating Formulations of Stable Boundary Layer Height. J. Appl. Meteorol., 43, 1736-1749, doi:10.1175/JAM2160.1.

Wallace, J. M., and P. V. Hobbs, 2006: Atmospheric Science: An Introductory Survey. Academic Press, $505 \mathrm{pp}$.

Ware, R., R. Carpenter, J. Güldner, J. Liljegren, T. Nehrkorn, F. Solheim, and F. Vandenberghe, 2003: A multichannel radiometric profiler of temperature, humidity, and cloud liquid. Radio Sci., 38, 8079, doi:10.1029/2002RS002856.

Ware, R., and Coauthors, 2013: Thermodynamic and liquid profiling during the 2010 Winter Olympics. Atmospheric Res., 132-133, 278-290, doi:10.1016/j.atmosres.2013.05.019.

Warner, T. T., 2010: Numerical Weather and Climate Prediction. Cambridge University Press, 550 pp.

—_, 2011: Quality Assurance in Atmospheric Modeling. Bull. Am. Meteorol. Soc., 92, 1601-1610, doi:10.1175/BAMS-D-11-00054.1.

Webster, J. G., and H. Eren, 2014: Measurement, Instrumentation, and Sensors Handbook, Second Edition: Electromagnetic, Optical, Radiation, Chemical, and Biomedical Measurement. CRC Press, $1881 \mathrm{pp}$.

Weitkamp, C., ed., 2005: Lidar: range-resolved optical remote sensing of the atmosphere. Springer, New York, $455 \mathrm{pp}$.

Wharton, S., and J. K. Lundquist, 2012: Atmospheric stability affects wind turbine power collection. Environ. Res. Lett., 7, 14005, doi:10.1088/1748-9326/7/1/014005.

Whitmore, S. A., 2006: Frequency Response Model for Branched Pneumatic Sensing Systems. J. Aircr., 43, 1845-1853, doi:10.2514/1.20759. 
Wilczak, J., and Coauthors, 2015: The Wind Forecast Improvement Project (WFIP): A Public-Private Partnership Addressing Wind Energy Forecast Needs. Bull. Am. Meteorol. Soc., 96, 1699-1718, doi:10.1175/BAMS-D-14-00107.1.

Wilczak, J. M., and Coauthors, 1995: Contamination of Wind Profiler Data by Migrating Birds: Characteristics of Corrupted Data and Potential Solutions. J. Atmospheric Ocean. Technol., 12, 449-467, doi:10.1175/1520-0426(1995)012<0449:COWPDB>2.0.CO;2.

Wilczak, J. M., and Coauthors. Forthcoming. The Second Wind Forecast Improvement Project (WFIP2): Observational Field Campaign. Bulletin of the American Meteorological Society, in review.

Wildmann, N., M. Mauz, and J. Bange, 2013: Two fast temperature sensors for probing of the atmospheric boundary layer using small remotely piloted aircraft (RPA). Atmos Meas Tech, 6, 2101-2113, doi:10.5194/amt-6-2101-2013.

- S. Ravi, and J. Bange, 2014: Towards higher accuracy and better frequency response with standard multi-hole probes in turbulence measurement with remotely piloted aircraft (RPA). Atmos Meas Tech, 7, 1027-1041, doi:10.5194/amt-7-1027-2014.

Wildmann, N., G. A. Rau, and J. Bange, 2015: Observations of the Early Morning Boundary-Layer Transition with Small Remotely-Piloted Aircraft. Bound.-Layer Meteorol., 157, 345-373, doi:10.1007/s10546-015-0059-z.

Wildmann, N., N. Vasiljevic, and T. Gerz, 2018: Wind turbine wake measurements with automatically adjusting scanning trajectories in a multi-Doppler lidar setup. Atmospheric Meas. Tech., 11, 3801-3814, doi:10.5194/amt-11-3801-2018.

Winstroth, J., L. Schoen, B. Ernst, and J. R. Seume, 2014: Wind turbine rotor blade monitoring using digital image correlation: a comparison to aeroelastic simulations of a multi-megawatt wind turbine. J. Phys. Conf. Ser., 524, 12064, doi:10.1088/1742-6596/524/1/012064.

Wolfe, D. E., and R. J. Lataitis, 2018: Boulder Atmospheric Observatory: 1977-2016: The End of an Era and Lessons Learned. Bull. Am. Meteorol. Soc., 99, 1345-1358, doi:10.1175/BAMS-D-170054.1.

Xie, Y., M. Sengupta, and J. Dudhia, 2016: A Fast All-sky Radiation Model for Solar applications (FARMS): Algorithm and performance evaluation. Sol. Energy, 135, 435-445, doi:10.1016/j.solener.2016.06.003.

Yazicioglu, H., N. Angelou, T. Mikkelsen, and J.-J. Trujillo, 2016: Characterization of wind velocities in the wake of a full scale wind turbine using three ground-based synchronized WindScanners. $J$. Phys. Conf. Ser., 753, doi:http://dx.doi.org/10.1088/1742-6596/753/3/032032.

Zeweldi, D. A., M. Gebremichael, J. Wang, T. Sammis, J. Kleissl, and D. Miller, 2010: Intercomparison of Sensible Heat Flux from Large Aperture Scintillometer and Eddy Covariance Methods: Field Experiment over a Homogeneous Semi-arid Region. Bound.-Layer Meteorol., 135, 151-159, doi:10.1007/s10546-009-9460-9.

Zhou, B., and F. K. Chow, 2011: Large-Eddy Simulation of the Stable Boundary Layer with Explicit Filtering and Reconstruction Turbulence Modeling. J. Atmospheric Sci., 68, 2142-2155, doi:10.1175/2011JAS3693.1. 
Zilliac, G. G., 1989: Calibration of Seven-Hole Pressure Probes for Use in Fluid Flows with Large Angularity. NASA Ames Research Center, Moffett Field, CA, http://citeseerx.ist.psu.edu/viewdoc/download?doi=10.1.1.605.8500\&rep=rep1\&type=pdf (Accessed March 30, 2017). 


\section{Appendix}

\section{Technology Readiness Levels}

Technology readiness levels (TRLs) describe the suitability of a product or technology for a particular task, based on U.S. Department of Energy definitions. ${ }^{5}$

Table A1. TRL Definitions

\begin{tabular}{|c|c|c|}
\hline $\begin{array}{l}\text { Relative Level of Technology } \\
\text { Development }\end{array}$ & $\begin{array}{c}\text { Technology } \\
\text { Readiness } \\
\text { Level }\end{array}$ & TRL Definition \\
\hline Systems Operation & 9 & $\begin{array}{l}\text { Actual system operated over the full range of expected } \\
\text { mission conditions }\end{array}$ \\
\hline \multirow[t]{2}{*}{ System Commissioning } & 8 & $\begin{array}{l}\text { Actual system completed and qualified through test and } \\
\text { demonstration }\end{array}$ \\
\hline & 7 & $\begin{array}{l}\text { Full-scale, similar (prototypical) system demonstrated in } \\
\text { relevant environment }\end{array}$ \\
\hline Technology Demonstration & 6 & $\begin{array}{l}\text { Engineering/pilot-scale, similar (prototypical) system } \\
\text { validation in relevant environment }\end{array}$ \\
\hline \multirow[t]{2}{*}{ Technology Development } & 5 & $\begin{array}{l}\text { Laboratory-scale, similar system validation in relevant } \\
\text { environment }\end{array}$ \\
\hline & 4 & $\begin{array}{l}\text { Component and/or system validation in laboratory } \\
\text { environment }\end{array}$ \\
\hline \multirow[t]{2}{*}{ Research to Prove Feasibility } & 3 & $\begin{array}{l}\text { Analytical and experimental critical function and/or } \\
\text { characteristic proof of concept }\end{array}$ \\
\hline & 2 & Technology concept and/or application formulated \\
\hline \multirow[t]{2}{*}{ Basic Technology Research } & & \\
\hline & 1 & Basic principles observed and reported \\
\hline
\end{tabular}

${ }^{5}$ In Table 4 from https://www.directives.doe.gov/directives-documents/400-series/0413.3-EGuide-04-admchg1. 